Universidade de São Paulo

Instituto de Física

\title{
Dispersões lipídicas de dimiristoil fosfatidilglicerol: um estudo termo-estrutural
}

\author{
Rafael Pianca Barroso
}

Orientadora: Prof. ${ }^{a}$ Dr. ${ }^{a}$ Maria Teresa Moura Lamy

Tese apresentada ao Instituto de Física para a obtenção do título de Doutor em Ciências

São Paulo 



\section{Agradecimentos}

Aos meus pais, pelo incentivo e apoio incondicionais.

À Teresa, pela orientação, amizade e por tudo que me ensinou e vem ensinando ao longo destes onze anos de convivência.

À Karin, pela amizade, co-orientação e auxílio durante todo este trabalho.

À professora Vera Henriques, pelas discussões, colaborações e disposição para ajudar sempre.

À Kátia, pela amizade, discussões e ajuda enorme nas medidas de cromatografia e mobilidade eletroforética.

À professora Iolanda Cuccovia, pela atenção despendida, discussões e ter cedido seu laboratório para a realização de vários experimentos.

Aos amigos Tiago e Evandro, sempre dispostos a ajudar.

À Thaís, por compartilhar seus resultados de espalhamento de luz.

À Ana Paula, ex-aluna de iniciação científica do grupo, pela amizade e auxílio em alguns experimentos de condutividade e viscosidade.

Aos colegas de trabalho Cíntia, Marcus, Antônio e Daniela.

Às professoras Carla Goldman e Kaline Coutinho.

À minha namorada Ana Paula, pelo amor, paciência, apoio e compreensão nestes anos de doutorado.

À minha querida irmã Cássia e aos meus familiares, pelo incentivo.

A todos que de alguma forma contribuíram para a elaboração deste trabalho.

À CAPES pelo apoio financeiro. 



\section{Resumo}

Dispersões do fosfolipídio saturado aniônico dimiristoil fosfatidil glicerol (DMPG) têm sido extensivamente estudadas devido ao seu comportamento termo-estrutural muito peculiar. Em baixa força iônica, a transição gel-fluida acontece ao longo de uma faixa de temperatura em torno de $17{ }^{\circ} \mathrm{C}$, apresentando vários eventos térmicos em seu perfil calorimétrico, bem diferente do pico calorimétrico único em torno de $23{ }^{\circ} \mathrm{C}$, visto em dispersões de DMPG em alta força iônica. Esta região de temperatura também é caracterizada por apresentar baixa turbidez, alta condutividade elétrica e alta viscosidade. A presente tese teve por objetivo aprofundar os conhecimentos acerca deste peculiar comportamento termoestrutural. Para tanto, a dependência térmica das dispersões foi investigada, em função da concentração lipídica e força iônica, através da técnica de calorimetria exploratória diferencial (DSC) e medidas de turbidez, condutividade elétrica, viscosidade e mobilidade eletroforética. Além disso, o encapsulamento de sacarose radioativa no volume interno de agregados de DMPG claramente indicou que o DMPG forma vesículas, e não micelas ou bicelas. No entanto, medidas de viscosidade indicaram que as vesículas formadas ao longo da região de transição são certamente diferentes das formadas nas fases gel e fluida. As concentrações lipídicas estudadas variaram de 1 a $50 \mathrm{mM}$, e dispersões de $10 \mathrm{mM}$ de DMPG foram estudadas em diferentes forças iônicas, de 2 a $250 \mathrm{mM}$ de $\mathrm{NaCl}$ adicionado. As propriedades térmicas das dispersões mostraram-se dependentes da concentração lipídica e tal dependência mostrou-se similar à dependência com a força iônica: o aumento de concentração lipídica diminuía a região de transição. A similaridade entre os dois regimes, tanto o aumento de sal quanto da concentração lipídica, foi discutida em termos da correlação com os íons de sódio da dispersão. Através de medidas de condutividade elétrica da amostra e da mobilidade eletroforética de vesículas de DMPG, foi possível calcular a dependência térmica do grau de ionização de vesículas de DMPG, em diferentes concentrações lipídicas e de sal. Mostramos que as vesículas estão mais ionizadas ao longo da região de transição, e menos ionizadas com o aumento de concentração lipídica ou de concentração de sal. Além do aumento na condutividade ao longo da região de transição, foi observado um aumento brusco na condutividade na pré-transição das bicamadas, indicando que ela está relacionada ao começo do processo de fusão das cadeias. Será discutida aqui a relevância da curvatura da bicamada e o grau de ionização no peculiar comportamento térmico de dispersões de DMPG. Vesículas altamente deformadas e ionizadas parecem estar presentes ao longo da região de transição das bicamadas de DMPG, exibindo grandes flutuações de forma e densidade da bicamada. É interessante especular se estas grandes flutuações da bicamada podem ter relevância biológica. 



\section{Abstract}

Dispersions of the saturated anionic phospholipid dimyristoyl phosphatidyl glycerol (DMPG) have been extensively studied regarding their peculiar thermo-structural behavior. At low ionic strength, the gel-fluid transition is spread along nearly $17^{\circ} \mathrm{C}$, displaying several thermal events in the calorimetric profile, quite different from the single sharp peak around $23{ }^{\circ} \mathrm{C}$ found for higher ionic strength DMPG dispersions. This extended transition region is also characterized by low turbidity, high conductivity and high viscosity. The purpose of this thesis was to extend the knowledge about this peculiar thermostructural behavior of DMPG dispersions. Accordingly, the thermal dependence of the dispersions was investigated as a function of lipid and ionic strength concentrations, using several techniques: differential scanning calorimetry (DSC), and measurements of turbidity, electrical conductivity, viscosity and electrophoretic mobility. Moreover, the encapsulation of radioactive sucrose in the internal aqueous volume of DMPG aggregates clearly indicated that DMPG forms vesicles and not micelles or bicelles. However, viscosity measurements indicated that the DMPG vesicles formed along the transition region are certainly different from those formed in the gel and fluid phases. The studied lipid concentrations varied from 1 to $50 \mathrm{mM}$, and the $10 \mathrm{mM}$ DMPG dispersion was studied at different ionic strengths, from 2 to $250 \mathrm{mM}$ of added $\mathrm{NaCl}$. The thermal properties of the dispersions were shown to be dependent on the lipid concentration, and this dependence was shown to be similar to the dependence on the ionic strength: the increase in lipid or salt concentrations decreased the temperature range of the transition region. The similarity between the two regimes, either the increase in salt or lipid concentration, is discussed here, in the light of their correlation with the concentration of bulk $\mathrm{Na}^{+}$. By measuring the sample electrical conductivity, and the electrophoretic mobility of the DMPG vesicles, it was possible to calculate the temperature dependence of the degree of ionization of DMPG vesicles, at different lipid and salt concentrations. It could be shown that the vesicles are more ionized along the transition region, and less ionized as the lipid or salt concentration increases. Besides the increase in conductivity along the transition region, a sharp increase in conductivity was observed at the pre-transition of the bilayers, indicating that this temperature is related to the beginning of the chain melting process. The relevance of the bilayer curvature and ionization degree to the peculiar thermal behavior of DMPG dispersions will be discussed here. Highly ionized and deformed vesicles seem to be present along the extended thermal transition of DMPG bilayers, presenting large fluctuations of form and bilayer density. It is interesting to speculate if those large bilayer fluctuations could be biologically relevant. 



\section{Sumário}

1 Introdução 11

1.1 Lipídios e membranas celulares . . . . . . . . . . . . . . . . . 11

1.1.1 Transição de fase de bicamadas lipídicas . . . . . . . . . . . . . . . 14

1.1.2 Características termo-estruturais de dispersões de DMPG . . . . . . 16

2 Materiais e Métodos 21

2.1 Materiais . . . . . . . . . . . . . . . . . 21

2.2 Métodos . . . . . . . . . . . . . . . . . . . . . . 22

$2.2 .1 \quad$ Ajuste de $\mathrm{pH} \ldots \ldots \ldots \ldots \ldots \ldots \ldots \ldots$

2.2.2 Preparação das amostras . . . . . . . . . . . . . . . . . . . . . . 22

2.2.3 Medidas de Calorimetria Exploratória Diferencial (DSC) . . . . . . 23

2.2.4 Medidas de Viscosidade . . . . . . . . . . . . . . . . 26

2.2.5 Medidas de condutividade . . . . . . . . . . . . . . . . 28

2.2.6 Medidas de mobilidade eletroforética . . . . . . . . . . . . . 30

2.2.7 Determinação da incorporação de $\left[{ }^{14} \mathrm{C}\right]$ sacarose . . . . . . . . . . . . 30

2.2.8 Medidas de absorbância (turbidez) . . . . . . . . . . . . . 31

3 Técnicas experimentais 33

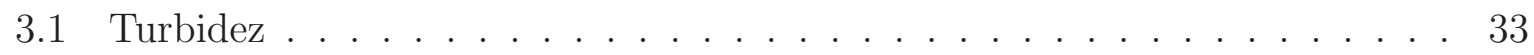

3.2 Calorimetria exploratória diferencial (DSC) . . . . . . . . . . . . . 34

3.3 Condutividade elétrica e mobilidade eletroforética . . . . . . . . . . . . 35

3.4 Estimativa da fração de volume interno e do grau de ionização de vesículas 37

3.5 Viscosidade . . . . . . . . . . . . . . . . . . . 41

3.5.1 Definição de viscosidade . . . . . . . . . . . . . . . . 41

3.5.2 Viscosidade de soluções . . . . . . . . . . . . . . . . . . . . 43 
4.1 Presença de vesículas de DMPG: incorporação de $\left[{ }^{14} \mathrm{C}\right]$-sacarose em volume interno . . . . . . . . . . . . . . . . . . . . 47

4.2 Efeito da concentração lipídica nas dispersões de DMPG . . . . . . . . . . 60

4.2.1 Calorimetria Exploratória Diferencial (DSC) . . . . . . . . . . 61

4.2 .2 Turbidez . . . . . . . . . . . . . . . . . . 70

4.2.3 Condutividade elétrica . . . . . . . . . . . . . . . 75

4.2.4 Mobilidade eletroforética e grau de ionização: carga e estrutura dos agregados de DMPG . . . . . . . . . . . . . . . . 84

4.2.5 Viscosidade . . . . . . . . . . . . . . . . . . . 88

4.2.5.1 Efeito da concentração lipídica na viscosidade . . . . . . . 88

4.2.5.2 Viscosidade local vs. macro-viscosidade . . . . . . . . . . 98

4.3 Efeito da força iônica . . . . . . . . . . . . . . . . . . . 100

4.3.1 Calorimetria Exploratória Diferencial . . . . . . . . . . . . . . 101

4.3 .2 Turbidez . . . . . . . . . . . . . . . . . . 106

4.3 .3 Condutividade elétrica . . . . . . . . . . . . . . . . . . 109

4.3.4 Mobilidade eletroforética . . . . . . . . . . . . . . . . 113

4.3.5 Viscosidade . . . . . . . . . . . . . . . . 116

4.3.6 A correspondência entre aumentar a concentração lipídica ou a de

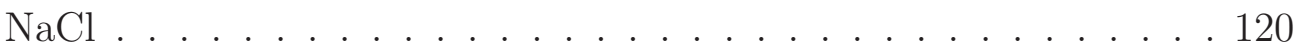

5 Discussão geral e conclusões 123

Referências Bibliográficas $\quad 131$ 


\section{Capítulo 1}

\section{Introdução}

\subsection{Lipídios e membranas celulares}

Lipídios são biomoléculas insolúveis em água e altamente solúveis em solventes orgânicos. Desempenham várias funções, tais como servir como combustíveis moleculares, moléculas sinalizadoras e componentes de membrana (Strayer, 1997). Em particular estaremos interessados apenas nos lipídios que desempenham esta última função, ou seja, nos lipídios de membrana. As membranas circundam as células, tornando possível a compartimentalização das atividades metabólicas dentro das células. Elas contêm muitas proteínas e sistemas importantes de transporte. Além disso, na superfície externa das membranas celulares estão localizados muitos sítios receptores ou de reconhecimento, que podem reconhecer outras células, ligar certos hormônios e detectar outros tipos de sinais do meio ambiente externo (Lehninger, 1984). Muitos lipídios de membrana são moléculas anfifílicas, possuindo uma região hidrofóbica e outra hidrofílica. A unidade hidrofílica (polar) é denominada cabeça polar. Geralmente, as cabeças polares dos lipídios apresentam cargas elétricas. Podemos classificar os lipídios quanto à sua carga, em pH neutro, como aniônicos (carga negativa), catiônicos (carga positiva) e zwitteriônicos ${ }^{1}$ (cargas negativa e positiva). Devido ao caráter anfifílico, em sistemas aquosos, os lipídios espontaneamente se dispersam formando estruturas que minimizam o contato da região hidrofóbica com as moléculas de água. Esse fenômeno é conhecido como efeito hidrofóbico, e é devido ao balanço das contribuições energéticas e entrópicas entre as moléculas apolares e as de água. Os diferentes tipos de estrutura formados devido ao efeito hidrofóbico depen-

\footnotetext{
${ }^{1} \mathrm{O}$ termo zwitter vem do alemão, que quer dizer híbrido.
} 
dem de vários fatores, como concentração lipídica, temperatura, pressão, força iônica, pH (Gennis, 1989) e, principalmente, da forma geométrica do anfifílico. A figura 1.1 apresenta um desenho esquemático da estrutura de um fosfolipídio e de algumas estruturas de agregação, relevantes para o presente trabalho, formadas em meio aquoso.

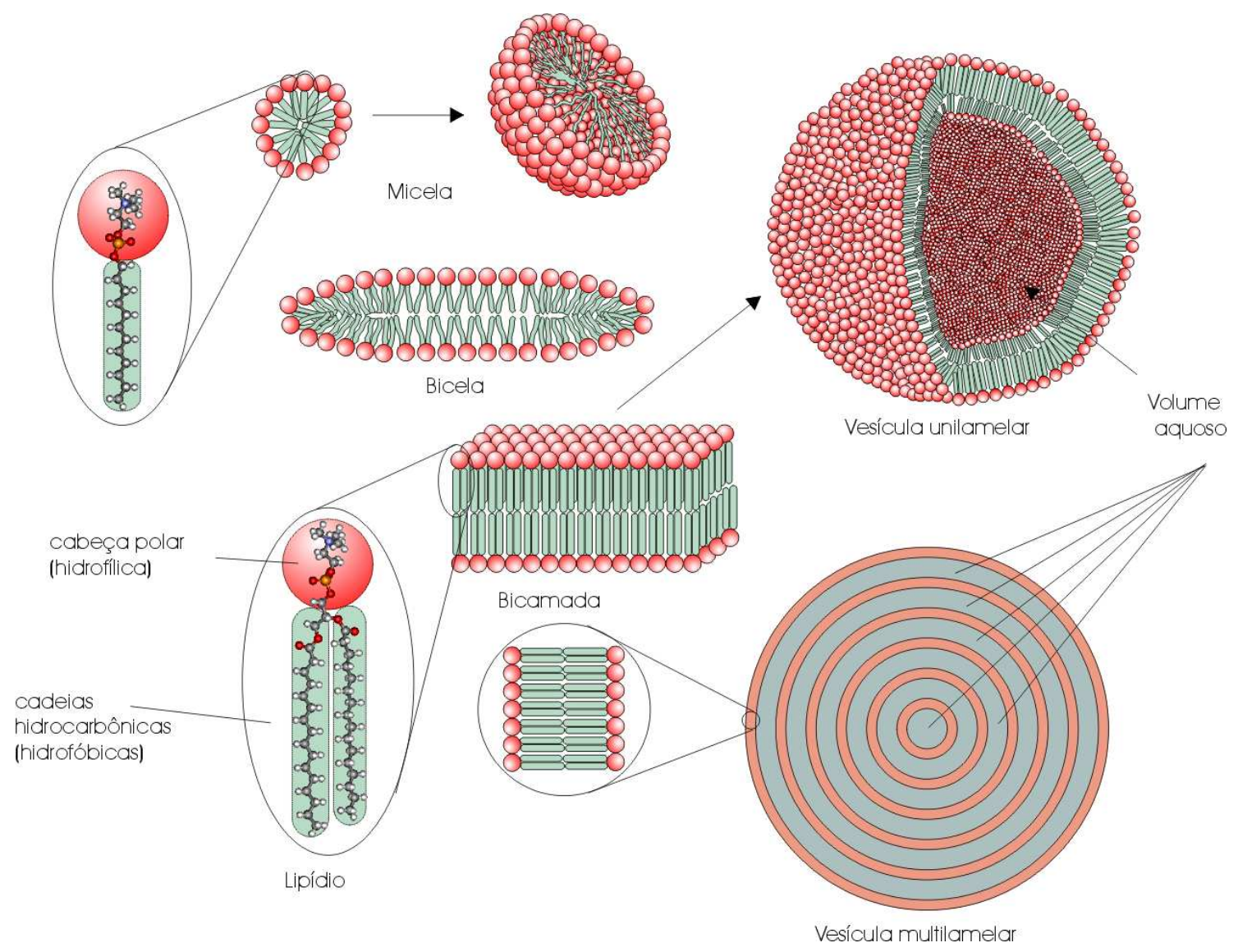

Figura 1.1: Estrutura típica de um lipídio de membrana e algumas estruturas formadas por lipídios em sistemas aquosos.

Lipídios com forma geométrica cônica, em geral, tendem a formar micelas, estruturas em que as cadeias hidrocarbônicas dos lipídios ficam protegidas do meio aquoso e as cabeças hidrofílicas, polares, são expostas na superfície voltadas para o meio aquoso (figura 1.1). Por outro lado, lipídios com forma geométrica cilíndrica, tendem a formar bicamadas lipídicas. Nestas estruturas, que separam dois compartimentos aquosos, as cadeias hidrocarbônicas das moléculas dos lipídios se estendem para dentro das duas superfícies, formando uma base interna hidrocarbonada, e as cabeças hidrofílicas se voltam para fora, estendendo-se para as fases aquosas. Evitando ainda o contato da região hidrofóbica com a água, as bicamadas podem se fechar sobre si mesmas formando estruturas vesiculares, também chamadas de lipossomos. A estrutura constituída por bicamadas é denominada 
lamelar, uma vez que se pode fazer uma analogia entre as bicamadas lipídicas e lamelas. Vesículas podem conter mais de uma bicamada, formando estruturas que lembram a morfologia de uma cebola. Tais estruturas são conhecidas por vesículas multilamelares ou multibicamadas, enquanto que as que possuem apenas uma bicamada são denominadas vesículas unilamelares. Há ainda a possibilidade da existência de vesículas dentro de vesículas maiores, podendo as vesículas internas e externas serem unilamelares, multilamelares ou uma combinação destas.

(a)

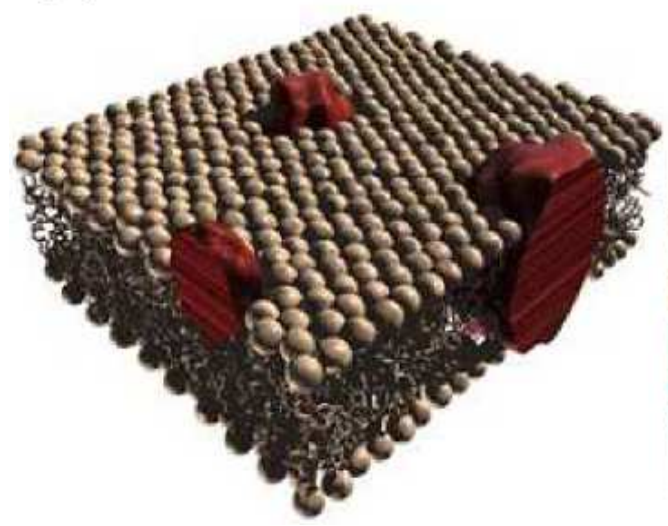

(b)

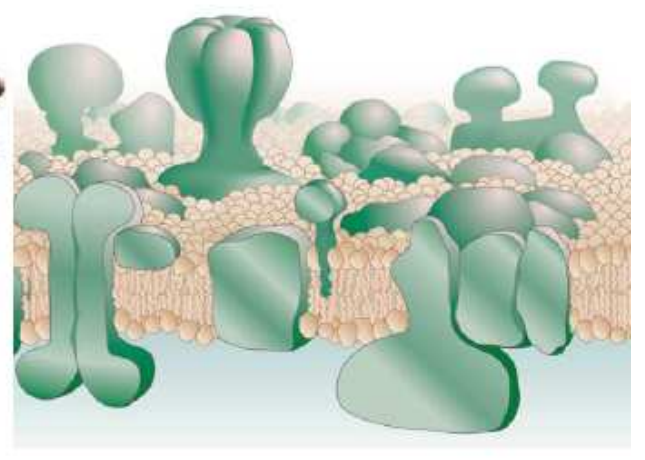

Figura 1.2: (a) Modelo de membrana proposto por Singer \& Nicolson, 1972 e (b) representação atual do modelo (adaptada de Engelman, 2005).

A partir da semelhança nas propriedades das membranas naturais com as bicamadas de fosfolipídios sintéticos, S. Jonathan Singer e Garth Nicolson apresentaram em 1972 um modelo para a estrutura da membrana chamado modelo de mosaico fluido (figura 1.2(a)). Eles propuseram que a matriz, ou parte contínua da estrutura de membrana, fosse uma bicamada polar. A membrana seria constituída por lipídios e proteínas, estas últimas estariam distribuídas aleatoriamente pela extensão da membrana, podendo estar ligadas apenas à superfície (proteínas periféricas), ou inseridas na membrana (proteínas integrais). Embora o modelo de Singer-Nicolson explique muitas das propriedades físicas, químicas e biológicas das membranas e tenha sido largamente aceito como o mais provável arranjo molecular dos lipídios e das proteínas das membranas, alguns ajustes e refinamentos foram propostos ao modelo (Mouritsen \& Bloom, 1984; Vereb et al., 2003; Engelman, 2005). 


\subsubsection{Transição de fase de bicamadas lipídicas}

Bicamadas lipídicas apresentam uma transição de fase, chamada de principal, na qual as cadeias hidrocarbônicas passam de um alto empacotamento (fase gel) para uma membrana fluida (fase líquido-cristalina ou fluida) em uma dada temperatura, chamada $T_{m}{ }^{2}$. Na fase gel, as ligações entre os carbonos da cadeia dos lipídios encontram-se principalmente na conformação trans. Quando a ligação central de uma cadeia de pelo menos quatro carbonos na conformação trans sofre uma rotação de $120^{\circ}$, o resultado é uma nova conformação denominada gauche. Lipídios na fase fluida são caracterizados por apresentarem uma ou mais conformações gauche em suas cadeias hidrocarbônicas. A fase fluida, também chamada de fase lamelar $L_{\alpha}$, é a forma em que se costuma apresentar o conjunto de lipídios em uma membrana biológica. Existe uma ordem bidimensional, embora haja uma considerável desordem nas cadeias hidrocarbônicas devido à presença das dobras gauche. Na fase gel, ou fase lamelar $L_{\beta}$, formada em temperaturas baixas, as moléculas estão empacotadas mais rigidamente (a área superficial por molécula é menor) e as cadeias acila encontram-se muito mais organizadas (em razão da interação de van der Waals), com a maioria das ligações de carbono na configuração trans. Como as cadeias estão estendidas ao máximo na fase gel, a espessura da bicamada é maior do que na fase fluida. Além disto, como as cadeias estão mais próximas, a densidade da fase gel é ligeiramente maior que a da fase fluida. Dependendo da forma geométrica dos lipídios da bicamada, a fase gel ainda pode adotar uma conformação em que as cadeias hidrocarbônicas ficam inclinadas em relação ao plano da bicamada. Esta fase é denominada laminar $L_{\beta^{\prime}}$.

\footnotetext{
${ }^{2} \mathrm{O}$ subscrito $m$ vem do inglês melting, cujo significado é fusão.
} 
A figura 1.3 apresenta um desenho esquemático da transição de fase gel-fluida.

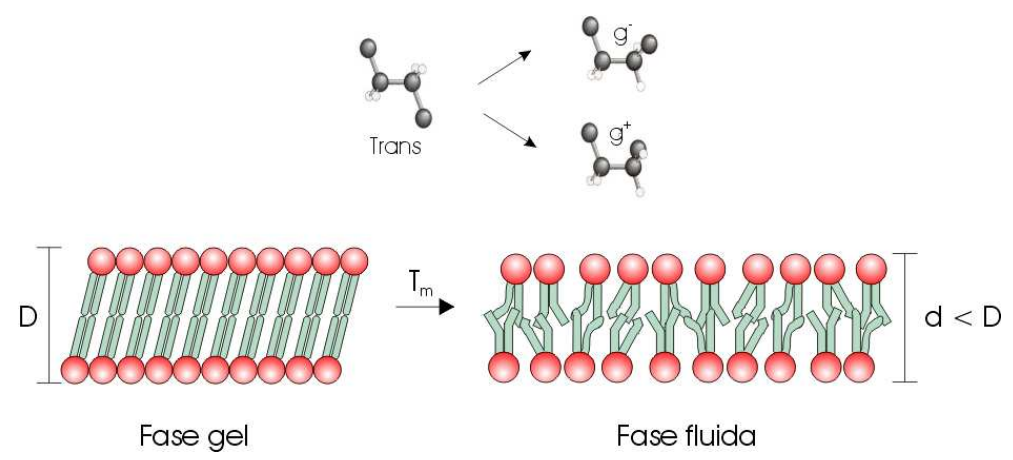

Figura 1.3: Representação esquemática da transição gel-fluida. Acima, conformação das ligações entre os carbonos das cadeias: à esquerda, conformação trans; à direita, conformação gauche, resultado de uma rotação de $120^{\circ}$ no sentido horário $\left(g^{+}\right)$ou anti-horário $\left(g^{-}\right)$. Embaixo, configurações da bicamada lipídica nas fases gel e fluida. Note que após a transição a área ocupada por cada lipídio da bicamada aumenta e sua espessura, $D$, diminui.

Alguns lipídios sofrem ainda uma outra transição de fase, em temperaturas mais baixas do que a transição de fase gel-fluida, denominada pré-transição de fase (Janiak et al., 1976), em que a membrana plana na fase gel se transforma em uma bicamada periodicamente ondulada, conforme ilustrado na figura 1.4. Esta fase é denominada fase ripple ou $P_{\beta^{\prime}}$. Alguns trabalhos propõem que a transição de fase gel-fluida já tenha início na pré-transição (Heimburg, 2000; Riske et al., 2009b).

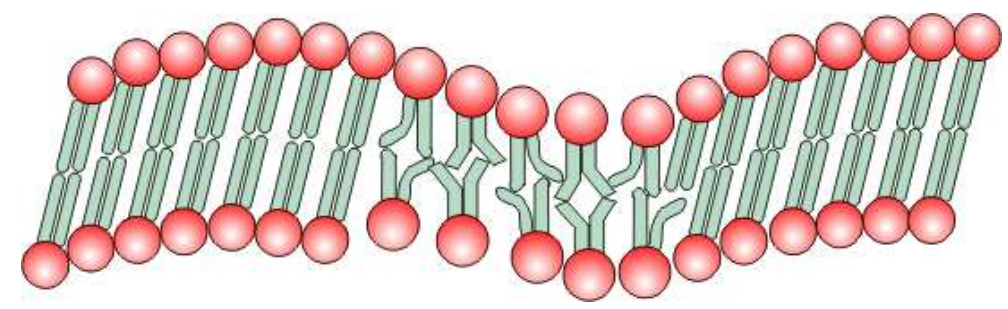

Figura 1.4: Representação de bicamada lipídica na fase ripple. 


\subsubsection{Características termo-estruturais de dispersões de DMPG}

O dimiristoil fosfatidil glicerol (DMPG), lipídio saturado com 14 carbonos na cadeia hidrocarbônica e um grupo fosfato na cabeça polar, é o principal componente da parede celular de bactérias gram-positivas (Paradis-Bleau et al., 2007; Umeyama et al., 2006), motivo pelo qual tem sido usado, através de misturas com fosfolipídios zwitteriônicos, para mimetizar as bicamadas lipídicas destes tipos de bactérias (Chia et al., 2002). Além disso, o DMPG tem sido muito usado para estudar a interação de peptídeos com bicamadas lipídicas (Prenner et al., 1999; Mozsolits et al., 2001; Amon et al., 2008; Broemstrup \& Reuter, 2010), uma vez que é esperado que bicamadas ricas em DMPG, devido à sua carga negativa, tenham grande afinidade com peptídeos compostos por aminoácidos básicos (Umeyama et al., 2006). Nosso próprio grupo de pesquisa iniciou seus estudos usando o DMPG para estudar a interação de peptídeos com membranas carregadas negativamente (Biaggi et al., 1997; Turchiello et al., 1999; Turchiello et al., 2000; Turchiello et al., 2002). Para que tal interação seja mais intensa, geralmente as dispersões lipídicas são feitas em baixa força iônica (abaixo de 100 mM).

Em condições fisiológicas (força iônica em torno de $150 \mathrm{mM}$ ), bicamadas lipídicas de DMPG apresentam uma transição de fase gel-fluido altamente cooperativa, em torno de $23^{\circ} \mathrm{C}$, similar à transição de dispersões de dimiristoil fosfatidil colina (DMPC), fosfolipídio zwitteriônico com o mesmo número de carbonos nas cadeias hidrocarbônicas que o DMPG, porém com a cabeça polar neutra. No entanto, em baixa força iônica, dispersões de DMPG exibem um comportamento termo-estrutural muito peculiar (Salonen et al., 1989; Heimburg \& Biltonen, 1994; Riske et al., 1997; Riske et al., 1999; Riske et al., 2001; Riske et al., 2003; Riske et al., 2004; Lamy-Freund \& Riske, 2003), apresentando uma "região de transição de fase", nomeado estado intermediário, entre aproximadamente $18\left(T_{m}{ }^{\text {on }}\right)$ e 35 ${ }^{\circ} \mathrm{C}\left(T_{m}{ }^{\text {off }}\right)$. Em $T_{m}{ }^{\text {on }}$ aparece um pico estreito de absorção de calor, seguido por outros mais largos, inclusive o último em $T_{m}{ }^{o f f}$. Marcadores de spin e fluorescentes, incorporados à bicamada lipídica, mostraram uma diminuição no empacotamento da membrana nesta região. Com alguns marcadores de spin, é possível observar, nitidamente, a existência de uma queda mais acentuada no empacotamento da bicamada no início da transição. Mais marcantes são as variações bruscas de turbidez da amostra, diminuição em $T_{m}{ }^{\text {on }}$, e aumento em $T_{m}{ }^{\text {ff }}$, sendo que a dispersão de DMPG é visualmente transparente no estado intermediário. Nesta fase a dispersão de DMPG é mais viscosa do que nas outras fases 
(gel e fluida). A observação de vesículas gigantes de DMPG, em baixa força iônica, indica seu desaparecimento óptico nesta região de transição, mas não seu rompimento, portanto há perda de contraste óptico da bicamada com o meio. Além do baixo espalhamento de luz, esta região também apresenta um baixo espalhamento de raios-X a baixo ângulo (SAXS). Dados de SAXS também mostraram a presença de um pico (não muito estreito) de interferência a muito baixo ângulo, correspondendo a uma distância de repetição da ordem de $40 \mathrm{~nm}$.

Algumas outras características importantes são observadas no estado intermediário. Espectros de ressonância paramagnética eletrônica (EPR) de marcadores de spin derivados de fosfolipídio, marcados no carbono 16 da cadeia acila (16-PCSL), incorporados na bicamada, indicaram a presença de dois sinais de EPR, sugerindo a coexistência de dois domínios com microviscosidades diferentes no estado intermediário, sendo um deles altamente fluido e hidratado, semelhante à organização de anfifílicos em micelas, possivelmente em regiões de alta curvatura. Para temperaturas acima de $T_{m}{ }^{\text {off }}$ a bicamada se reorganiza em uma fase fluida convencional. Várias das características do estado intermediário discutidas acima, levaram a uma proposta de vesículas perfuradas para o estado intermediário do DMPG em baixa força iônica (Riske et al., 2004). Entretanto, alguns dos dados experimentais ainda necessitam ser mais bem compreendidos, por exemplo, o grande aumento da viscosidade no estado intermediário, e a necessidade de formação de poros a distâncias suficientemente repetitivas para dar origem a um pico de Bragg no SAXS.

Por outro lado, em trabalhos anteriores do nosso grupo, foi proposta a existência de vesículas de DMPG agregadas nas fases gel e fluida, que desagregariam no estado intermediário (Riske et al., 1997). Como também foi observado um aumento da condutividade elétrica no estado intermediário, foi sugerido que a brusca diminuição de espalhamento de luz em $T_{m}{ }^{\text {on }}$ estivesse relacionada com um aumento do grau de ionização dos lipídios, o que só é possível se postularmos uma diminuição da constante de ligação $\mathrm{Na}^{+}-\mathrm{PG}^{-}$ em $T_{m}{ }^{o n}$. Esta ionização das cabeças polares, acarretando forte repulsão eletrostática entre os lipídios, dispararia o processo de fusão das cadeias hidrocarbônicas, que só estaria terminado em $T_{m}{ }^{\text {off }}$. As razões deste possível processo de ionização em $T_{m}{ }^{o n}$, e posterior re-condensação dos íons em $T_{m}{ }^{\text {off }}$ necessitam ser estudadas. Considerando os resultados experimentais de espalhamento de luz e raios-X de dispersões aquosas de DMPG, foi feita 
uma interpretação alternativa, através de um modelo teórico que estuda as propriedades estatísticas de dispersões de agregados anfifílicos, levando em consideração tanto os graus de liberdade internos, expressos, por exemplo, através de flutuações na forma dos agregados, bem como algumas propriedades relevantes da dispersão, tal como polidispersidade. Os resultados obtidos para a termodinâmica de um sistema modelo, com base em regras de soma formuladas adequadamente para a densidade de anfifílicos (Goldman et al., 1999), incluindo a presença de sal (Goldman, 2001), sugeriram que a estatística da dispersão poderia ser, de fato, determinante no estado dos anfifílicos agregados. Apesar de não apresentar transições de fase, o modelo estudado foi capaz de interpretar, qualitativamente, dados obtidos por espalhamento de luz e SAXS em dispersões de DMPG a baixa força iônica. Neste modelo, aparece uma distribuição de partículas de diferentes tamanhos, dependente da temperatura. Relativo ao pico de Bragg mencionado acima, existiria a possibilidade das partículas menores serem pequenos fragmentos de bicamada, bicelas, e o pico de Bragg estar relacionado à distância entre bicelas. Portanto, para a compreensão do comportamento termo-estrutural do DMPG em baixa força iônica necessitamos de mais estudo, tanto experimental como de modelos teóricos consistentes.

Baseado nos vários trabalhos publicados com dispersões de DMPG, em baixa força iônica e pH em torno de 7,4, não é possível chegar a um consenso acerca da estrutura e forma assumidas pelos agregados de DMPG nestas condições. Epand \& Hui, 1986, em água e pH 7, observaram uma mistura de poucas vesículas e muitas estruturas em forma de conchas, na fase gel. Estruturas em forma de folhas lipídicas, em tampão Hepes 10 $\mathrm{mM}$ com $2 \mathrm{mM}$ de $\mathrm{NaCl}$ à $15{ }^{\circ} \mathrm{C}$, foram observadas por Kinoshita et al., 2008. Por outro lado, em condições semelhantes (tampão Hepes $2 \mathrm{mM}+1 \mathrm{mM}$ de EDTA pH 7,5), Schneider et al., 1999, à $9{ }^{\circ} \mathrm{C}$, portanto também na fase gel, constataram a presença de vesículas grandes. Esta divergência entre os dois últimos trabalhos citados, juntamente com a diversidade de formas estruturais relatadas em outros trabalhos, são suficientes para justificar um estudo mais aprofundado sobre o assunto.

Além do interesse físico-químico, é possível que as características peculiares de dispersões de DMPG tenham aplicações diretas na indústria. Por exemplo, a alta viscosidade, em temperatura ambiente, pode ser útil na confecção de espessantes. A dependência da turbidez com a temperatura talvez possa ser utilizada em algum sistema controlador de passagem de luz. 
A presente tese teve por objetivo entender melhor o comportamento termoestrutural de dispersões de DMPG. Para a compreensão do balanço de forças entre as interações repulsivas das cabeças polares e atrativas das cadeias hidrocarbônicas, estudamos as dispersões de DMPG em várias forças iônicas. Suas propriedades foram comparadas com a de seu análogo zwitteriônico, DMPC. Em particular, estivemos interessados na caracterização dos agregados presentes no meio, em suas interações intra-agregado e interagregados, e na compreensão dos processos de transição de fase das bicamadas lipídicas. Para entender as estruturas de agregação e as possíveis interações inter-agregados das dispersões de DMPG, foi feito um estudo cuidadoso em função da concentração lipídica. Para atingir o objetivo do trabalho, foram utilizadas várias técnicas experimentais para obter propriedades macroscópicas das dispersões (variação de calor específico, turbidez, condutividade e viscosidade). Através destas propriedades, que se mostraram complementares, foi possível compreender melhor, em nível microscópico, tanto a estrutura dos agregados quanto suas possíveis interações inter-agregados. 


\section{Capítulo 2}

\section{Materiais e Métodos}

\subsection{Materiais}

\section{Reagentes:}

Lipídios - o sal de sódio DMPG (1,2-Dimiristoil-sn-glícero-3-[Fosfo-rac-(1-glicerol)]) e o DMPC (1,2-Dimiristoil-sn-glícero-3-Fosfocolina) foram adquiridos da Avanti Polar Lipids. As figuras 2.1 e 2.2 mostram suas respectivas estruturas moleculares. O pK aparente do grupo fosfato do DMPG, em baixa força iônica, é 4,7 (Riske et al., 2002).

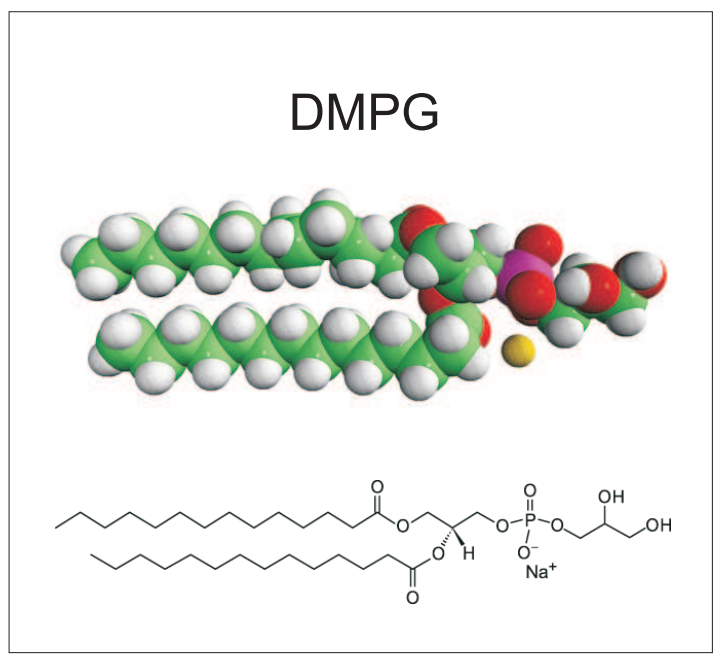

Figura 2.1: Estrutura molecular do DMPG.

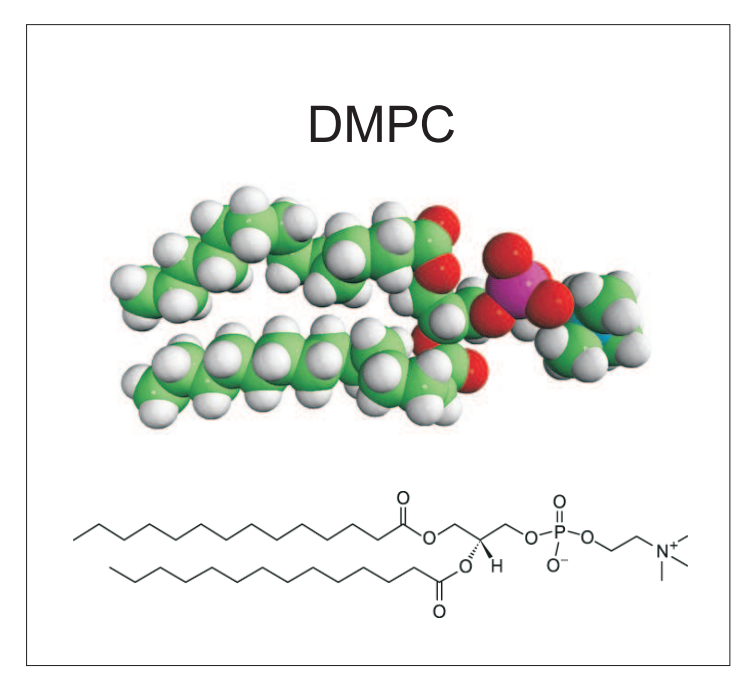

Figura 2.2: Estrutura molecular do DMPC.

Solventes - Os solventes orgânicos usados foram clorofórmio e metanol, ambos P.A., sendo o primeiro comprado da Casa Americana e o segundo da Merck. O tampão Hepes (ácido de N-(2-Hidroxietil)-Piperazina-N'-2-etano sulfônico) foi comprado da Sigma Chemical Co. 
Sais - utilizou-se apenas cloreto de sódio ( $\mathrm{NaCl})$, comprado da Sigma Chemical Co.

\section{$2.2 \quad$ Métodos}

\subsubsection{Ajuste de $\mathrm{pH}$}

O ajuste do tampão Hepes, que possui $\mathrm{pK}=7,55$, foi feito adicionando-se pequenas quantidades de $\mathrm{NaOH}$ (hidróxido de sódio) até que o pH de 7,4 fosse atingido.

\subsubsection{Preparação das amostras}

Inicialmente foram preparados filmes lipídicos através da evaporação (feita por fluxo de nitrogênio gasoso) de uma solução de DMPG ou DMPC, conforme desejado, dissolvida em clorofórmio e algumas gotas de metanol. Em seguida, os tubos de ensaio contendo os filmes foram deixados por pelo menos duas horas à baixa pressão para que não houvesse mais traços do solvente orgânico. Após isso, o solvente (Hepes $10 \mathrm{mM}+$ concentração de $\mathrm{NaCl}$ desejada) foi posto no tubo de ensaio que ficava em um banho térmico a $50{ }^{\circ} \mathrm{C}$ por cerca de 10 minutos e em seguida agitado em um vórtex por 2 minutos.

Para altas concentrações de DMPG (acima de $40 \mathrm{mM}$ ), o pH da dispersão varia um pouco, decrescendo de 7,4 para 7,2. 


\subsubsection{Medidas de Calorimetria Exploratória Diferencial (DSC)}

As medidas de DSC, com compensação de potência, foram feitas em um calorímetro da Microcal, modelo VP-DSC, a uma taxa de aquecimento variando de 10 a 20 ${ }^{\circ} \mathrm{C} / \mathrm{h}$, dependendo da concentração lipídica (maiores detalhes na seção de Resultados e Discussões). O calorímetro consiste de duas celas dentro de um invólucro de isolamento térmico (figura 2.3). Uma das celas contém a amostra (dispersão lipídica), e a outra a referência (tampão), sendo o volume das celas de $0,51 \mathrm{~mL}$.

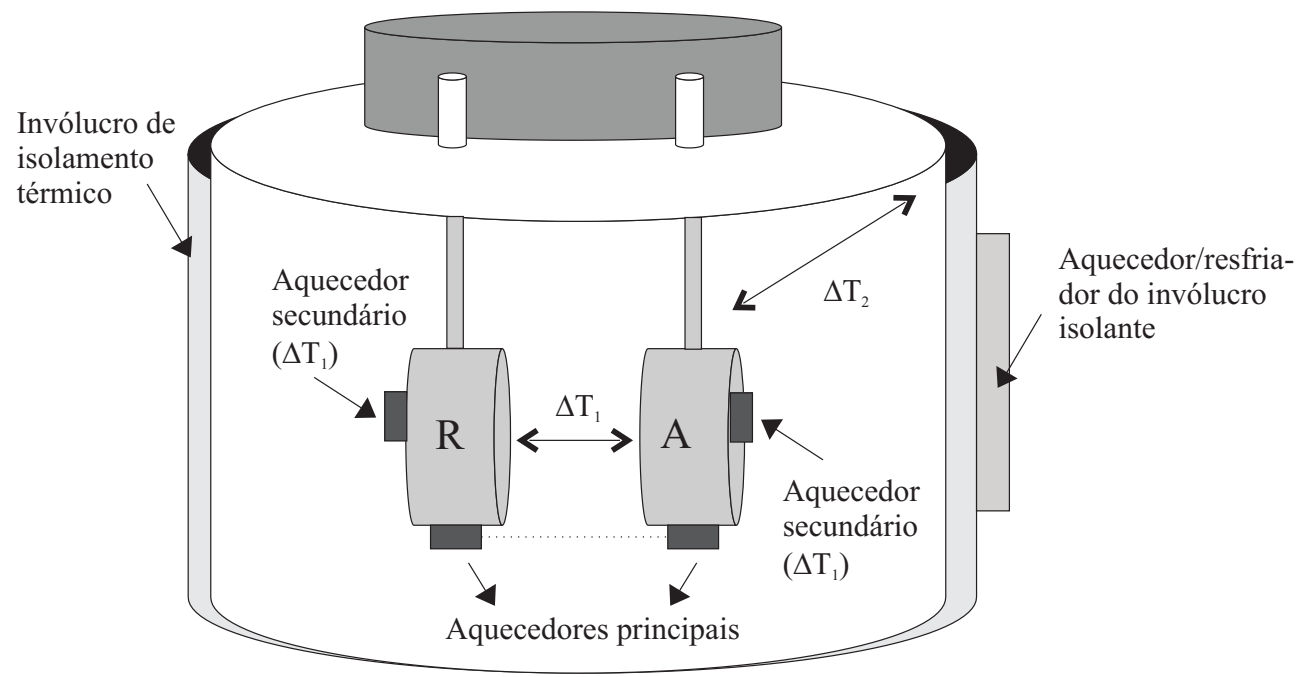

Figura 2.3: Desenho esquemático de um calorímetro de DSC com compensação de potência. Os símbolos $\mathrm{R}$ e A referem-se à cela de referência e da amostra, respectivamente.

Ambas as celas são esquentadas com aquecedores tipo Peltier a uma taxa constante (um para cada cela, nomeados aquecedores principais na figura 2.3). A diferença de temperatura entre as duas celas, $\Delta T_{1}$, é mantida constante. Na transição de fase, a amostra absorve mais calor que é compensado pelos aquecedores. A potência dos dois aquecedores é ajustada de tal forma que a taxa de aquecimento seja constante e não haja diferença de temperatura entre as duas celas. Pequenas variações na diferença de temperatura entre as celas são compensadas por aquecedores auxiliares conectados a cada uma das celas (aquecedores secundários). Além disso, a diferença de temperatura entre as celas e o invólucro de isolamento, $\Delta T_{2}$, é constantemente medida e um aquecedor/resfriador ligado ao invólucro controla sua temperatura de modo a manter $\Delta T_{2} \cong 0$ (para obter uma descrição detalhada do instrumento, ver Plotnikov et al., 1997).

A diferença de potência entre as duas celas é gravada em função da temperatura. O software apresenta um gráfico desta diferença de potência, em mcal $/ \mathrm{min}$, em 
função da temperatura. Dividindo a diferença de potência por minuto pela taxa de aquecimento/resfriamento, em ${ }^{\circ} \mathrm{C} / \mathrm{h}$, obtemos a capacidade térmica, dada em unidades de cal $/{ }^{\circ} \mathrm{C}$ (figura 2.41). Finalmente, para obter o calor específico, dividimos a capacidade térmica pelo número de mols da amostra (concentração lipídica/volume da cela), obtendo assim unidades de calor específico, cal $/{ }^{\circ} \mathrm{C} / \mathrm{mol}$ (figura $2.4(2)$ ).

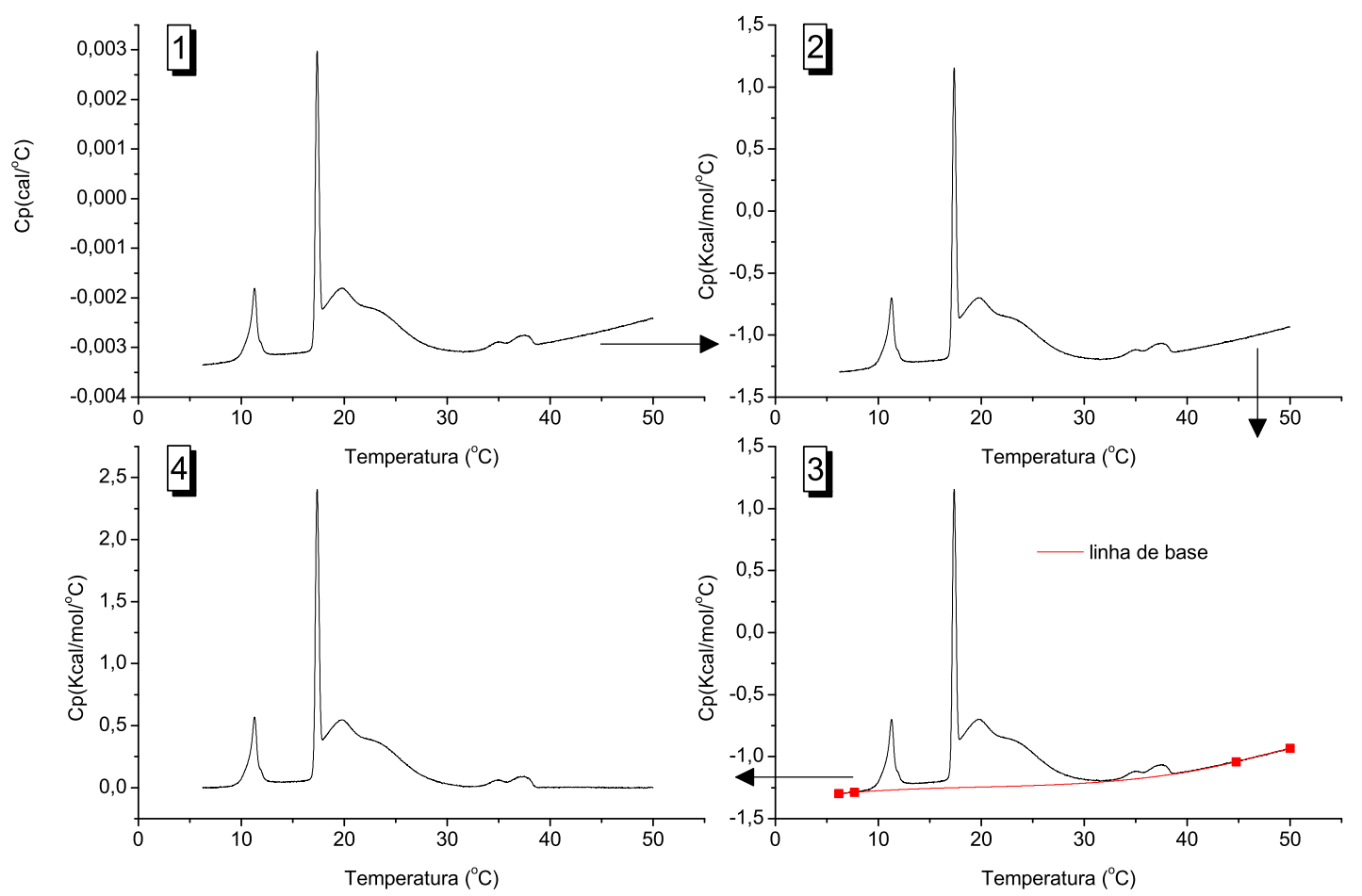

Figura 2.4: Tratamento dos dados de um experimento de DSC. O primeiro dado a sair do aparelho é uma curva da variação de potência por minuto, para manter as duas celas do calorímetro na mesma temperatura, em função da temperatura. A curva é normalizada pela taxa de aquecimento/resfriamento (1) e em seguida normalizada pela concentração de amostra (2). Após a criação de uma linha de base (3), a mesma é subtraída da curva original (2) resultando na curva DSC final (4).

Conforme podemos observar da figura 2.4(1), a curva DSC bruta apresenta uma linha de base, muitas vezes com uma certa inclinação. No nosso caso, a linha de base se deve, principalmente, à diferença entre o calor específico da água e dos lipídios. Uma vez que o calor específico da água é muito alto $\left(4183 \mathrm{~J} / \mathrm{gK}\right.$ a $\left.14^{\circ} \mathrm{C}\right)$, a diferença entre o volume ocupado pelos lipídios na amostra e a água na referência, causa uma linha de base que geralmente assume valores negativos (Heimburg, 2007). Para analisar os dados de maneira adequada, é necessário subtrair a linha de base da curva DSC. As subtrações 
das linhas de base foram feitas usando o software Microcal Origin com ferramentas adicionais específicas para análise de dados de DSC fornecidos pela Microcal. Inicialmente, selecionamos segmentos de reta no início e final da curva DSC (segmentos ligando os pontos vermelhos na figura 2.4(3)), os quais darão origem às extremidades da linha de base. Em seguida, o software cria a linha de base ligando estes dois segmentos através de um polinômio de ordem três (linha vermelha na figura 2.4(3)). Depois de feita a subtração da linha de base, a entalpia da transição era obtida, por intermédio do mesmo software, através do cálculo numérico da área sob a curva DSC. 


\subsubsection{Medidas de Viscosidade}

As medidas de viscosidade foram feitas através de um viscosímetro de Ostwald imerso em um banho térmico (modelo CT52). O viscosímetro é acoplado a um medidor de tempo de fluxo de líquidos (modelo Viscocloth D-55122). Os três instrumentos, que fazem parte de um mesmo conjunto, foram obtidos da Schott Instruments.

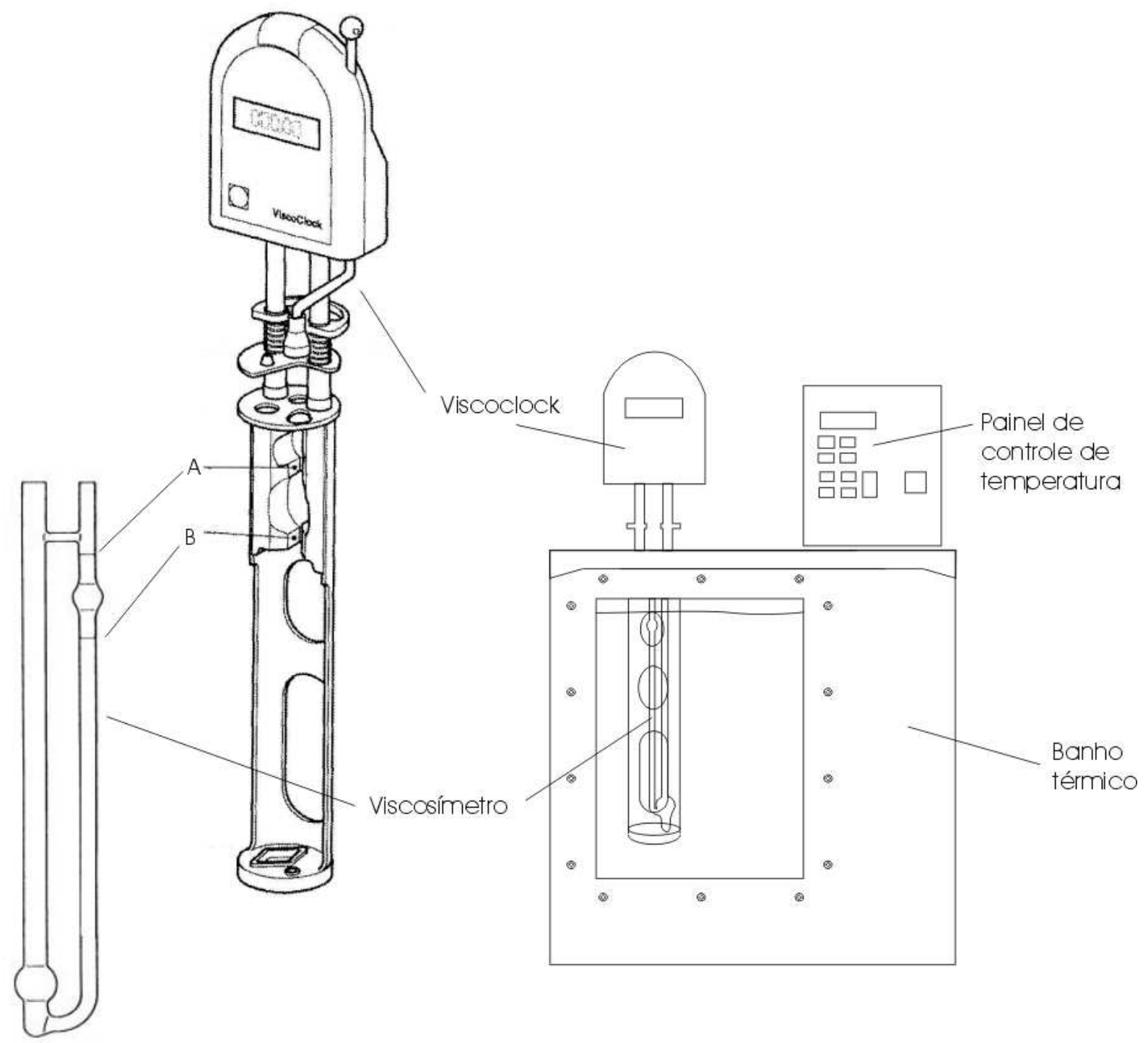

Figura 2.5: Desenho esquemático do aparato experimental usado nas medidas de viscosidade.

A figura 2.5 apresenta um desenho do arranjo experimental. $2 \mathrm{ml}$ de amostra são inseridos dentro do viscosímetro. Um pequeno fluxo de ar é injetado no viscosímetro, através de uma pequena bomba manual, empurrando o líquido até atingir uma altura maior do que o primeiro sensor (item A na figura 2.5). O fluxo de ar é retirado e o líquido flui, sob ação exclusiva da gravidade. Quando a altura do líquido atinge o primeiro sensor, 
o cronômetro é automaticamente disparado, sendo desligado quando a altura atinge o segundo sensor (item B na 2.5). O tempo de fluxo, indicado no painel do viscoclock, é utilizado para calcular a viscosidade cinemática, de acordo com a fórmula

$$
\eta=K t
$$

onde $K$ é uma constante que depende da geometria do capilar do viscosímetro e $t$ é o tempo de fluxo. A temperatura foi controlada através do banho térmico e medida com um termopar (modelo Fluke $51 \mathrm{~K} / \mathrm{J}$ ). O tempo de termalização de cada medida foi de 10 minutos. As incertezas nos dados são o desvio padrão da média de no mínimo três amostras distintas. Quando não houver barra de erro é porque a incerteza é menor do que o tamanho do símbolo usado para representar os dados. 


\subsubsection{Medidas de condutividade}

As medidas de condutividade foram feitas num condutivímetro da WTM modelo inoLab Cond 730. A cela medidora de condutividade trata-se de uma ponteira contendo quatro eletrodos (modelo TetraCon 325). A figura 2.6 apresenta um desenho esquemático do aparato experimental.

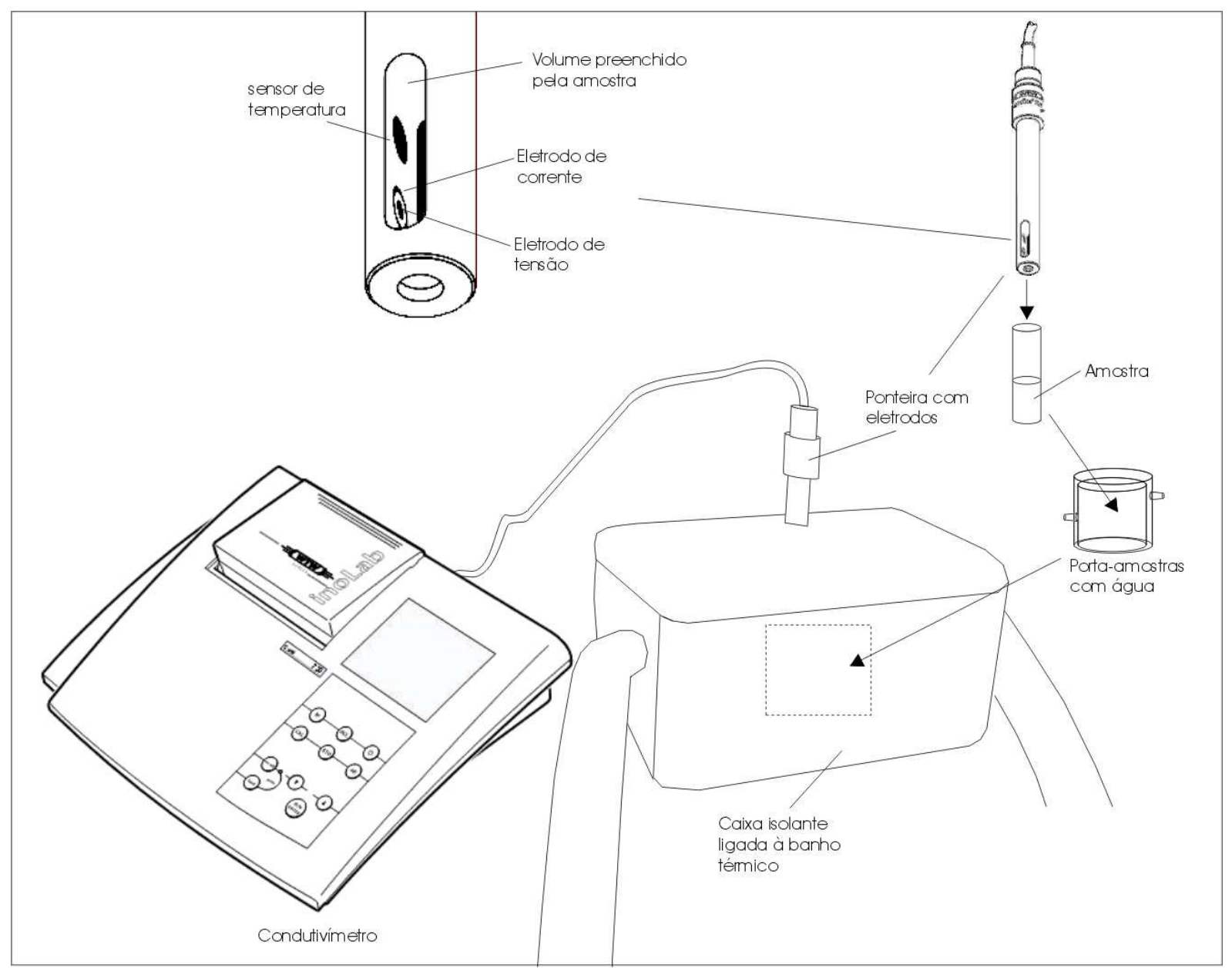

Figura 2.6: Desenho esquemático do aparato experimental usado nas medidas de condutividade.

A amostra era colocada num cilindro de vidro com diâmetro levemente maior do que da ponteira que, por sua vez, era imersa no cilindro de tal forma que o volume de amostra fosse suficiente para cobrir os eletrodos (cerca de 3,5 ml). O vão entre a ponteira e o frasco de vidro era fechado com fita tipo paralfilm para evitar evaporação de amostra. Finalmente, a ponteira envolta pela amostra era colocada num porta-amostras com água, dentro de uma caixa de isopor preenchida com um isolante térmico. O porta-amostras estava ligado diretamente a um banho térmico (modelo HP25 da Julabo). 
Resumidamente, a medida é feita da seguinte maneira: aplica-se uma corrente alternada em dois eletrodos (eletrodos de corrente, na figura 2.6) e mede-se a tensão entre os outros dois eletrodos (eletrodos de tensão, figura 2.6). A partir destes valores, calcula-se a condutância da amostra, $G$, dada por,

$$
G=\frac{I}{V}
$$

onde $I$ é a corrente e $V$ a tensão. A condutividade da amostra, $\sigma$, é obtida através da fórmula

$$
\sigma=G K
$$

onde $K$, obtida através de calibração com uma solução de $\mathrm{KCl}$ de condutividade conhecida, é uma constante relacionada à geometria dos eletrodos (razão entre a área e distância entre os mesmos). Para uma descrição detalhada da eletrônica da cela de condutividade, ver Anderson et al., 1969.

O condutivímetro tem uma função de armazenagem automática dos dados, guardando os valores da condutividade a cada intervalo de tempo definido pelo usuário. Como o banho térmico pode ser controlado remotamente via computador (através de interface RS-232), desenvolvemos um programa para mudar automaticamente a temperatura do banho a cada 10 minutos. Com isso, programando o condutivímetro para armazenar a condutividade a cada 10 minutos e, iniciando o processo concomitantemente ao programa do computador, pudemos criar um sistema de aquisição de dados automatizado.

As incertezas nos dados são o desvio padrão da média de no mínimo três amostras distintas. Quando não houver barra de erro é porque a incerteza é menor do que o tamanho do símbolo usado para representar os dados 


\subsubsection{Medidas de mobilidade eletroforética}

As medidas de mobilidade eletroforética foram feitas num aparelho Zetasizer da Malvern (modelo Nano317), no laboratório de Bioquímica do Instituto de Química da USP, gentilmente cedido pela Profa. Dra. Iolanda Cuccovia. A dispersão era colocada dentro de uma célula contendo dois eletrodos, aos quais era aplicada uma tensão alternada. Os agregados em solução, sob efeito do campo elétrico proveniente da tensão, movem-se em direção aos eletrodos. Um feixe de laser incide sobre a amostra e é espalhado pelos agregados lipídicos contidos em solução. Isto gera uma flutuação ao longo do tempo na diferença de fase entre o feixe incidente e o espalhado. Esta flutuação é proporcional à velocidade dos agregados. Tendo a velocidade, a mobilidade $(\mu)$ é obtida através da fórmula $\mu=v / E$, onde $v$ é a velocidade e $E$ o campo elétrico aplicado (razão entre a tensão aplicada e a distância entre os eletrodos). Para as dispersões em baixa força iônica, utilizamos uma tensão de $149 \mathrm{~V}$, enquanto que para forças iônicas maiores, a tensão foi diminuída (variando entre 40 e $80 \mathrm{~V}$ ) para evitar oxidação dos eletrodos.

\subsubsection{Determinação da incorporação de $\left[{ }^{14} \mathrm{C}\right]$ sacarose}

A sacarose foi introduzida nas dispersões lipídicas de duas maneiras distintas. Na primeira, cujo método denominaremos por dentro e fora, as dispersões foram preparadas através de filmes lipídicos (conforme descrito acima), os quais foram suspensos em tampão Hepes $10 \mathrm{mM}$ com $2 \mathrm{mM}$ de $\mathrm{NaCl}$ contendo sacarose radioativa. Já na segunda maneira, denominada por fora, a sacarose foi adicionada à dispersão já contendo os agregados lipídicos. Para remover a sacarose livre, a dispersão foi passada por uma coluna cromatográfica (Sephadex G-25), previamente saturada com dispersão do lipídio desejado, e coletada em frações de volume por um coletor de frações.

Foram utilizadas duas colunas diferentes para dispersões de DMPG e DMPC, ambas com volume de 31,7 ml (altura de 28,6 cm e diâmetro de 1,2 cm). As colunas foram mantidas à temperatura constante $\left(6{ }^{\circ} \mathrm{C}\right.$ ou $\left.45^{\circ} \mathrm{C}\right)$ durante todo o processo de eluição. Para tanto, as colunas foram montadas dentro de uma estufa $\left(45^{\circ} \mathrm{C}\right)$ ou de uma geladeira $\left(6{ }^{\circ} \mathrm{C}\right)$. A fração coletada por tubo foi de $0,7 \mathrm{ml}$. Parte do volume coletado em cada fração (400 $\mu$ l) foi misturada a um tubo de cintilação contendo $10 \mathrm{ml}$ de líquido de cintilação. A radiação contida na mistura foi medida em um cintilador modelo 1600TR Packard e descontada da radiação de fundo (medida previamente em cada tubo de cintilação, 
contendo apenas o líquido de cintilação).

Para determinar em que frações estavam saindo os agregados lipídicos, parte do volume das frações $(100 \mu \mathrm{l})$ foi usada para fazer dosagem de fosfato, usando o método descrito em Rouser et al., 1970. Resumidamente, o grupo fosfato da cabeça polar do fosfolipídio é convertido em fosfato inorgânico através de reação com ácido perclórico em alta temperatura. O fosfato inorgânico reage com o molibidato de amônio formando um complexo de fosfomolibdato de amônio. Finalmente, por ação de ácido ascórbico, em meio alcalino, o complexo formado é reduzido a azul de molibdênio, cuja absorbância medida em $797 \mathrm{~nm}$ é diretamente proporcional à quantidade de fósforo na amostra analisada. Portanto, medindo a absorbância em cada fração de volume, após passar pelo processo supradescrito, é possível detectar a presença ou não de agregados lipídicos.

A incorporação da sacarose é detectada se houver um pico de contagem de radiação na mesma faixa de frações em que os agregados lipídicos estão saindo.

As medidas de absorbância relativas à dosagem de fosfato foram feitas num espectrofotômetro Hitachi, em cubetas com caminho óptico de $1 \mathrm{~cm}$.

\subsubsection{Medidas de absorbância (turbidez)}

As medidas de absorbância foram feitas em um espectrofotômetro da Varian, modelo Cary 50, onde a amostra foi colocada em uma cubeta de quartzo, com caminho ótico de $2 \mathrm{~mm}$. A temperatura foi controlada e mantida através de um banho térmico Julabo HP25, e medida com uma sonda de temperatura do próprio espectrofotômetro. A absorbância foi medida em 350 nm. 


\section{Capítulo 3}

\section{Técnicas experimentais}

\subsection{Turbidez}

A luz incidente sobre um sistema pode ser transmitida, refratada, espalhada ou absorvida. A absorbância $A$ é definida como o logaritmo decimal da luz transmitida $I_{T}$ pela luz incidente $I_{0}$ (Hiemenz, 1986)

$$
A=-\log \left(\frac{I_{T}}{I_{0}}\right)
$$

Em um experimento de espalhamento de luz com materiais não absorvedores, a intensidade de luz transmitida é igual à intensidade inicial menos a intensidade de luz espalhada em todas as direções $I_{S}$ :

$$
I_{T}=I_{0}-I_{S}
$$

Combinando as equações 3.1 e 3.2 :

$$
A=-\log \left(\frac{I_{0}-I_{S}}{I_{0}}\right)=-\log \left(1-\frac{I_{S}}{I_{0}}\right)
$$

A grandeza $I_{S} / I_{0}$ é denominada turbidez $\tau$ e relaciona-se com a absorbância conforme a equação abaixo

$$
\tau=1-10^{-A}
$$




\subsection{Calorimetria exploratória diferencial (DSC)}

Técnica na qual se mede a diferença de energia fornecida à substância e a um material referência, em função da temperatura, enquanto a substância e o material são submetidos a uma programação controlada de temperatura (Höhne et al., 2003). A técnica de DSC tem sido extensivamente aplicada no estudo de sistemas biológicos (Sturtevant, 1987; Heerklotz, 2004), sendo capaz de obter informações termodinâmicas acerca do sistema investigado. A capacidade térmica, à pressão constante, é definida como o aumento de calor, $d Q$, por incremento de temperatura, $d T$ (Callen, 1985):

$$
C_{p}=\left(\frac{d Q}{d T}\right)_{p}
$$

A variação de entalpia de um sistema, pode ser obtida da seguinte relação termodinâmica:

$$
d H=d Q+V d p
$$

onde $V$ é o volume e $d p$ a variação de pressão. Portanto, à pressão constante, obtemos

$$
C_{p}=\left(\frac{d H}{d T}\right)_{p}
$$

Como também $d Q=T d S$, onde $d S$ é a variação de entropia do sistema, a capacidade térmica, à pressão constante é dada por

$$
C_{p}=T\left(\frac{d S}{d T}\right)_{p}
$$

O calor específico à pressão constante, $c_{p}$, é definido como a capacidade térmica por partícula, ou seja,

$$
c_{p}=\frac{T}{N}\left(\frac{d S}{d T}\right)_{p}
$$

onde $N$ é o número de partículas. Usando as equações acima, é possível determinar mudanças de entalpia, $\Delta H$, e de entropia, $\Delta S$, conhecendo a capacidade térmica em função da temperatura:

$$
\begin{aligned}
& \Delta H=\int C_{p} d T \\
& \Delta S=\int \frac{C_{p}}{T} d T
\end{aligned}
$$

Portanto, através da determinação da capacidade térmica é possível obter informações termodinâmicas de um sistema. 
A existência de flutuações em um estado em torno de um estado mais provável é uma das mais fundamentais características da termodinâmica. Usando o teorema da flutuação-dissipação de energia (Kubo, 1966), é possível escrever a capacidade térmica, à pressão constante, em termos de flutuações de entalpia

$$
C_{p}=\frac{d\langle H\rangle}{d T}=\frac{\left\langle H^{2}\right\rangle-\langle H\rangle^{2}}{R T^{2}}
$$

\subsection{Condutividade elétrica e mobilidade eletroforética}

A condutividade elétrica de uma solução aquosa trata-se de uma medida da capacidade que esta tem de conduzir corrente elétrica. Neste caso, a condução é iônica, isto é, a corrente é transportada pelos íons presentes na solução (eletrólitos).

O modelo mais simplificado para a condutividade de eletrólitos baseia-se em considerá-los como esferas não interagentes sujeitas apenas a uma força elétrica, $\vec{F}=q \vec{E}$, onde $q$ é a carga do eletrólito e $E$ a intensidade do campo elétrico, e uma força de atrito viscoso, $\vec{F}_{a}=-b \vec{v}$, sendo $b$ o coeficiente de atrito viscoso da partícula no meio. Quando ambas as forças se igualam, o eletrólito caminha com uma velocidade constante (velocidade limite) cujo módulo é dado por:

$$
v=\frac{q E}{b}
$$

A razão $q / b$ está ligada à facilidade de locomoção do íon e quanto maior ela for, conforme a equação 3.13, maior será a velocidade do íon. Essa razão é denominada mobilidade eletroforética $\mu$ e também pode ser expressa diretamente pela razão entre a velocidade e o campo elétrico $v / E$. Segundo a lei de Ohm (microscópica), a densidade de corrente elétrica $J$ é proporcional ao campo elétrico, isto é, $J=\sigma E$. A constante de proporcionalidade $\sigma$ é a condutividade. A densidade de corrente elétrica também pode ser escrita como:

$$
J=n q v
$$

onde $n$ é o número de íons por unidade de volume. Inserindo a equação 3.13 na equação 3.14 e usando a lei de Ohm, obtemos a seguinte expressão para a condutividade:

$$
\sigma=\frac{n q^{2}}{b}
$$


que pode ser ainda reescrita em termos da mobilidade eletroforética como:

$$
\sigma=\mu q n
$$

Embora as medidas de condutividade iônica de dispersões lipídicas sejam relativamente simples, sua interpretação teórica, ao nível molecular, não é tão simples. Primeiramente devemos levar em conta a forma dos agregados lipídicos. Caso eles possuam volume interno (vesículas, por exemplo), parte dos íons presentes na dispersão ficará aprisionada dentro dos agregados e, portanto, não contribuirá para a condutividade. Em seguida, temos que levar em conta a carga dos agregados, pois, se eles forem carregados, certamente haverá contraíons livres em solução, provenientes das cabeças polares dos anfifílicos dos agregados, aumentando a condutividade medida. Além disso, os próprios agregados devem ser considerados como íons grandes, trazendo também uma contribuição à condutividade medida. Assim sendo, para o caso de dispersões lipídicas carregadas, basicamente existem três transportadores de carga: os íons do tampão, os agregados lipídicos, comportando-se como macro-íons, e os contraíons das cabeças polares dos lipídios. Portanto, mudanças na condutividade elétrica de uma dispersão estão diretamente relacionadas à associação/dissociação dos lipídios (variação na quantidade de contraíons) bem como ao tamanho e/ou forma dos agregados (variação na velocidade dos íons causa variação na condutividade). 


\subsection{Estimativa da fração de volume interno e do grau de ionização de vesículas}

A fração de volume interno de vesículas, $\phi$, é definida como a razão entre o volume ocupado pelas vesículas e o volume total da solução. Como esta grandeza será bastante utilizada ao longo da tese, apresentamos a seguir a dedução da fórmula que usaremos para o cálculo de $\phi$.

Supondo vesículas esféricas de raio $R$, temos que

$$
\phi=\frac{4 \pi R^{3}}{3 V} N_{v}
$$

onde $N_{v}$ é o número de vesículas e $V$ o volume total da solução. O número de vesículas é dado pela razão entre o número total de lipídios na solução, $n_{T}$, e o número de lipídios por vesícula, isto é,

$$
N_{v}=\frac{n_{T}}{n_{e x t}+n_{\text {int }}}
$$

onde $n_{\text {ext }}$ é o número de lipídios da camada externa da vesícula e $n_{\text {int }}$ o da interna. O número total de lipídios, pode ser obtido através da concentração lipídica molar, ou seja,

$$
n_{T}=[\text { lipídios }] N_{A} V
$$

onde $N_{A}$ é o número de Avogadro. Vamos supor ainda que a área ocupada pela cabeça polar de cada lipídio seja a mesma para os lipídios das camadas interna e externa, e dada por $a$. Com isso, podemos estimar $n_{\text {ext }}$ e $n_{\text {int }}$ aproximando as áreas superficiais externa e interna da vesícula como sendo a soma das áreas de todos os lipídios contidos na monocamada externa e interna:

$$
4 \pi R^{2}=n_{e x t} a
$$

analogamente:

$$
4 \pi(R-d)^{2}=n_{\text {int }} a
$$

onde $d$ é a espessura da bicamada (ver figura 3.1). Inserindo as equações 3.19, 3.20 e 3.21 na equação 3.18, obtemos o número de vesículas

$$
N_{v}=\frac{a[\text { lipídios }] N_{A} V}{4 \pi\left[R^{2}+(R-d)^{2}\right]}
$$


que, por sua vez, inserida na equação 3.17, resulta em

$$
\phi=\frac{N_{A}[\text { lipídios }] a R^{3}}{3\left[R^{2}+(R-d)^{2}\right]}
$$

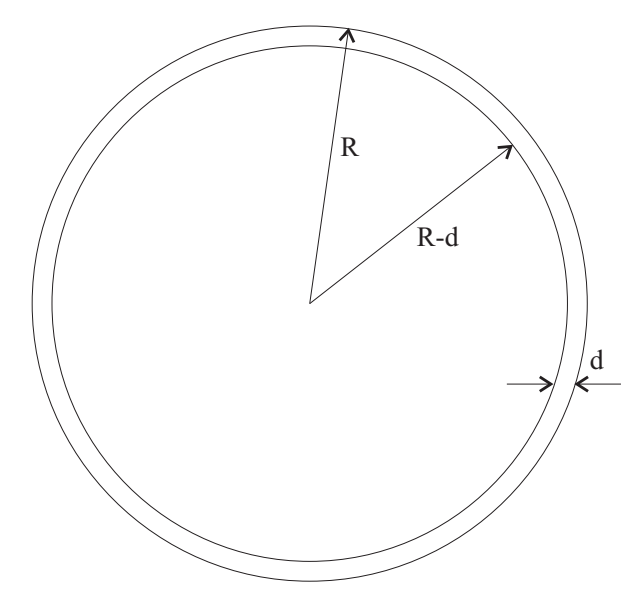

Figura 3.1: Desenho esquemático de uma vesícula esférica de raio $R$ e espessura de bicamada $d$.

As tabelas 3.1 e 3.2 apresentam os parâmetros utilizados para os cálculos de $\phi$ na presente tese:

\begin{tabular}{ccc}
\hline \hline Temperatura $\left({ }^{\circ} \mathrm{C}\right)$ & $\mathrm{a}\left(\mathrm{nm}^{2}\right)$ & $\mathrm{d}(\mathrm{nm})$ \\
\hline \hline 5 a 18 & 0,48 & 5,22 \\
18,5 a 32 & 0,60 & 5,02 \\
33 a 50 & 0,60 & 4,48 \\
\hline
\end{tabular}

Tabela 3.1: Parâmetros utilizados para o cálculo da fração de volume ocupado por agregados de DMPG, $\phi$. Área por cabeça polar, $a$, obtida de Marsh \& Phil, 1990 e espessura da bicamada, $d$, obtida de Riske et al., 2001. Os agregados serão considerados vesículas de raio $R=35 \mathrm{~nm}$, estimado por medidas de espalhamento de luz (Enoki et al., em fase de escrita). 


\begin{tabular}{ccc}
\hline \hline fase & $\mathrm{a}\left(\mathrm{nm}^{2}\right)$ & $\mathrm{d}(\mathrm{nm})$ \\
\hline \hline gel & 0,53 & 5,02 \\
fluida & 0,65 & 4,48 \\
\hline
\end{tabular}

Tabela 3.2: Parâmetros utilizados para o cálculo da fração de volume ocupado por vesículas de DMPC, $\phi$, com raio $R=50 \mathrm{~nm}$ (dispersões extrusadas 11 vezes por filtro de $100 \mathrm{~nm}$ ). Parâmetros obtidos de Marsh \& Phil, 1990.

Tendo definido a fração de volume interno, apresentamos a seguir uma dedução do grau de ionização aparente das bicamadas de vesículas lipídicas unilamelares.

O grau de ionização de um agregado lipídico, $\alpha$, é definido como a fração de anfifílicos carregados, ou seja,

$$
\alpha=\frac{n^{ \pm}}{n_{T}}
$$

onde $n^{ \pm}$é o número de anfifílicos carregados e $n_{T}$ o número total de anfifílicos do agregado. Conhecendo a condutividade elétrica de uma dispersão lipídica, bem como a mobilidade dos agregados lipídicos e seus respectivos contraíons, é possível estimar o grau de ionização aparente das monocamadas das vesículas, como será apresentado a seguir.

Tratando as vesículas de uma dispersão como sendo íons grandes, a condutividade da dispersão será uma soma das condutividades do tampão $\left(\sigma_{0}\right)$, das vesículas $\left(\sigma_{v}\right)$ e de seus respectivos contraíons $\left(\sigma_{c}\right)$

$$
\sigma=\sigma_{0}+\sigma_{v}+\sigma_{c}
$$

que pode ser reescrita, com o auxílio da equação 3.16, como

$$
\sigma=\sigma_{0}+N_{v} \mu_{v} Q_{v}+N_{c} \mu_{c} Q_{c}
$$

onde $Q$ é a carga, $N_{v}$ é o número de vesículas por volume e $N_{c}$ o número de contraíons por volume.

Como as vesículas possuem volume interno aquoso, é preciso descontar os íons da solução que não contribuem para condutividade. Isto é feito substituindo-se o primeiro termo do lado direito da equação 3.26 por $\sigma_{0}(1-\phi)$, onde $\phi$ é a fração de volume ocupado pelas vesículas.

Considerando que apenas a carga devida à monocamada externa da vesícula con- 
tribuirá para a condutividade da dispersão lipídica, a carga da vesícula será dada por

$$
Q_{v}=z e n_{e x t}^{ \pm}=z e \alpha n_{e x t}
$$

onde $e$ é a carga do elétron e $z$ a valência dos contraíons. A carga de cada contraíon é dada por ze e o número de contraíons por volume é igual ao número de lipídios carregados vezes o número de vesículas por volume, isto é,

$$
N_{c}=n_{e x t} \alpha N_{v}
$$

Portanto, a equação 3.26 fica

$$
\sigma=\sigma_{0}(1-\phi)+N_{v} \mu_{v} z e \alpha n_{e x t}+n_{e x t} \alpha N_{v} \mu_{c} z e
$$

Finalmente, inserindo as equações 3.20 e 3.22 na equação 3.29 e isolando $\alpha$, obtemos o grau de ionização da monocamada externa em função da condutividade da dispersão, da mobilidade eletroforética dos contraíons e das vesículas e de suas respectivas propriedades geométricas:

$$
\alpha=\frac{\left[\sigma-\sigma_{0}(1-\phi)\right]\left[R^{2}+(R-d)^{2}\right]}{z e N_{A}[\text { lipídios }] R^{2}\left(\mu_{v}+\mu_{c}\right)}
$$




\subsection{Viscosidade}

\subsubsection{Definição de viscosidade}

Um fluido é definido como uma substância que se deforma continuamente sob a ação de esforços tangenciais. Na ausência destes esforços não ocorrem deformações. Os fluidos podem ser classificados, de um modo geral, de acordo com o valor da razão entre os esforços tangenciais aplicados e as respectivas taxas de deformação (Fox, 1988). Seja um elemento de fluido contido entre duas placas infinitas, planas e paralelas (figura 3.2).

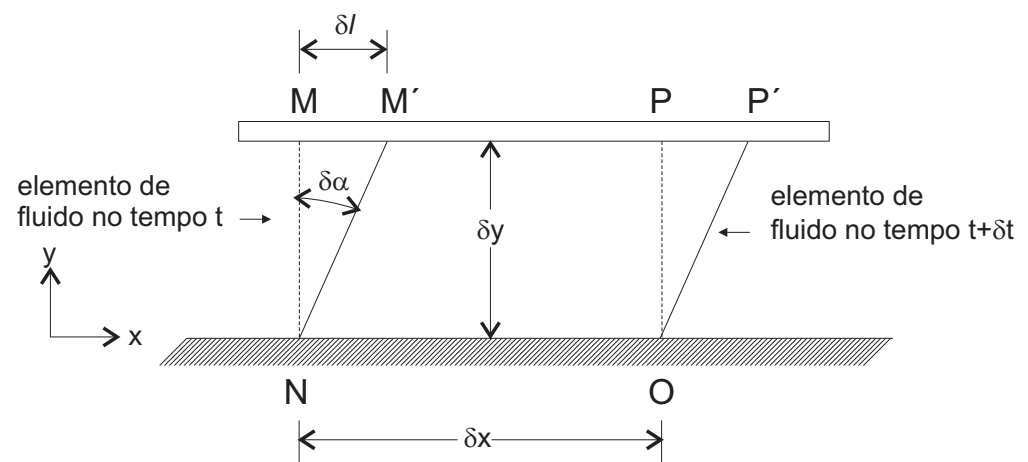

Figura 3.2: Deformação de um elemento de fluido. Adaptada de Fox, 1988.

A placa superior move-se com uma velocidade constante, $\delta u$, sob a ação da força constante, $\delta F_{x}$. A tensão tangencial, $\tau_{y x}$, aplicada ao elemento de fluido é dada por:

$$
\tau_{y x}=\lim _{\delta A_{y} \rightarrow 0} \frac{\delta F_{x}}{\delta A_{y}}=\frac{d F_{x}}{d A_{y}}
$$

onde $\delta A_{y}$ é a área do elemento fluido em contato com a placa. Durante o intervalo de tempo, $\delta t$, o elemento de fluido deforma-se da posição $M N O P$ para a posição $M^{\prime} N O P$. A taxa de deformação é dada por:

$$
\lim _{\delta t \rightarrow 0} \frac{\delta \alpha}{\delta t}=\frac{d \alpha}{d t}
$$

A distância, $\delta l$, entre os pontos $M$ e $M^{\prime}$ é dada por:

$$
\delta l=\delta u \delta t
$$

ou, alternativamente, para ângulos pequenos:

$$
\delta l=\delta y \delta \alpha
$$


Destas duas expressões tiramos:

$$
\frac{\delta \alpha}{\delta t}=\frac{\delta u}{\delta y}
$$

Tomando o limite de ambos os lados desta igualdade, obtemos:

$$
\frac{\delta \alpha}{\delta t}=\frac{d u}{d y}
$$

Portanto, estando o elemento de fluido da figura 3.2 sujeito ao esforço tangencial, $\tau_{y x}$, ele sofrerá uma deformação cuja taxa é dada por $d u / d y$. São denominados fluidos newtonianos aqueles para os quais as tensões tangenciais são diretamente proporcionais às respectivas taxas de deformação, isto é,

$$
\tau_{y x}=\nu \frac{d u}{d y}
$$

A constante de proporcionalidade, $\nu$, é denominada viscosidade absoluta (ou dinâmica) e tem unidades de $\mathrm{kg} / \mathrm{m} \cdot \mathrm{s}$. É frequente o uso da relação entre a viscosidade absoluta, $\nu$, e a densidade, $\rho$, expressa na equação abaixo. A esta relação dá-se o nome de viscosidade cinemática, a qual representaremos pelo símbolo $\eta$ e cuja unidade é o $\mathrm{m}^{2} / \mathrm{s}$.

$$
\eta=\frac{\nu}{\rho}
$$

No Sistema Métrico Absoluto a unidade de $\eta$ é o stoke (St).

Os escoamentos de fluidos classificam-se em laminares e turbulentos. Nos primeiros, a estrutura de escoamento é caracterizada pelo suave movimento do fluido em lâminas ou camadas. Já o regime turbulento é caracterizado pelo escoamento tridimensional das partículas fluidas cujos movimentos caóticos superpõem-se ao movimento médio. 


\subsubsection{Viscosidade de soluções}

Sejam $\eta$ e $\eta_{0}$ as viscosidades da solução e do solvente, respectivamente. A razão entre elas é definida como viscosidade relativa, $\eta_{r}$,

$$
\eta_{r}=\frac{\eta}{\eta_{0}}
$$

Supondo o soluto constituído por esferas sem carga e não interagentes, Einstein, 1906, mostrou que

$$
\eta_{r}=1+2,5 \phi
$$

onde $\phi$ é a fração de volume ocupada pelas esferas.

Além da viscosidade relativa, também são definidas as seguintes relações:

$$
\begin{gathered}
\text { incremento de viscosidade relativa } \equiv \eta_{i}=\frac{\eta-\eta_{0}}{\eta_{0}}=\eta_{r}-1 \\
\text { viscosidade intrínseca } \equiv[\eta]=\lim _{\phi \rightarrow 0} \frac{\eta_{i}}{\phi}
\end{gathered}
$$

Muitas vezes é difícil obter a fração de volume ocupada pelas macromoléculas de uma solução. Devido à tal dificuldade, é comum apresentar a viscosidade intrínseca em unidades recíprocas de concentração $(\mathrm{g} / \mathrm{mL})$. Neste caso, a viscosidade intrínseca é definida por

$$
\text { viscosidade intrínseca } \equiv[\eta]=\lim _{c \rightarrow 0} \frac{\eta_{i}}{c}
$$

onde $c$ é a concentração do soluto (em $g / m L)$.

O incremento de viscosidade relativa ${ }^{1}, \eta_{i}$, significa de quanto aumenta a viscosidade do solvente devido à presença do soluto. No entanto, $\eta_{i}$ por si só é dependente da concentração, motivo pelo qual utilizamos a viscosidade intrínseca, [ $\eta]$, obtida, geralmente, da extrapolação de um gráfico de $\eta_{i} / \phi$ vs. $c$ (Chang, 2000).

A equação de Einstein pode ser reescrita em termos da viscosidade intrínseca da seguinte forma:

$$
\eta_{r}=1+[\eta] \phi
$$

onde a viscosidade intrínseca, neste caso, é um número adimensional e igual a 2,5 para o caso de partículas esféricas, sem carga e não interagentes. Qualquer valor de $[\eta]$ diferente

\footnotetext{
${ }^{1}$ esta grandeza é usualmente denominada viscosidade específica, termo que, segundo a IUPAC, deve ser evitado.
} 
de 2,5 é atribuído à assimetria da partícula. Assim sendo, a relação de Einstein também pode ser utilizada para inferir sobre a forma do soluto. No caso de partículas assimétricas, Simha, 1940 modificou a relação de Einstein para

$$
\eta_{r}=1+p \phi
$$

onde $p$ está relacionado à razão entre os eixos da partícula, definida como um elipsoide oblato ou prolato.

Para suspensões mais concentradas, com frações de volume maiores que 0,05, a relação de Einstein não é mais válida, pois as esferas ficam sujeitas a interações hidrodinâmicas entre elas. Tais interações entre duas esferas levam a uma contribuição à $\eta_{r}$ que é proporcional a $\phi^{2}$. O efeito de dois corpos sobre $\eta_{r}$, combinado à expressão de Einstein, resulta em (Batchelor, 1972)

$$
\eta_{r}=1+2,5 \phi+6,2 \phi^{2}
$$

Esta relação, a qual denominaremos relação de Batchelor, é válida apenas para frações de volume menores que 0,10. Para suspensões mais concentradas, as quais fogem ao escopo deste trabalho, foram propostas várias outras relações (para uma revisão detalhada, ver, por exemplo, Larson, 1999).

A dependência de $\eta_{r}$ com a concentração, de maneira mais geral, pode ser obtida de uma expansão em Taylor da equação de Einstein.

$$
\eta_{r}=1+[\eta] c+k[\eta]^{2} c^{2}+k^{\prime}[\eta]^{3} c^{3}+\ldots
$$

onde os coeficientes da expansão levam em conta a interação entre os corpos. Uma maneira alternativa de obter a viscosidade intrínseca, $[\eta]$, é ajustar um polinômio aos pontos experimentais de uma curva de $\eta_{r}$ vs. $c$ e extrair $[\eta]$ como sendo o coeficiente que multiplica o termo linear do polinômio.

Para o caso de suspensões contendo partículas carregadas eletricamente, também surgirão interações eletrostáticas entre as partículas, que afetarão a viscosidade medida, aumentando-a. Em suspensões de partículas esféricas carregadas, com frações de volume de até 0,10, a viscosidade relativa pode ser escrita como (Russel, 1978):

$$
\eta_{r}=1+2,5 \phi+\left[2,5+\frac{3}{40}\left(\frac{d_{\text {eff }}}{R}\right)^{5}\right] \phi^{2}
$$


onde $R$ é o raio das partículas e $d_{e f f}$ é um diâmetro efetivo, dado por

$$
d_{\text {eff }} \approx \ln A / \ln [A / \ln (A / \ldots)]
$$

onde as infinitas concatenações dos logaritmos podem, na prática, serem truncadas após a terceira. A variável $A$ é obtida de

$$
A \equiv \frac{4 \pi \epsilon \epsilon_{0} \Psi_{0}^{2} R^{2} \kappa \exp (2 R \kappa)}{k_{B} T}
$$

sendo $\epsilon$ a constante dielétrica do meio, $\epsilon_{0}$ a constante de permissividade, $\Psi_{0}$ o potencial elétrico na superfície das esferas, $k_{B}$ a constante de Boltzmann, $T$ a temperatura e $\kappa$ o inverso do comprimento de Debye, dado por

$$
\kappa^{2}=\frac{2 z^{2} n_{b} e^{2}}{\epsilon \epsilon_{0} k_{B} T}
$$

onde $n_{b}$ é a força iônica da solução e os demais símbolos têm o mesmo significado da seção anterior. 


\section{Capítulo 4}

\section{Resultados e discussões}

\subsection{Presença de vesículas de DMPG: incorporação de $\left[{ }^{14} \mathrm{C}\right]$-sacarose em volume interno}

Embora uma grande quantidade de trabalhos publicados acerca de dispersões de DMPG, em baixa força iônica, as considerem como sendo constituídas por vesículas, nas fases gel e fluida, este fato nunca foi demonstrado satisfatoriamente. Conforme veremos adiante, essa questão é importante para a proposição de modelos capazes de descrever o comportamento físico-químico de tais dispersões.

Vesículas lipídicas são caracterizadas pela presença de um compartimento aquoso interno, conforme descrito no capítulo de introdução (ver figura 1.1). Uma maneira de demonstrar a presença de vesículas, em uma dispersão lipídica, é incorporando moléculas em seu volume aquoso.

Moléculas de sacarose radiativa $\left(\left[{ }^{14} \mathrm{C}\right]\right.$-sacarose $)$ são largamente utilizadas para medir a eficiência de encapsulamento de vesículas (Poste \& Papahadjopoulos, 1976; Zborowski et al., 1977; Allen \& Everest, 1983). Por ser uma molécula grande e não reagir com bicamadas lipídicas, realizamos experimentos para medir a eficiência de incorporação de sacarose no possível volume interno dos agregados de DMPG, conforme descrito na seção de materiais e métodos. É sabido que na temperatura de transição de fase de bicamadas lipídicas, as mesmas apresentam um grande aumento na permeabilidade a moléculas (Papahadjopoulos et al., 1973; Deamer \& Bramhall, 1986). Portanto, para evitar um vazamento prematuro de sacarose das possíveis vesículas, realizamos os experimentos a 
6 e $45{ }^{\circ} \mathrm{C}$, temperaturas representativas das fases gel e fluida, respectivamente. Além disso, ao longo da região de transição de fase do $\mathrm{DMPG}$, entre $\sim 18$ e $35^{\circ} \mathrm{C}$, a dispersão é altamente viscosa, não sendo possível realizar a cromatografia nesta situação (maiores detalhes na seção de materiais e métodos).

É importante salientar que, antes do procedimento descrito acima, foram feitas outras tentativas, mais convencionais, para demonstrar a existência de vesículas, com marcadores de spin e fluorescentes. No caso de marcadores de spin, não encontramos um marcador aquo-solúvel adequado, pois, em geral, são catiônicos, e ligam-se à membrana aniônica do DMPG. Além disso, fazendo um experimento utilizando um marcador de spin lipossolúvel neutro, também não foi possível obter bons resultados. Quanto às sondas fluorescentes, também não conseguimos encontrar uma sonda adequada.

Hipoteticamente, apenas para facilitar o raciocínio, vamos assumir que nossos agregados lipídicos sejam vesículas. Conforme descrito na seção de materiais e métodos, a sacarose foi introduzida nas dispersões de duas maneiras distintas. Na primeira, cujo método denominaremos por dentro e fora, as "vesículas" foram preparadas de modo que, inicialmente, havia sacarose distribuída dentro e fora das vesículas. Já na segunda maneira, denominada por fora, a sacarose foi adicionada à dispersão já contendo vesículas prontas. Esta distinção de métodos foi realizada, em princípio, para verificar se havia adsorção de sacarose às bicamadas lipídicas, circunstância que será discutida mais detalhadamente no decorrer da apresentação dos dados. 
À guisa de controle, primeiramente foram realizados experimentos de incorporação de sacarose em agregados de DMPC extrusados, os quais, se sabe, formam vesículas lipídicas (Schenkman et al., 1981). O perfil de eluição de uma dispersão de $25 \mathrm{mM}$ de DMPC (extrusada por filtro de $100 \mathrm{~nm}$ ) é apresentado na figura 4.1.

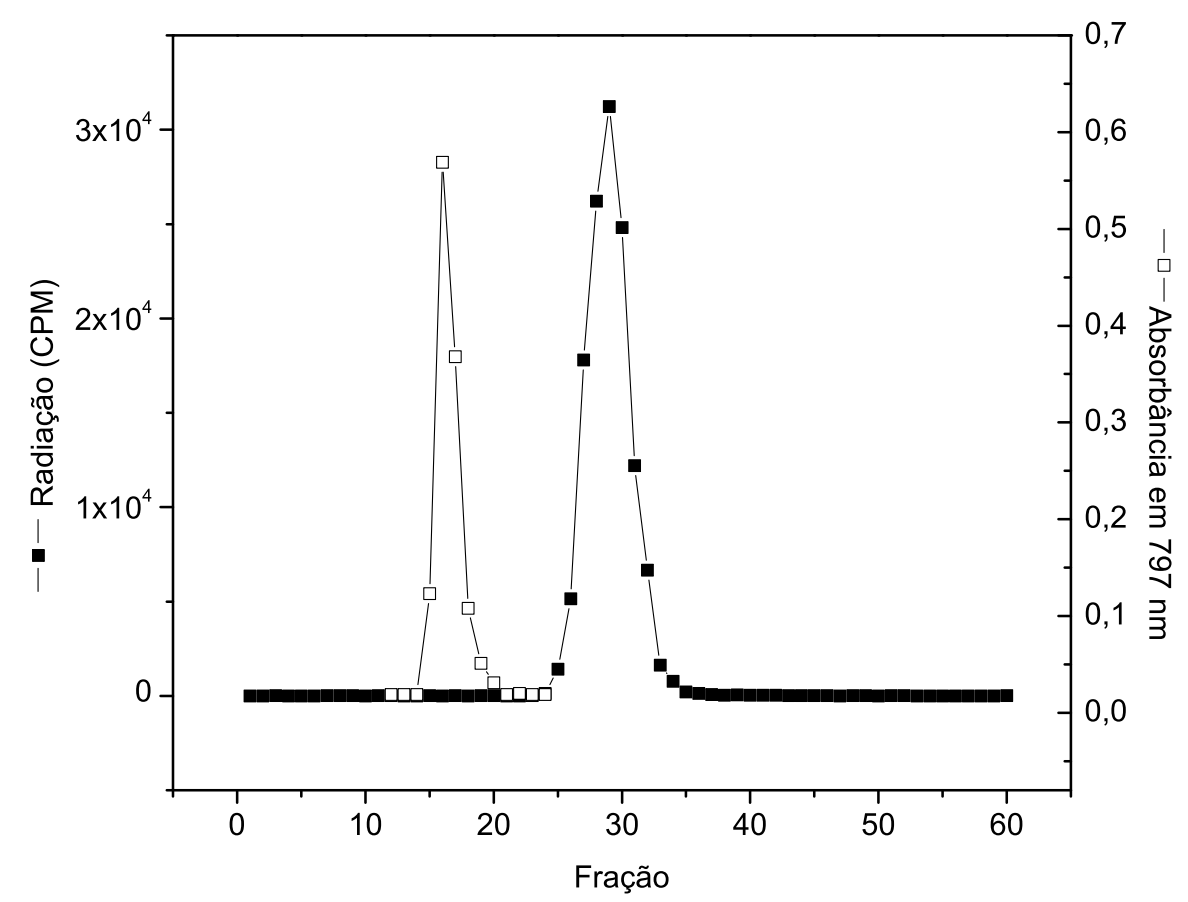

Figura 4.1: Perfil de eluição de dispersão $25 \mathrm{mM}$ de vesículas de DMPC na fase gel, a $6^{\circ} \mathrm{C}$, contendo $\left[{ }^{14} \mathrm{C}\right]$-sacarose inicialmente por fora. Caminho óptico usado nas medidas de absorbância: $1 \mathrm{~cm}$.

No eixo das ordenadas (lado esquerdo da figura 4.1) é indicada a radiação da fração de volume eluído, em contagens por minuto (CPM), já descontada a radiação de fundo (maiores detalhes ver seção de materiais e métodos), enquanto o número da fração é expresso no eixo das abscissas. Para descobrir em que frações havia agregados lipídicos, utilizou-se a dosagem de fosfato, realizada conforme descrito no trabalho de Rouser et al., 1970. A presença do fosfato, localizado na cabeça polar de fosfolipídios, é detectada pela existência de um pico de absorbância em 797 nm. Portanto, medindo a absorbância em cada fração de volume (indicada no eixo das ordenadas, lado direito, na figura 4.1), é possível detectar a presença ou não de agregados lipídicos.

As vesículas de DMPC estão contidas entre as frações 15 e 20, de acordo com a figura 4.1. Por sua vez, a sacarose livre está entre as frações 25 e 34, representada pelo 
pico de contagem de radiação. Mesmo ampliando a escala da figura 4.1, entre as frações que englobam o pico de absorção (4.2), observamos que não há contagem significativa de radiação nesta região e, portanto, concluímos que não houve incorporação de sacarose nem adsorção da mesma às monocamadas externas das vesículas.

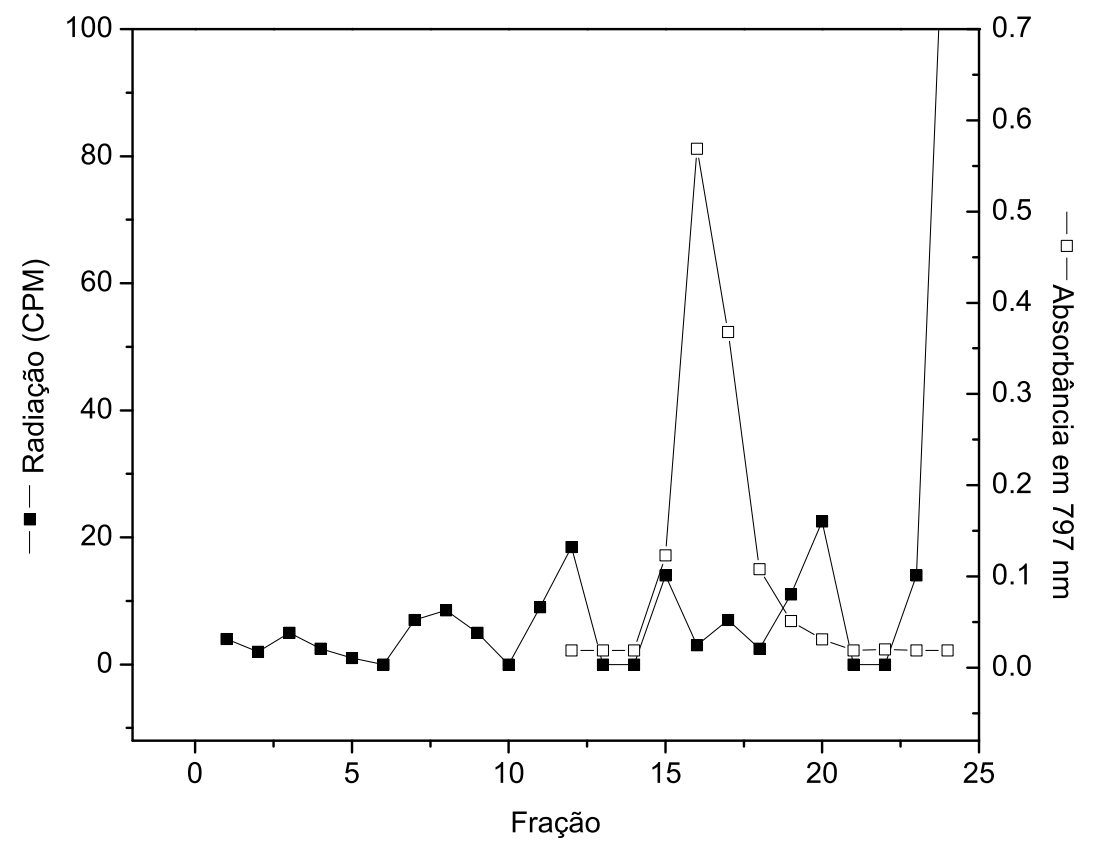

Figura 4.2: Perfil de eluição de dispersão $25 \mathrm{mM}$ de vesículas de DMPC na fase gel, a $6^{\circ} \mathrm{C}$, contendo $\left[{ }^{14} \mathrm{C}\right]$-sacarose inicialmente por fora: ampliação da figura 4.1. 
O perfil de eluição de DMPC, pelo método de sacarose dentro e fora, é apresentado na figura 4.3.

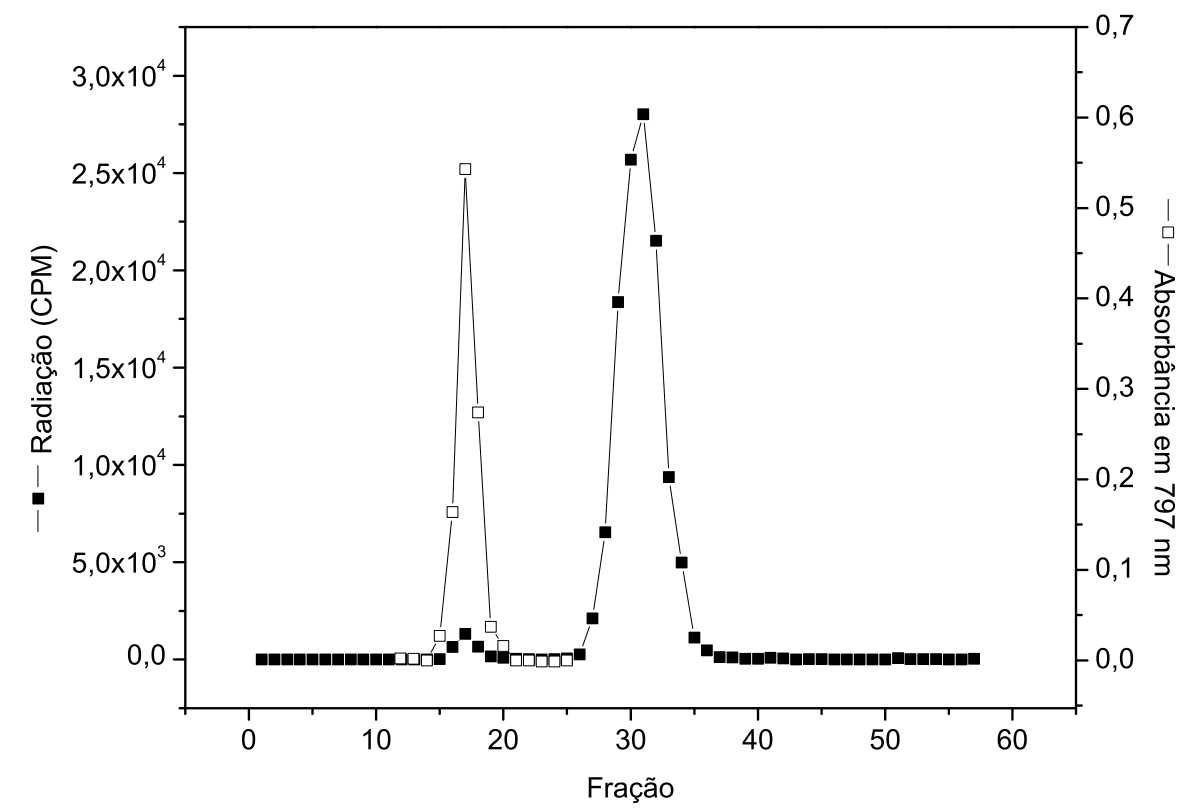

Figura 4.3: Perfil de eluição de dispersão $25 \mathrm{mM}$ de vesículas de DMPC na fase gel, a $6^{\circ} \mathrm{C}$, contendo $\left[{ }^{14} \mathrm{C}\right]$-sacarose inicialmente por dentro e fora. Caminho óptico usado nas medidas de absorbância: $1 \mathrm{~cm}$.

A existência de um pequeno pico de radiação coincidente com o pico de absorção (figura 4.3), mostra que parte da sacarose foi incorporada aos agregados fosfolipídicos. Para calcularmos a eficiência de incorporação, $E_{i}$, somamos as contagens de radiação das frações que possuíam vesículas e dividimos pela contagem total de radiação (soma de todas as frações). Matematicamente, isto pode ser expresso pela seguinte fórmula

$$
E_{i}=\frac{\sum_{j=a}^{b} f_{j}}{\sum_{j=1}^{N} f_{j}}
$$

onde $f_{j}$ é a contagem de radiação da fração $j,[a, b]$ representa o intervalo de frações em que há absorção de luz dos agregados fosfolipídicos e $N$ é o número total de frações. Para o caso da figura 4.3, obtivemos uma eficiência $E_{i}=2,3(1) \%$ (usando $a=15$, $b=20$ e $N=57$ ), ou seja, de toda a sacarose disponível, apenas $2,3 \%$ foi encapsulada pelas vesículas de DMPC. Uma maneira alternativa para visualizar o perfil de eluição, é 
normalizar a contagem de radiação, em cada fração, pela radiação total e multiplicar o resultado por 100. Desta forma, o eixo das ordenadas indica diretamente a porcentagem do total de radiação por fração, sendo possível obter graficamente a porcentagem de incorporação de sacarose: basta somar os valores das ordenadas contidos no intervalo de frações em que há lipídio (figura 4.4). Por sua conveniência, adotaremos esta representação para o perfil de eluição dos experimentos seguintes.

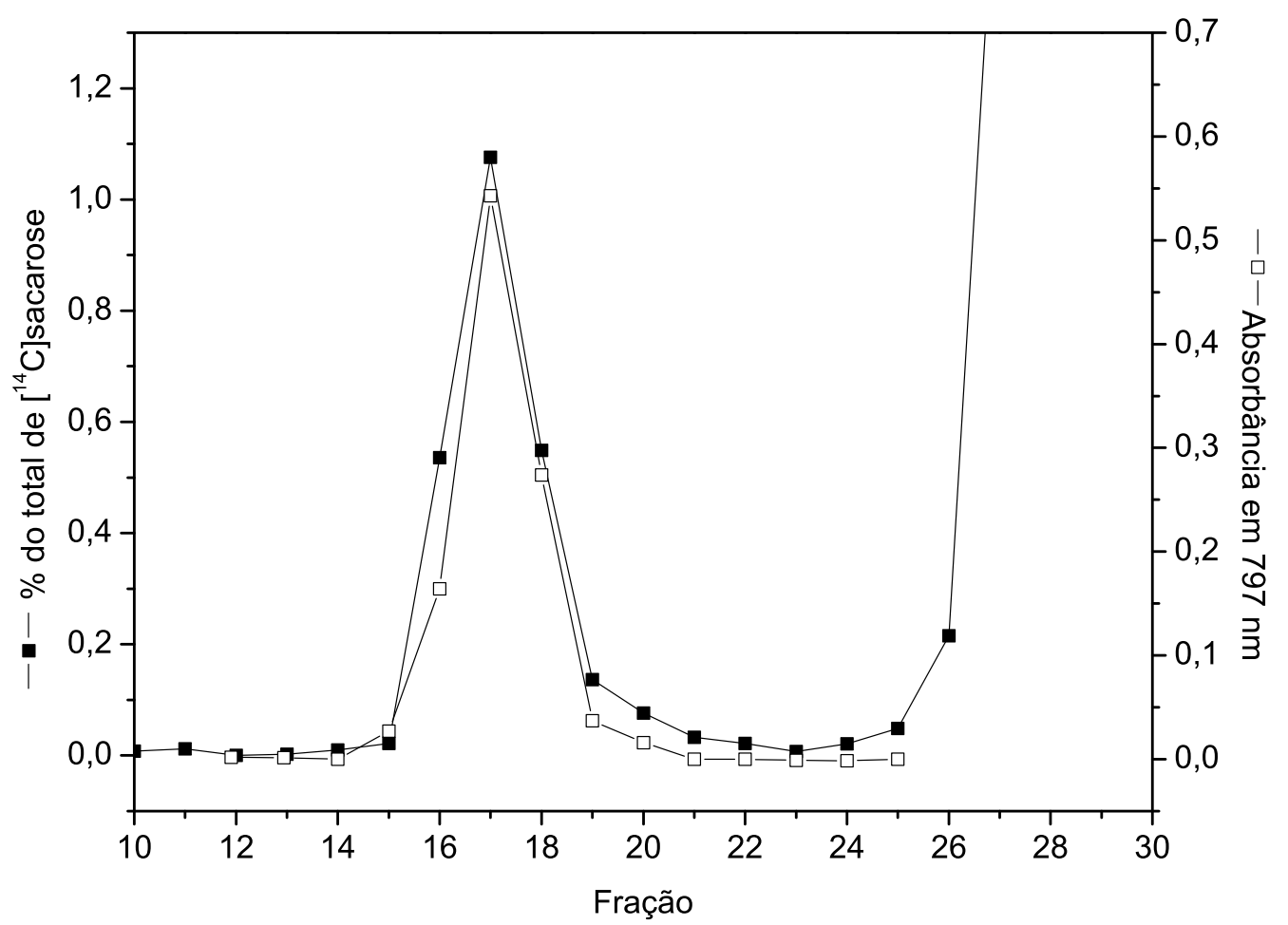

Figura 4.4: Perfil de eluição de dispersão de $25 \mathrm{mM}$ de vesículas de DMPC na fase gel, a $6^{\circ} \mathrm{C}$, contendo $\left[{ }^{14} \mathrm{C}\right]$-sacarose inicialmente por dentro e fora: ampliação da figura 4.3. Caminho óptico usado nas medidas de absorbância: $1 \mathrm{~cm}$. 
$\mathrm{Na}$ fase fluida (figura 4.5), verificamos incorporação para ambos os procedimentos, sacarose por dentro e fora e por fora, com eficiências de incorporação de $2,5(1) \%$ e 0,12(1)\%, respectivamente. Podemos descartar a hipótese de haver somente adsorção de sacarose, pois, neste caso, no intervalo de frações em que há fosfolipídios, esperaríamos uma contagem de radiação no método sacarose por dentro e fora de aproximadamene o dobro da contagem pelo método de sacarose por fora. Isto porque a sacarose estaria adsorvida em ambas as monocamadas, externa e interna das membranas. O fato de observarmos uma pequena incorporação de sacarose quando a mesma é colocada externamente às vesículas, provavelmente seja uma indicação de que as bicamadas são bastante permeáveis à sacarose.
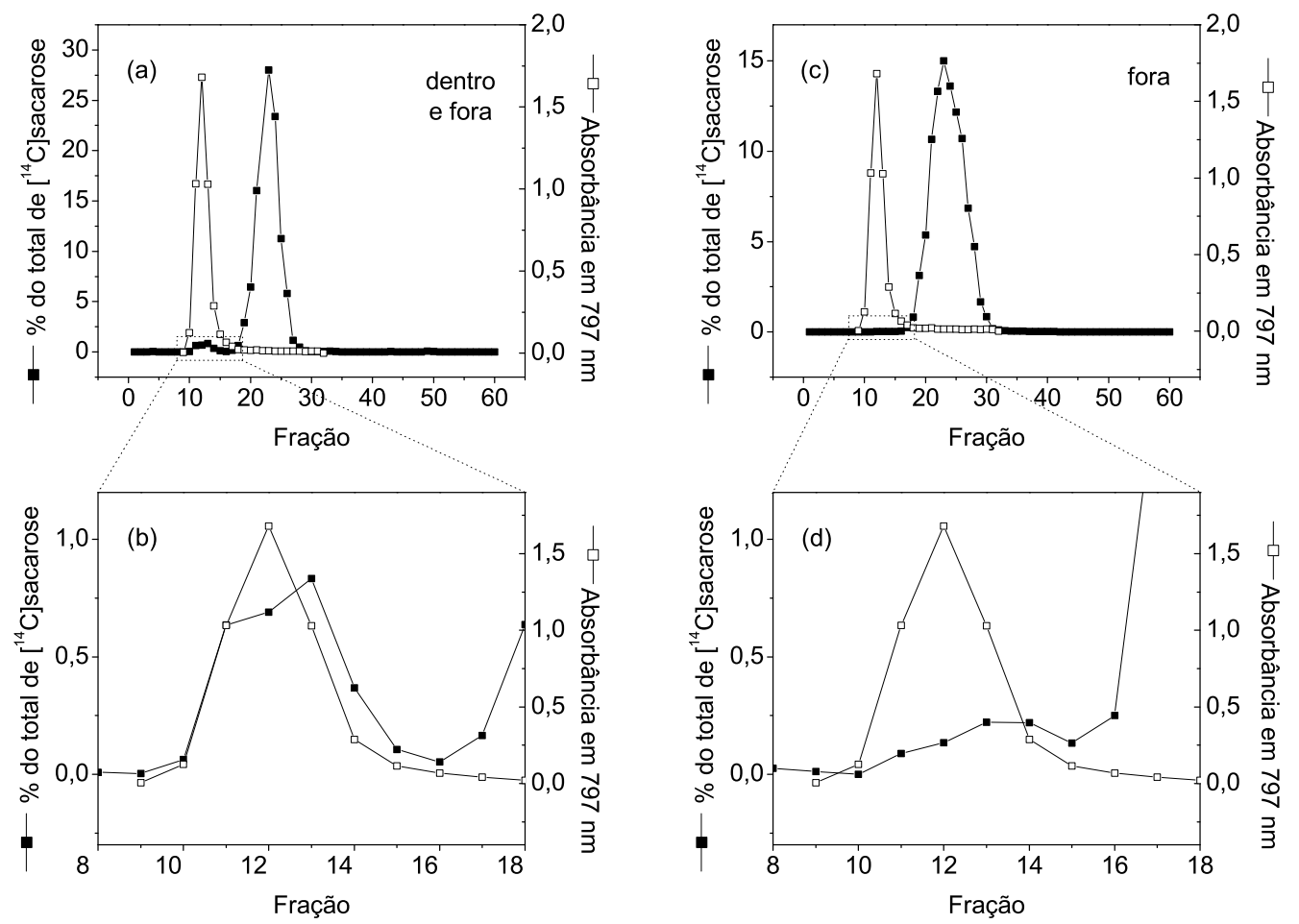

Figura 4.5: Perfil de eluição de dispersões $25 \mathrm{mM}$ de vesículas de DMPC na fase fluida $\left(45^{\circ} \mathrm{C}\right):(\mathrm{a})$ $\left[{ }^{14} \mathrm{C}\right]$-sacarose inicialmente por dentro e fora; (b) ampliação de (a); (c) $\left[{ }^{14} \mathrm{C}\right]$-sacarose inicialmente por fora; (d) ampliação de (c). Caminho óptico usado nas medidas de absorbância: $1 \mathrm{~cm}$. 
A tabela 4.1 apresenta um resumo das porcentagens de incorporação de sacarose nas vesículas de DMPC.

\begin{tabular}{c|c|c}
\multicolumn{3}{c}{ Eficiência de incorporação de sacarose radioativa $(\%)$} \\
\hline Método de preparo & Fase gel $\left(6^{\circ} \mathrm{C}\right)$ & Fase fluida $\left(45^{\circ} \mathrm{C}\right)$ \\
\hline Por fora & 0 & $0,12(1)$ \\
Por dentro e fora & $2,3(1)$ & $2,5(1)$ \\
\hline
\end{tabular}

Tabela 4.1: Porcentagens de incorporação de sacarose radiativa em dispersões lipídicas de $25 \mathrm{mM}$ de DMPC contendo vesículas unilamelares com raio de $50 \mathrm{~nm}$ (valor aproximado após dispersão ser extrusada onze vezes por filtro de $100 \mathrm{~nm}$ ).

Calculando a fração de volume ocupada pelas vesículas de DMPC, através da equação 3.23, e usando os parâmetros da tabela 3.2, obtemos frações de volume de 0,074 e 0,089, para as fases gel e fluida, respectivamente. Isto significa que a eficiência máxima de incorporação de sacarose seria de 7,4 e 8,9\% nas fases gel e fluida. Portanto, dado que os valores experimentais obtidos são menores do que estes (tabela 4.1), podemos concluir que as bicamadas das vesículas de DMPC são parcialmente permeáveis à sacarose. Além disso, não houve diferença entre as fases gel e fluida quanto à esta permeabilidade.

Dado que a técnica foi capaz de detectar a existência de volume interno nos agregados de DMPC, repetimos o experimento com dispersões de DMPG. 

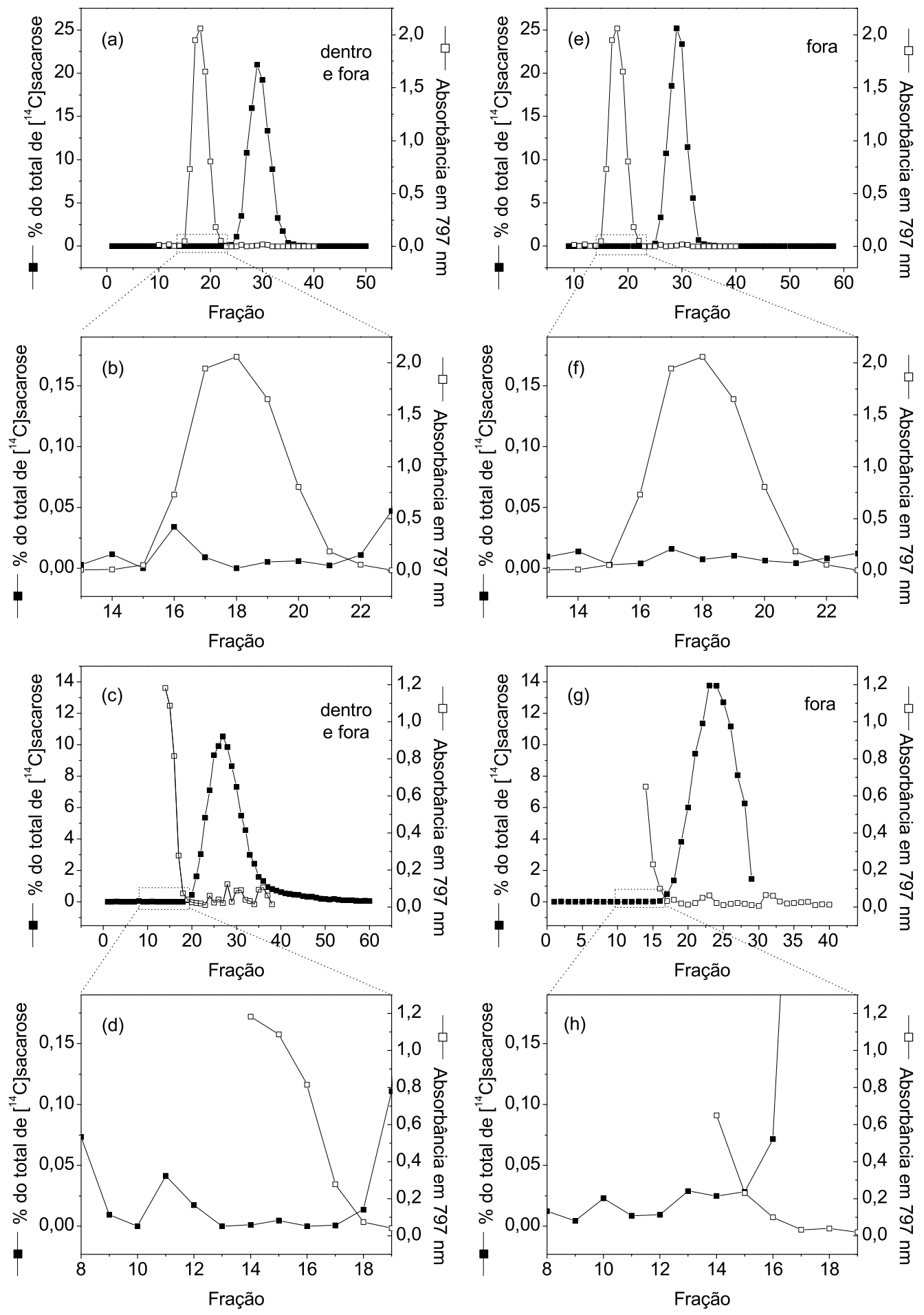

Figura 4.6: Perfis de eluição de quatro dispersões de $25 \mathrm{mM}$ de DMPG na fase gel $\left(6^{\circ} \mathrm{C}\right)$ : (a) e (c) $\left[{ }^{14} \mathrm{C}\right]$-sacarose inicialmente por dentro e fora; (b) e (d) ampliação de (a) e (c), respectivamente; (e) e (g) $\left[{ }^{14} \mathrm{C}\right]$-sacarose inicialmente por fora; (f) e (h) ampliação de (e) e (f), respectivamente. Caminho óptico usado nas medidas de absorbância: $1 \mathrm{~cm}$. 
A figura 4.6 mostra o perfil de eluição de quatro amostras diferentes de dispersões de DMPG na fase gel ${ }^{1}$. Em nenhuma das amostras, tanto pelo método de sacarose por dentro e fora quanto por fora, foi possível detectar incorporação de sacarose. Observamos que os picos de absorbância das dispersões de DMPG são mais alargados do que as de DMPC, refletindo uma maior polidispersidade nas dispersões de DMPG. Isto está de acordo com o esperado, uma vez que as dispersões de DMPC foram extrusadas e as de DMPG não.

\footnotetext{
${ }^{1}$ Devido a problemas experimentais, não foi possível fazer a dosagem de fosfato integral para as amostras nos itens (c), (d), (g) e (h). Entretanto, o resultado não é dependente desta análise total.
} 

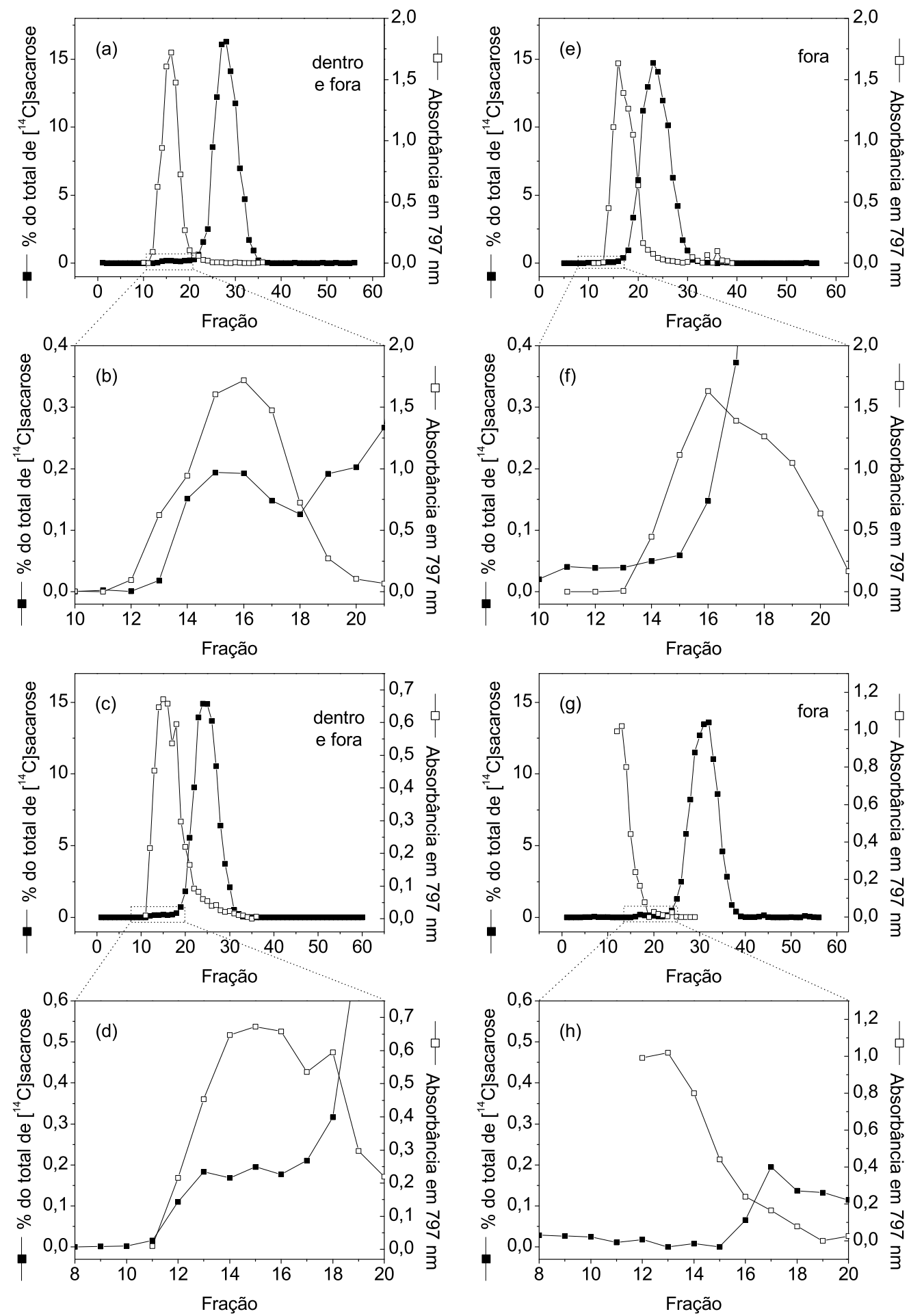

Figura 4.7: Perfis de eluição de quatro dispersões de $25 \mathrm{mM}$ de DMPG na fase fluida $\left(45^{\circ} \mathrm{C}\right)$ : (a) e (c) $\left[{ }^{14} \mathrm{C}\right]$-sacarose inicialmente por dentro e fora; (b) e (d) ampliação de (a) e (c), respectivamente; (e) e (g) $\left[{ }^{14} \mathrm{C}\right]$-sacarose inicialmente por fora; (f) e (h) ampliação de (e) e (f), respectivamente. Caminho óptico usado nas medidas de absorbância: $1 \mathrm{~cm}$. 
$\mathrm{Na}$ fase fluida, houve incorporação de sacarose (inicialmente por dentro e fora) em duas amostras $\left(E_{i}=0,8(1) \%\right.$ e $0,5(2) \%$, relativos aos itens (b) e (d) da figura 4.7, respectivamente). Com a sacarose por fora, parece que também houve uma pequena incorporação de sacarose para uma das amostras (itens (e) e (f)). Todavia, parte da sacarose encapsulada está saindo em frações que coincidem com aquelas em que se inicia a saída de sacarose livre. Com isto, não é possível obter com precisão a eficiência de incorporação, embora seja possível, qualitativamente, concluir que houve uma pequena incorporação de sacarose.

Numa tentativa de separar melhor os dois picos (de sacarose livre e encapsulada), repetimos os experimentos com dispersões de DMPG em uma coluna cromatográfica de volume maior (descrita em materiais e métodos). No entanto, não obtivemos bons resultados, pois encontramos eficiências de encapsulamento muito menores dos que as obtidas até então, provavelmente um reflexo de que o tempo de eluição nesta coluna maior era o dobro da coluna menor.

De maneira geral, nossos resultados mostram, definitivamente, que o DMPG forma vesículas na fase fluida. Apesar de na região de transição os agregados lipídicos se estruturarem de maneira diferente das fases gel e fluida, sabemos que não há troca lipídica entre os agregados (Lamy-Freund \& Riske, 2003). Em vista disso, é razoável esperar que se há vesículas na fase fluida, elas também estejam presentes na fase gel. No entanto, muito mais permeáveis à sacarose do que na fase fluida.

Tanto as vesículas de DMPC quanto de DMPG são permeáveis à sacarose, sendo que as de DMPG possuem permeabilidade maior comparada ao DMPC. Sabemos que os agregados de DMPG, além de serem carregados, são menores que os de DMPC. Logo, devem possuir um raio de curvatura maior, de modo que se espera uma incorporação menor em relação ao DMPC.

É interessante notar que espectros de EPR de marcadores de spin incorporados em bicamadas de DMPC e DMPG, nas fases gel e fluida, são muito semelhantes, mostrando uma mobilidade das cadeias hidrocarbônicas similar, conforme podemos observar das figuras 4.8 e 4.9. Esses espectros mostram claramente que o DMPG tem fase gel, confirmando a presença de bicamadas lipídicas. 


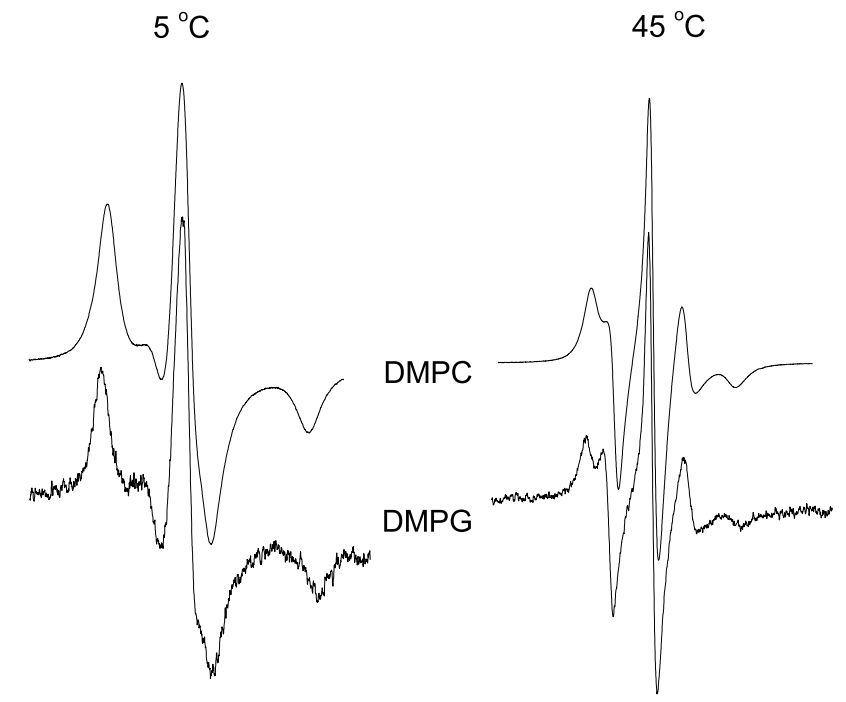

Figura 4.8: Espectros de EPR de marcador de spin incorporado próximo à região da superfície de bicamadas lipídicas de DMPG e DMPC nas fases gel $\left(5^{\circ} \mathrm{C}\right)$ e fluida $\left(45^{\circ} \mathrm{C}\right)$ em Hepes $+2 \mathrm{mM} \mathrm{de} \mathrm{NaCl}$.
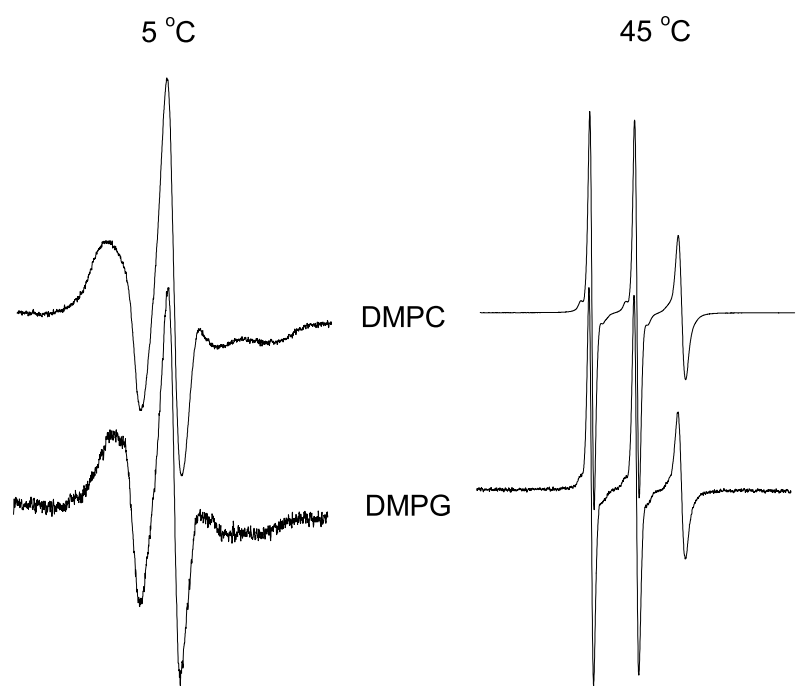

Figura 4.9: Espectros de EPR de marcador de spin incorporado à região central de bicamadas lipídicas de DMPG e DMPC nas fases gel $\left(5^{\circ} \mathrm{C}\right)$ e fluida $\left(45^{\circ} \mathrm{C}\right)$ em Hepes $+2 \mathrm{mM}$ de $\mathrm{NaCl}$. 


\subsection{Efeito da concentração lipídica nas dispersões de DMPG}

Com o objetivo de entender as estruturas de agregação e as possíveis interações inter-agregados de dispersões de DMPG, fizemos um estudo cuidadoso em função da concentração lipídica. Para tanto, foram utilizadas técnicas experimentais capazes de medir propriedades macroscópicas das dispersões (variação de calor específico, turbidez, condutividade e viscosidade). Através destas propriedades, que se complementam, foi possível compreender melhor, em nível microscópico, tanto a estrutura dos agregados quanto suas possíveis interações inter-agregados, concorde será apresentado a seguir. 


\subsubsection{Calorimetria Exploratória Diferencial (DSC)}

A técnica de DSC trata-se de uma ferramenta bastante adequada para estudar a transição de fase de bicamadas lipídicas, fornecendo informações termodinâmicas acerca da transição. A figura 4.10 apresenta a curva DSC de uma dispersão lipídica de vesículas multilamelares de DMPC.

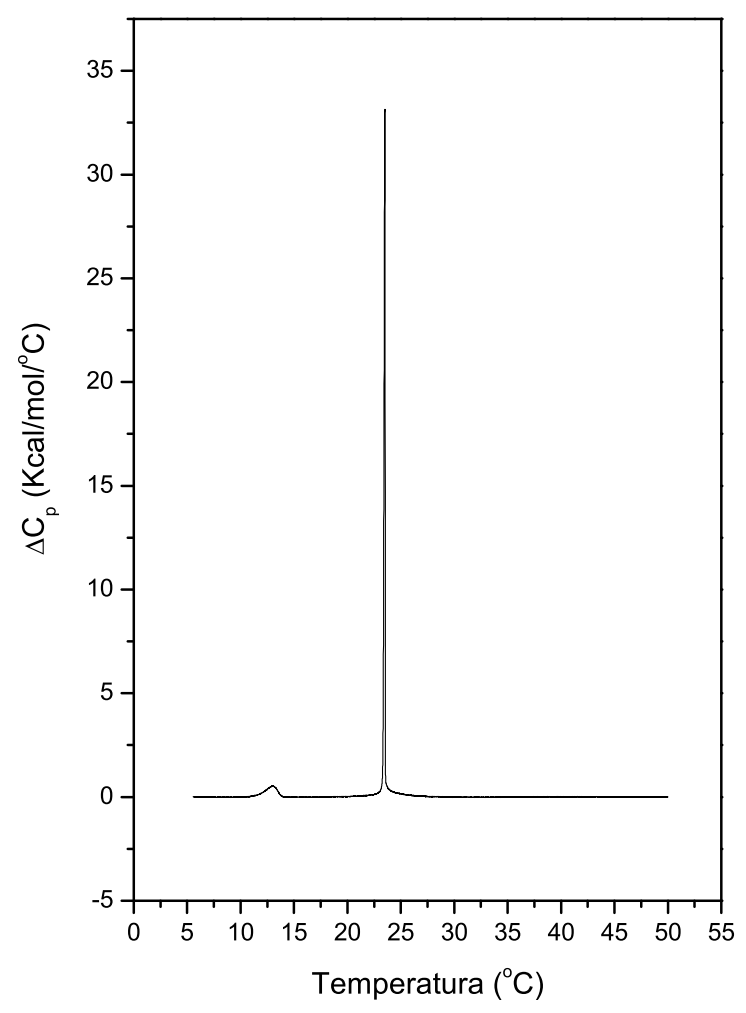

Figura 4.10: Curva DSC de dispersão lipídica de vesículas multilamelares de DMPC com concentração de $5 \mathrm{mM}$. Taxa de aquecimento: $20^{\circ} \mathrm{C} / \mathrm{h}$.

Além de um pico estreito de calor específico na temperatura de transição de fase gel-fluida, $T_{m}$ (em torno de $23^{\circ} \mathrm{C}$ ), observamos também um pico menor, mais alargado, por volta de $12{ }^{\circ} \mathrm{C}\left(T_{p}\right)$, relacionado à pré-transição de fase. Antes do pico calorimétrico de pré-transição (vindo de temperaturas mais baixas) as bicamadas estão na fase gel; entre os dois picos em $T_{p}$ e $T_{m}$, na fase ripple; após $T_{m}$, os lipídios se encontram na fase fluida.

Alguns trabalhos sugerem que o início da transição de fase gel-fluido se inicie na fase ripple (Heimburg, 2000; Riske et al., 2009b). No entanto, no presente trabalho, isto 
não será considerado, ou seja, não faremos distinção entre as fase gel e ripple. Portanto, ao longo da tese, quando nos referirmos à fase gel, a fase ripple estará implicitamente inclusa.

Diferentemente do DMPC, dispersões de DMPG, em baixa força iônica, exibem um perfil calorimétrico muito peculiar, caracterizado por uma transição larga, formada por vários picos de calor específico, entre aproximadamente 18 e $35^{\circ} \mathrm{C}$ (Salonen et al., 1989; Heimburg \& Biltonen, 1994; Riske et al., 2001; Lamy-Freund \& Riske, 2003; Alakoskela \& Kinnunen, 2007; Kinoshita et al., 2008; Riske et al., 2009a). Na figura 4.11 vemos uma curva DSC típica de dispersão de DMPG nas condições sobreditas.

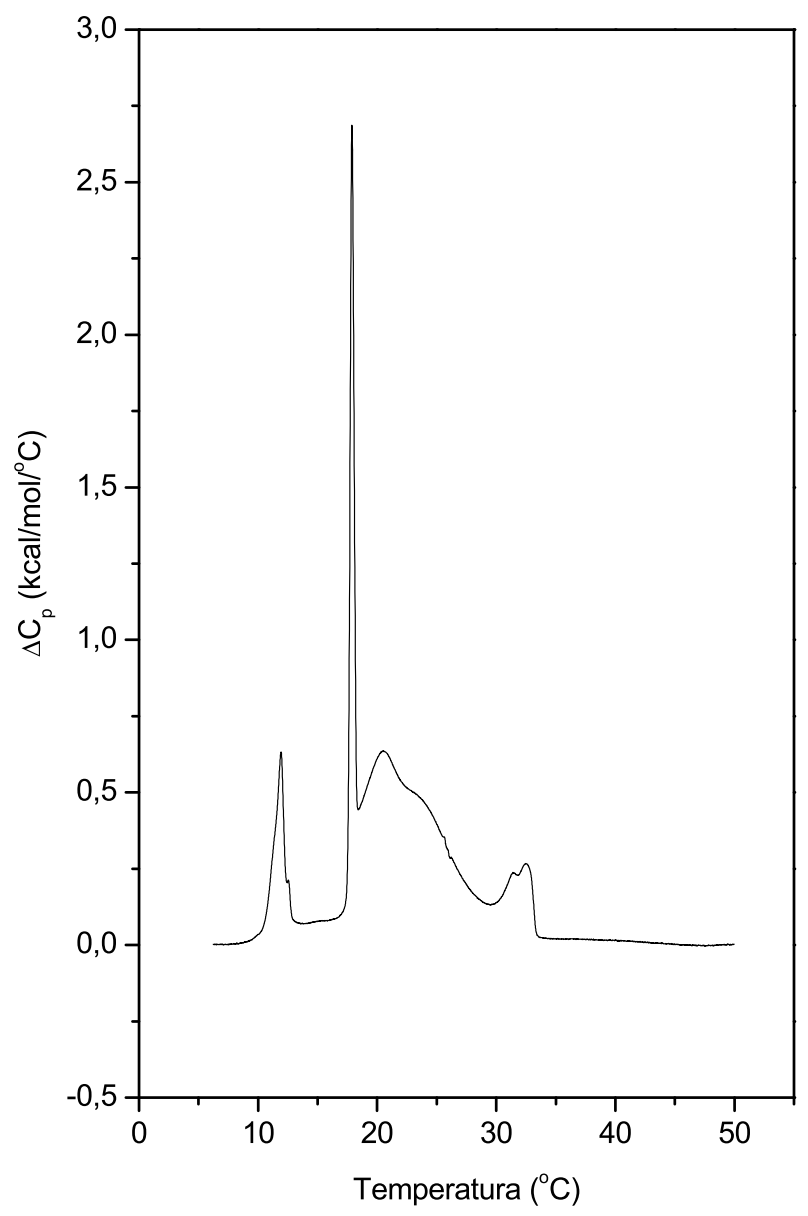

Figura 4.11: Curva DSC de dispersão de $10 \mathrm{mM}$ de DMPG em tampão Hepes com $2 \mathrm{mM}$ de $\mathrm{NaCl}$. Taxa de aquecimento: $20^{\circ} \mathrm{C} / \mathrm{h}$. 
Com o intuito inicial de estudar as possíveis interações entre os agregados de DMPG, bem como suas estruturas, monitoramos o comportamento térmico de dispersões de DMPG, via DSC, para várias concentrações lipídicas (1, 5, 10, 20, 30, 40 e 50 mM). Para garantir que os experimentos fossem realizados em situação de equilíbrio, inicialmente fizemos um estudo do perfil calorimétrico em função da taxa de aquecimento (figura 4.12).
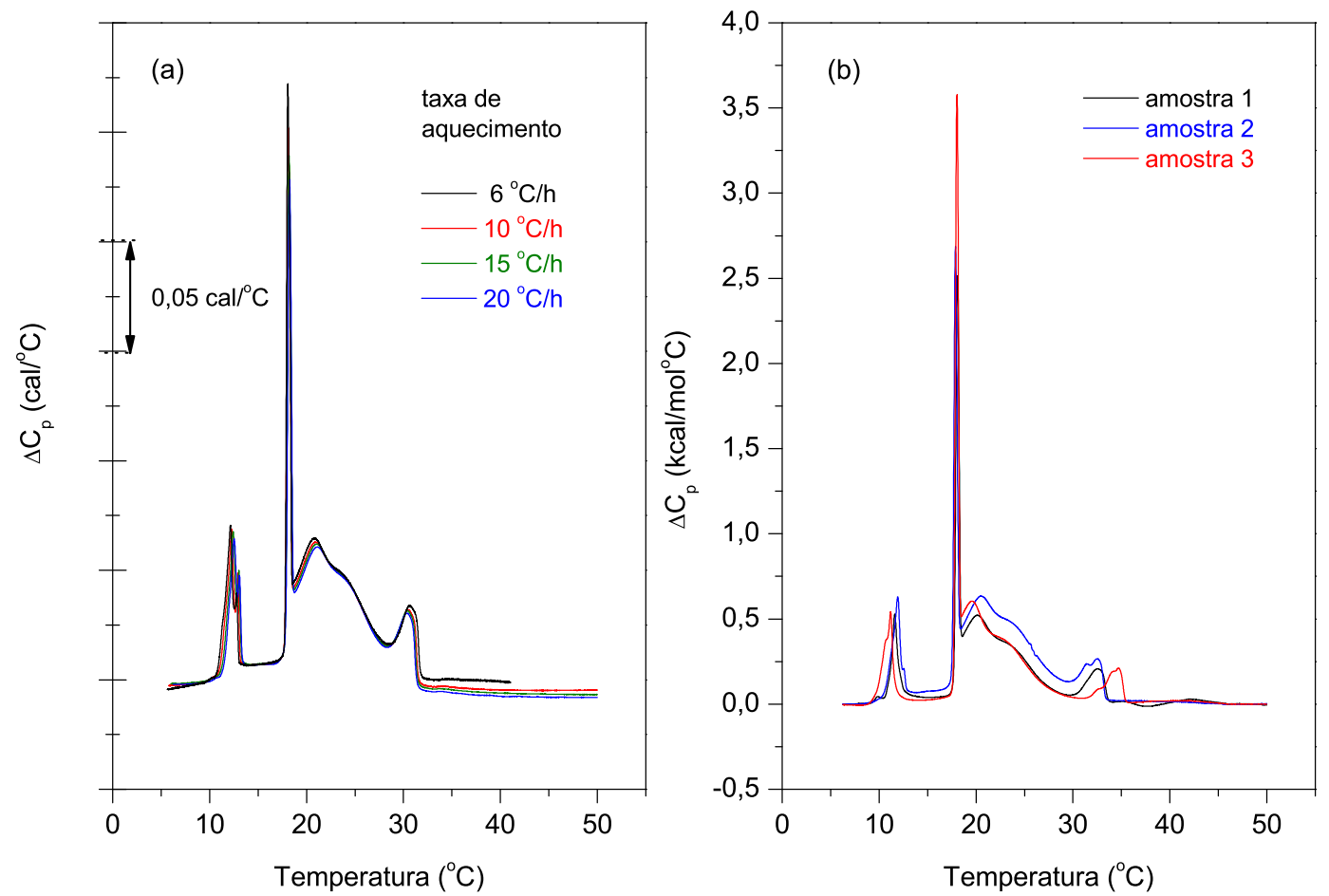

Figura 4.12: (a) Curvas DSC de uma dispersão de $20 \mathrm{mM}$ de DMPG obtidas com diferentes taxas de aquecimento. (b) Curvas DSC de amostras diferentes de dispersões de $10 \mathrm{mM}$ de DMPG tomadas a uma taxa de aquecimento de $20^{\circ} \mathrm{C} / \mathrm{h}$. 
Variando a taxa de aquecimento para uma mesma amostra (entre 6 e $20{ }^{\circ} \mathrm{C} / \mathrm{h}$ ), verificamos que há variações muito pequenas no perfil das curvas DSC (figura 4.12a). Estas variações são desprezíveis frente às variações observadas nas curvas DSC de amostras diferentes (figura 4.12b) e, portanto, não serão levadas em conta. Assim sendo, adotamos $20{ }^{\circ} \mathrm{C} / \mathrm{h}$ para todas as concentrações lipídicas estudadas abaixo de $40 \mathrm{mM}$. Para as concentrações de 40 e $50 \mathrm{mM}$ tivemos que diminuir a taxa de aquecimento para 15 e $10{ }^{\circ} \mathrm{C} / \mathrm{h}$, respectivamente, pois para estas concentrações lipídicas a taxa de $20{ }^{\circ} \mathrm{C} / \mathrm{h}$ mostrou-se muito rápida para detectar toda a transição.

Visando ainda estudar a estabilidade das dispersões de DMPG, foram feitas várias varreduras de DSC para uma mesma amostra, conforme podemos ver na figura 4.13. Observa-se uma reprodutibilidade razoável da primeira à sexta varredura. Mudanças significativas são observadas apenas após a sétima varredura. Concluímos daí, que a amostra é estável por cerca de 18 horas.

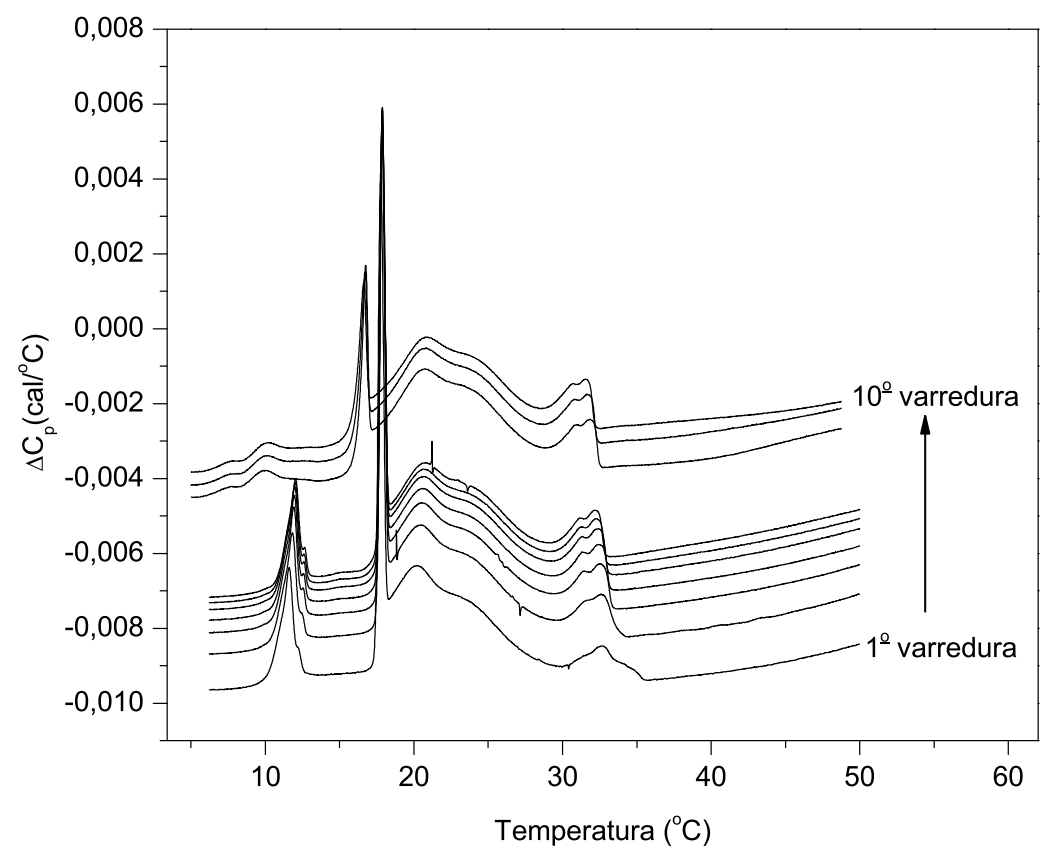

Figura 4.13: Dados brutos de curvas DSC de uma mesma dispersão de $10 \mathrm{mM}$ de DMPG ao longo do tempo. O intervalo entre varreduras consecutivas é de 3 horas. Velocidade de aquecimento: $20{ }^{\circ} \mathrm{C} / \mathrm{h}$. 
Também verificamos que a dispersão lipídica de DMPG, sob resfriamento, responde de maneira um pouco diferente comparada quando a amostra é esquentada (figura 4.14). Os dois primeiros picos calorimétricos (vindo de temperaturas mais baixas), os quais serão definidos e analisados mais adiante, são menos intensos na curva DSC obtida sob resfriamento. Também observamos um deslocamento em torno de $1{ }^{\circ} \mathrm{C} / \mathrm{h}$ do pico mais intenso das curvas DSC. É interessante notar que a curva DSC sob resfriamento tem um perfil muito semelhante ao observado após várias varreduras obtidos sob aquecimento (varreduras 8, 9 e 10 na figura 4.13).

Todos os experimentos apresentados a seguir serão feitos apenas com o aquecimento das amostras.

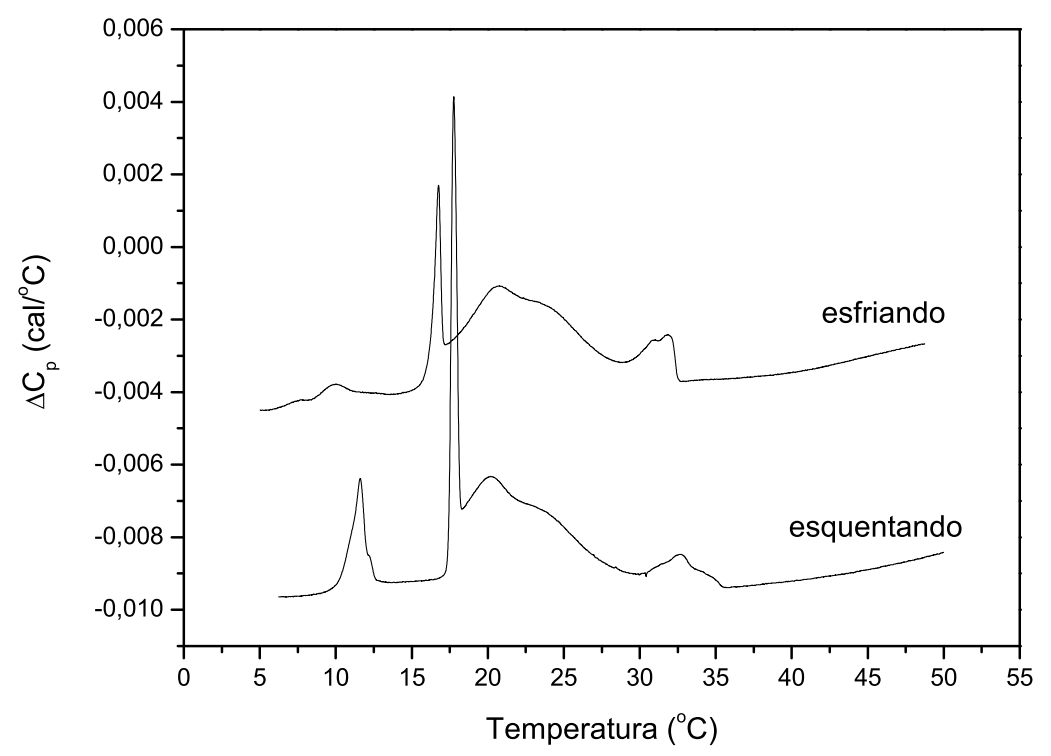

Figura 4.14: Curvas DSC de uma mesma dispersão de $10 \mathrm{mM}$ de DMPG tomadas sob aquecimento e resfriamento a uma taxa de $20{ }^{\circ} \mathrm{C} / \mathrm{h}$. 
Tendo estabelecido as condições de estabilidade das dispersões de DMPG, apresentamos a seguir seu comportamento calorimétrico em função da concentração lipídica.

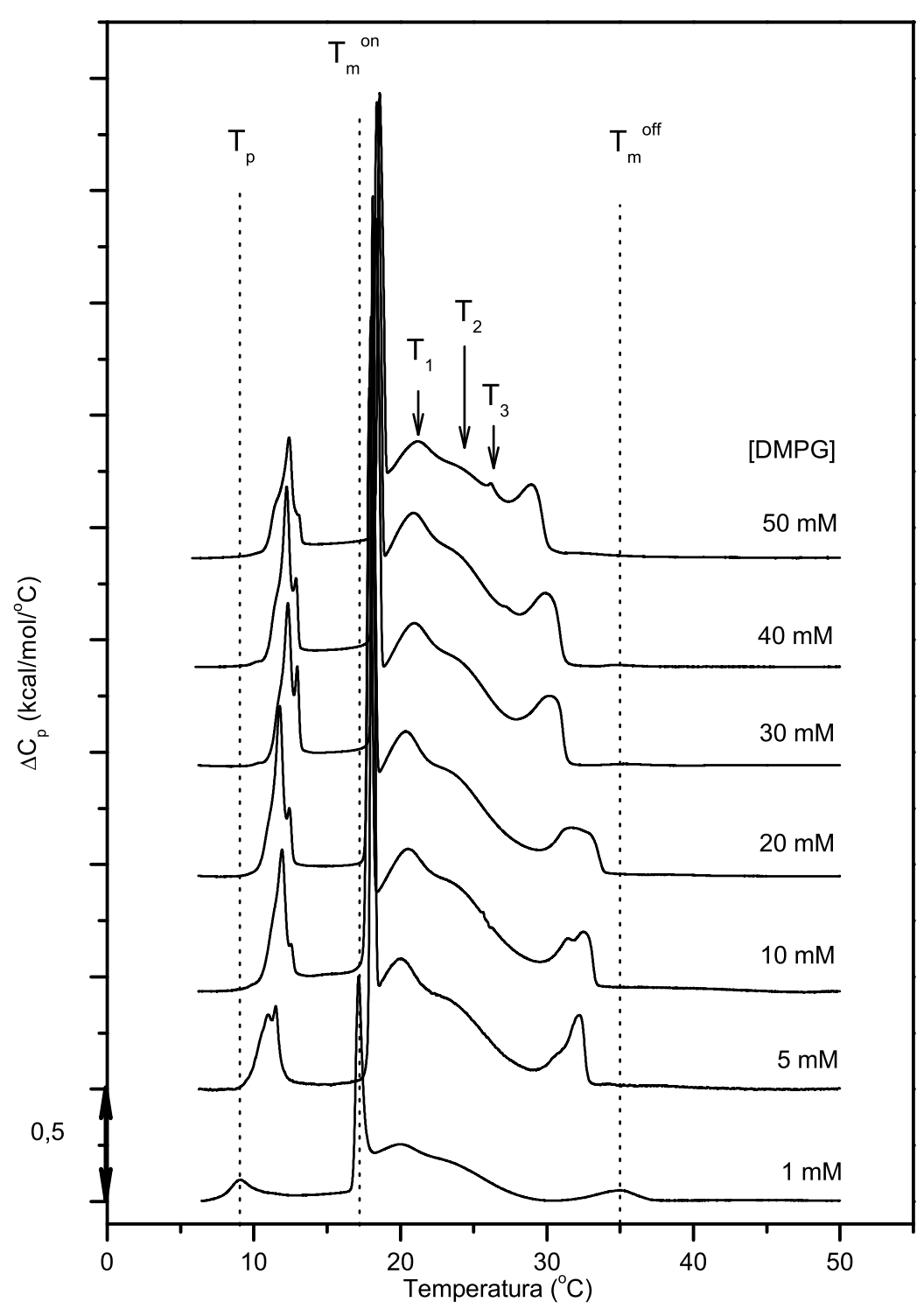

Figura 4.15: Curvas DSC de dispersões de DMPG com várias concentrações lipídicas. As curvas foram transladadas para melhor visualização. Taxa de aquecimento: $20^{\circ} \mathrm{C} / \mathrm{h}$ de 1 a $30 \mathrm{mM}$ de $\mathrm{DMPG}, 15^{\circ} \mathrm{C} / \mathrm{h}$ para $40 \mathrm{mM} \mathrm{e} 10{ }^{\circ} \mathrm{C} / \mathrm{h}$ para $50 \mathrm{mM}$.

As curvas DSC das dispersões de DMPG (figura 4.15) são representativas de no mínimo três amostras diferentes. A entalpia de transição (obtida da área sob as curvas DSC entre $T_{m}{ }^{\text {on }}$ e $T_{m}{ }^{\text {off }}$ ) manteve-se independente da concentração e foi igual a $6,1(5)$ $\mathrm{kcal} / \mathrm{mol}$. 
Para praticamente todas as concentrações, a transição do DMPG é caracterizada pela presença de pelo menos cinco picos de calor específico, cujas temperaturas em que ocorrem foram nomeadas conforme a figura 4.15. O primeiro, em $T_{p}$, entre 11,4 e $12,6^{\circ} C$, está associado à pré-transição de fase. O segundo pico em $T_{m}{ }^{o n}$, mais intenso e estreito, está associado ao início da transição de fase gel-fluida propriamente dita. O último pico, em $T_{m}{ }^{o f f}$, entre aproximadamente 28,5 e $32,5{ }^{\circ} \mathrm{C}$, está relacionado ao fim da transição. Finalmente, há ainda dois picos intermediários entre $T_{m}{ }^{o n}$ e $T_{m}{ }^{\text {off }}$, que denominamos $T_{1}$ e $T_{2}$, os quais ainda não sabemos a que podem estar associados. O pico em $T_{2}$ aparece sempre sobreposto a $T_{1}$, sendo difícil monitorar sua posição de maneira precisa. Para concentração de 50 mM de DMPG, os traços de DSC de algumas amostras exibem ainda um terceiro pico, $T_{3}$, entre $T_{2}$ e $T_{m}{ }^{\text {off }}$. 


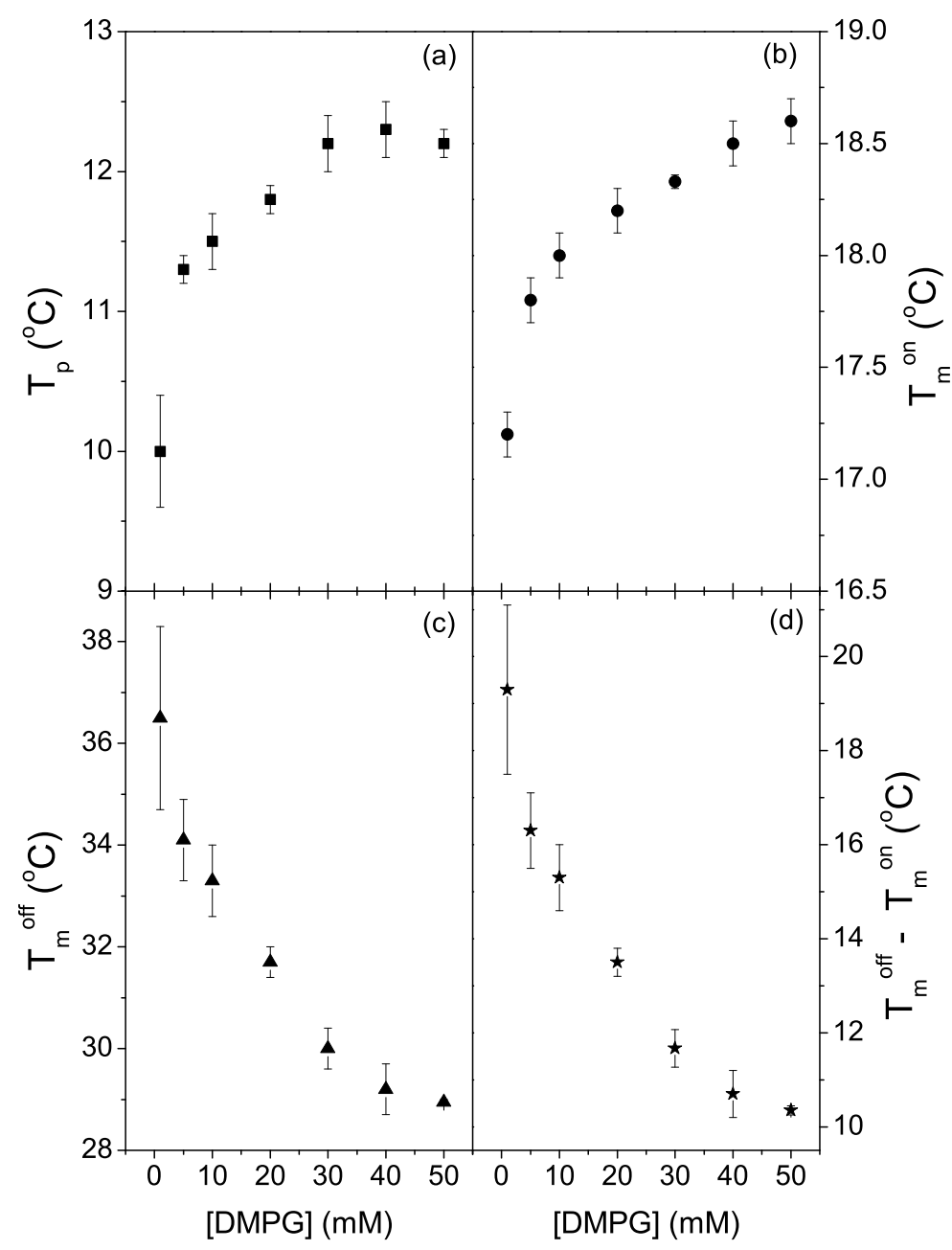

Figura 4.16: Temperaturas dos picos calorimétricos em função da concentração de DMPG.

A figura 4.16 apresenta a posição dos picos calorimétricos supracitados, em função da concentração de DMPG. Os pontos médios das temperaturas dos três picos principais, correspondendo a $T_{p}, T_{m}{ }^{\text {on }}$ e $T_{m}{ }^{\text {off }}$, mostraram-se dependentes da concentração lipídica (figura 4.16). $T_{p}$ e $T_{m}{ }^{o n}$ aumentam com a concentração lipídica, enquanto que o último evento, que sinaliza o final da transição, é o mais sensível: $T_{m}{ }^{\text {off }}$ decresce significativamente de 35 para $29{ }^{\circ} \mathrm{C}$, conforme a concentração de DMPG aumenta de 1 para 50 mM. Portanto, o intervalo de temperatura da região de transição (figura 4.16d) diminui com o aumento da concentração lipídica. Este comportamento é contrastante com o de dispersões lipídicas neutras, tais como de DMPC, para o qual as temperaturas de prétransição e de transição principais são independentes da concentração de lipídio (dados não mostrados). 
De um modo geral, como já dito, todos os picos mudam sua posição com a concentração. Esta situação aponta para a possibilidade de estar havendo interações entre os agregados e/ou a estrutura dos mesmos estar variando com a concentração. Apesar disso, os perfis calorimétricos, como um todo, são semelhantes, de modo que o que quer que esteja acontecendo na região de transição, se mantém durante todo o intervalo de concentração lipídica estudado. O efeito de diminuição do intervalo de temperatura da região de transição também ocorre quando se aumenta a força iônica da dispersão (Kodama \& Miyata, 1995, Riske et al., 2009a), situação que será melhor discutida mais adiante.

Teoricamente, é sabido que alto calor específico está ligado a grandes flutuações de energia (ver equação 3.12), densidade, área, entre outros, conforme pode ser extraído do teorema de flutuação-dissipação de energia (Kubo, 1966). Portanto, é muito plausível que os vários picos calorimétricos ao longo da região de transição estejam relacionados a flutuações. 


\subsubsection{Turbidez}

Uma das impressões digitais de dispersões de DMPG, em baixa força iônica e pH neutro, é a baixa turbidez, próxima de zero, entre as fases gel e fluida (Riske et al., 1997, Alakoskela \& Kinnunen, 2007, Alakoskela et al., 2010). Nesta região, a amostra é visualmente transparente, enquanto turva nas fases gel e fluida. Observamos na figura 4.17 que esta característica se mantém para concentrações lipídicas entre 1 e $50 \mathrm{mM}$ de DMPG. Entretanto, o intervalo de temperatura em que a turbidez fica baixa diminui com o aumento da concentração. Este comportamento é similar ao observado quando se varia a força iônica da dispersão, mantendo-se fixa a concentração lipídica (Riske et al., 2009a), conforme discutiremos mais adiante.
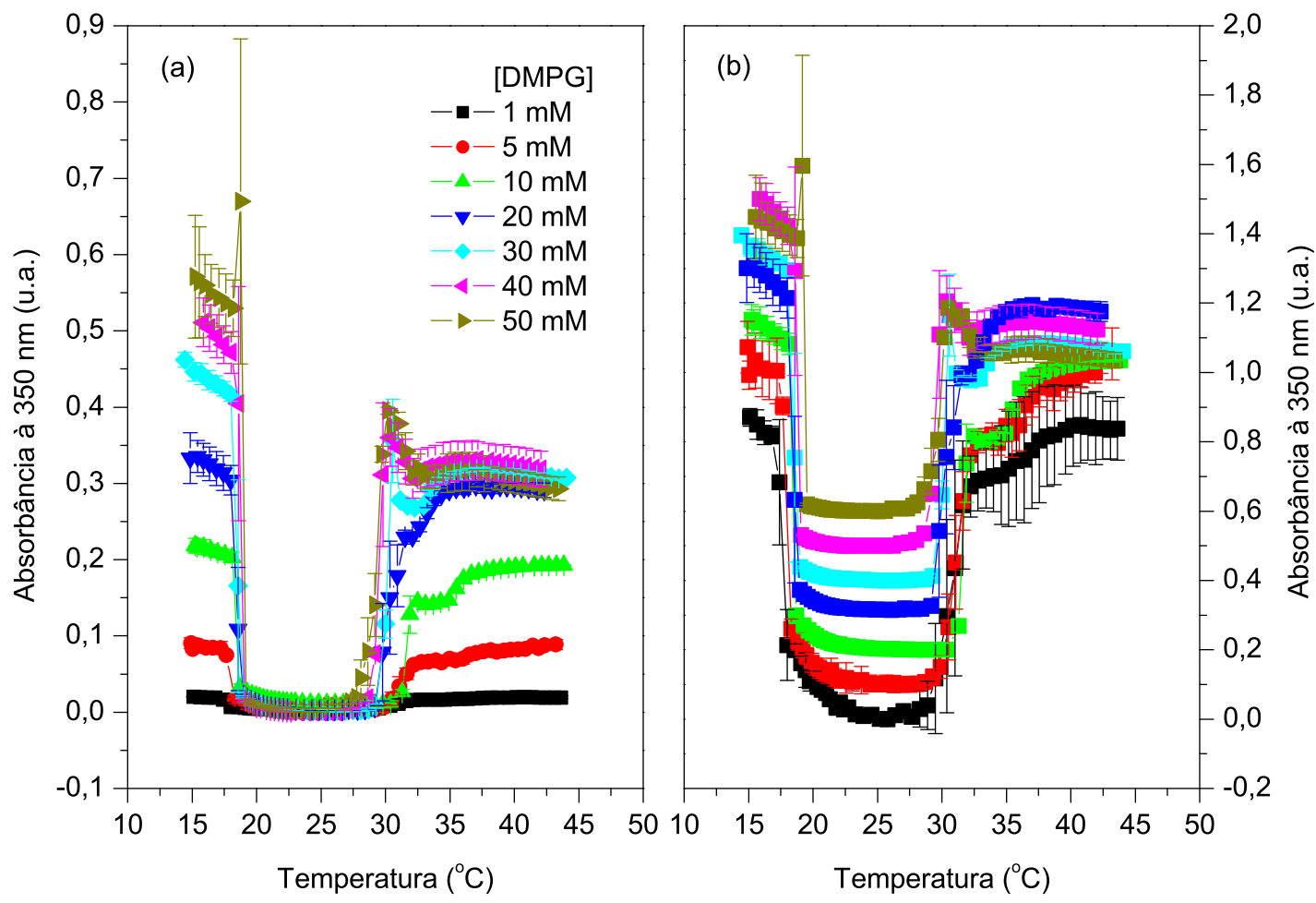

Figura 4.17: (a) Dependência térmica da absorbância medida a $350 \mathrm{~nm}$ de dispersões de DMPG com concentrações lipídicas entre 1 e 50 mM. (b) Para evidenciar e visualizar melhor a forma das curvas, os valores da turbidez para cada concentração foram normalizados pelo valor máximo da turbidez e as curvas foram transladadas. Caminho óptico $=2 \mathrm{~mm}$.

A absorbância na fase gel é maior do que na fase fluida, melhor evidenciado pelas concentrações lipídicas acima de $10 \mathrm{mM}$ (figura 4.18). Tal comportamento também 
é observado em outros sistemas lipídicos e atribuído à diferença de índice de refração entre as fases gel e fluida (Yi \& MacDonald, 1973; Disalvo, 1991). Na temperatura de transição há uma diminuição na espessura e densidade das bicamadas lipídicas, tendo por consequência um inchaço da vesícula, causando uma diferença no índice de refração das bicamadas entre as fases gel e fluida.

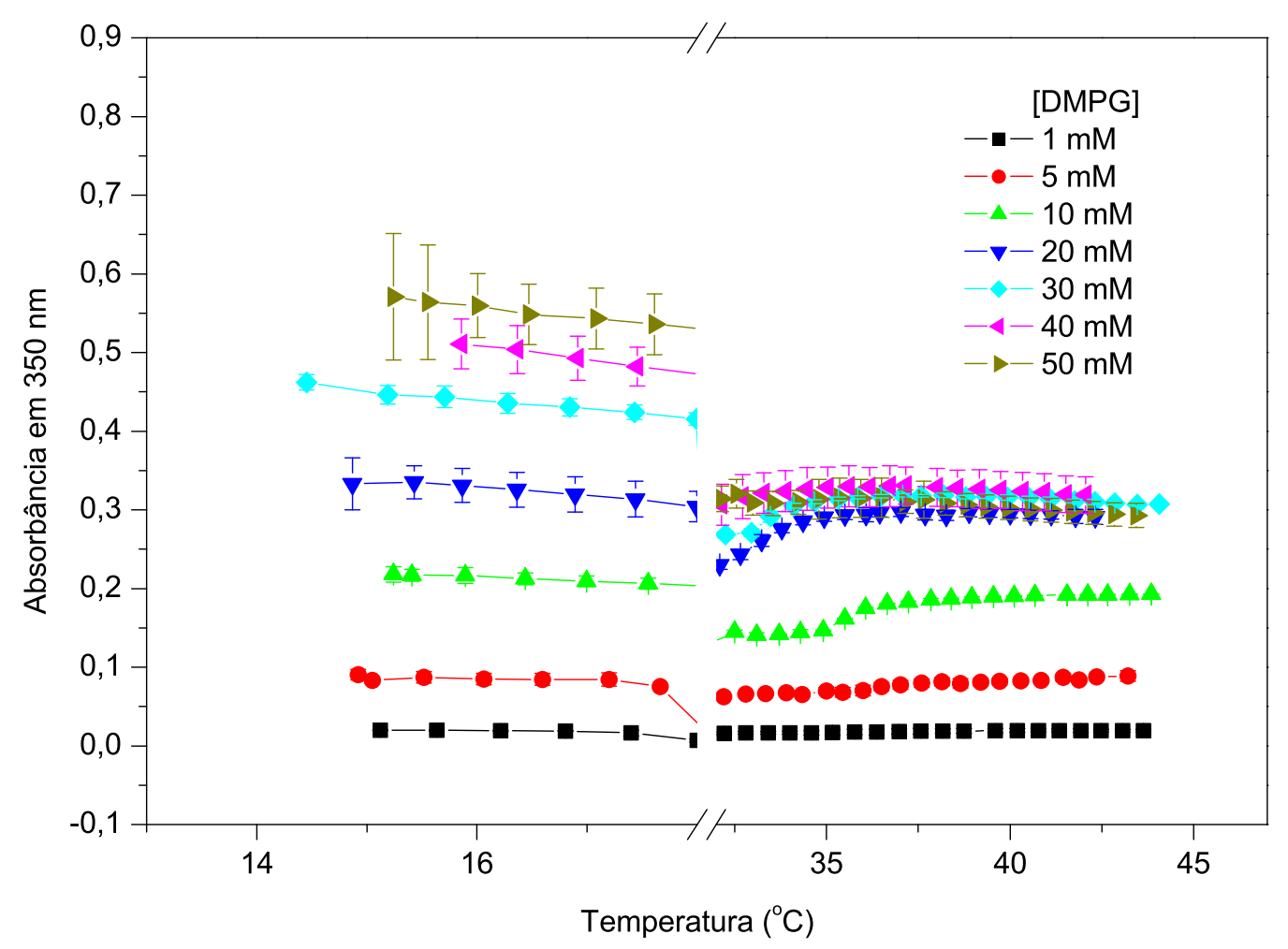

Figura 4.18: Dependência térmica da absorbância medida a $350 \mathrm{~nm}$ de dispersões de DMPG com concentrações lipídicas entre 1 e $50 \mathrm{mM}$ nas fases gel e fluida. Caminho óptico = $2 \mathrm{~mm}$. 
A figura 4.18 apresenta o comportamento da turbidez em função da concentração lipídica em temperaturas representativas da região de transição e das fases gel e fluida. $\mathrm{Na}$ região de transição, a absorbância se mantém próxima de zero para praticamente todas as concentrações lipídicas. Na fase gel, observamos um crescimento da absorbância com a concentração de DMPG. Este comportamento parece razoável, pois sugere que a luz espalhada é proporcional ao número de centros espalhadores. No entanto, para a fase fluida, tal comportamento é observado apenas até a concentração lipídica de $20 \mathrm{mM}$, a partir da qual a absorbância se mantém constante. Embora não saibamos explicar o que isto significa, ou seja, uma absorbância constante com a concentração de soluto, é provável que esta situação contenha alguma informação relevante para uma melhor compreensão de dispersões lipídicas de DMPG em baixa força iônica.

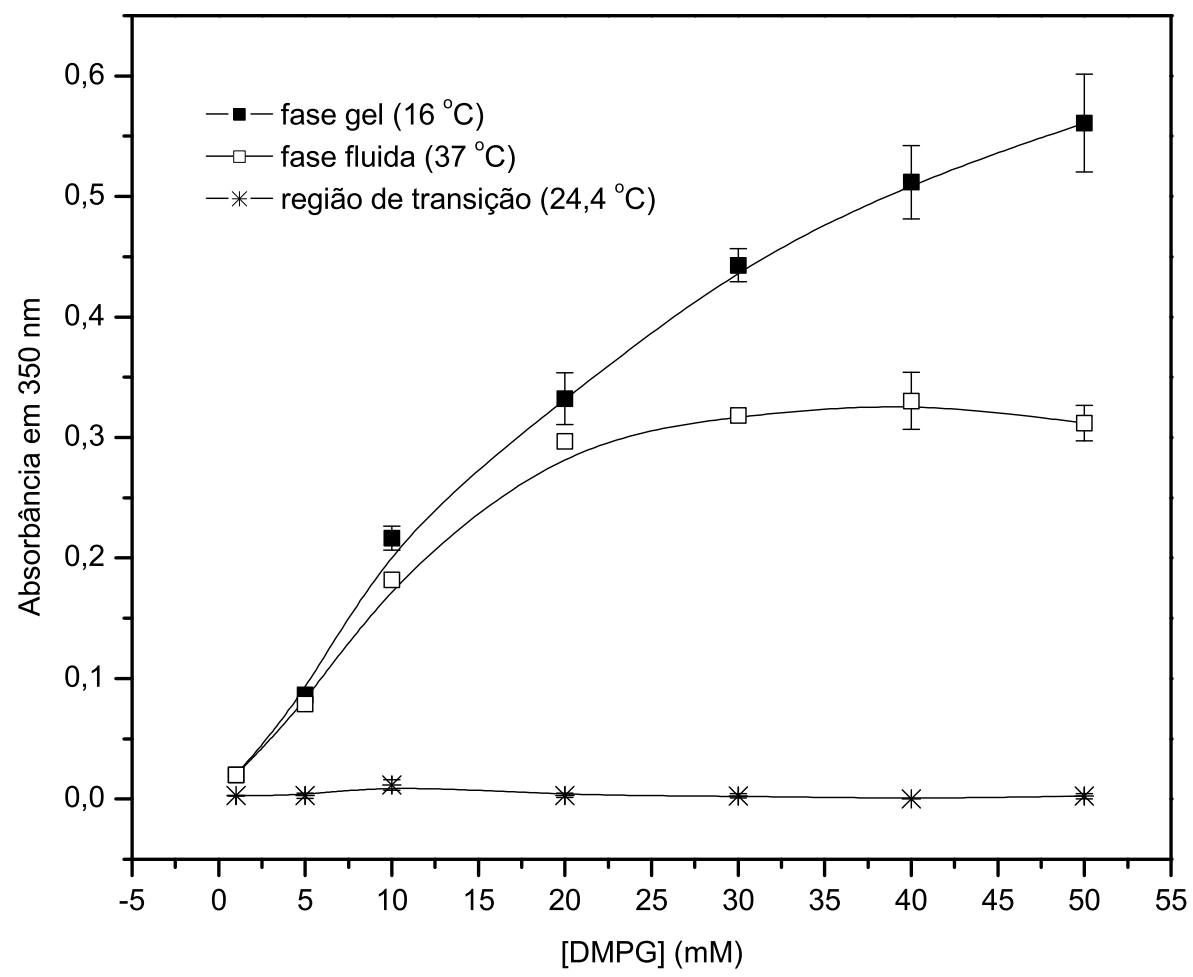

Figura 4.19: (a) Dependência térmica da absorbância medida a $350 \mathrm{~nm}$ de dispersões de DMPG com concentrações lipídicas entre 1 e $50 \mathrm{mM}$ nas fases gel e fluida. Caminho óptico $=2 \mathrm{~mm}$.

A figura 4.20 apresenta uma sobreposição das curvas de absorbância às de DSC. Observamos que há uma clara correlação entre elas: para praticamente todas as concen- 
trações, a turbidez cai abruptamente em $T_{m}{ }^{\text {on }}$ e volta a subir em temperaturas próximas de $T_{m}$ off. 

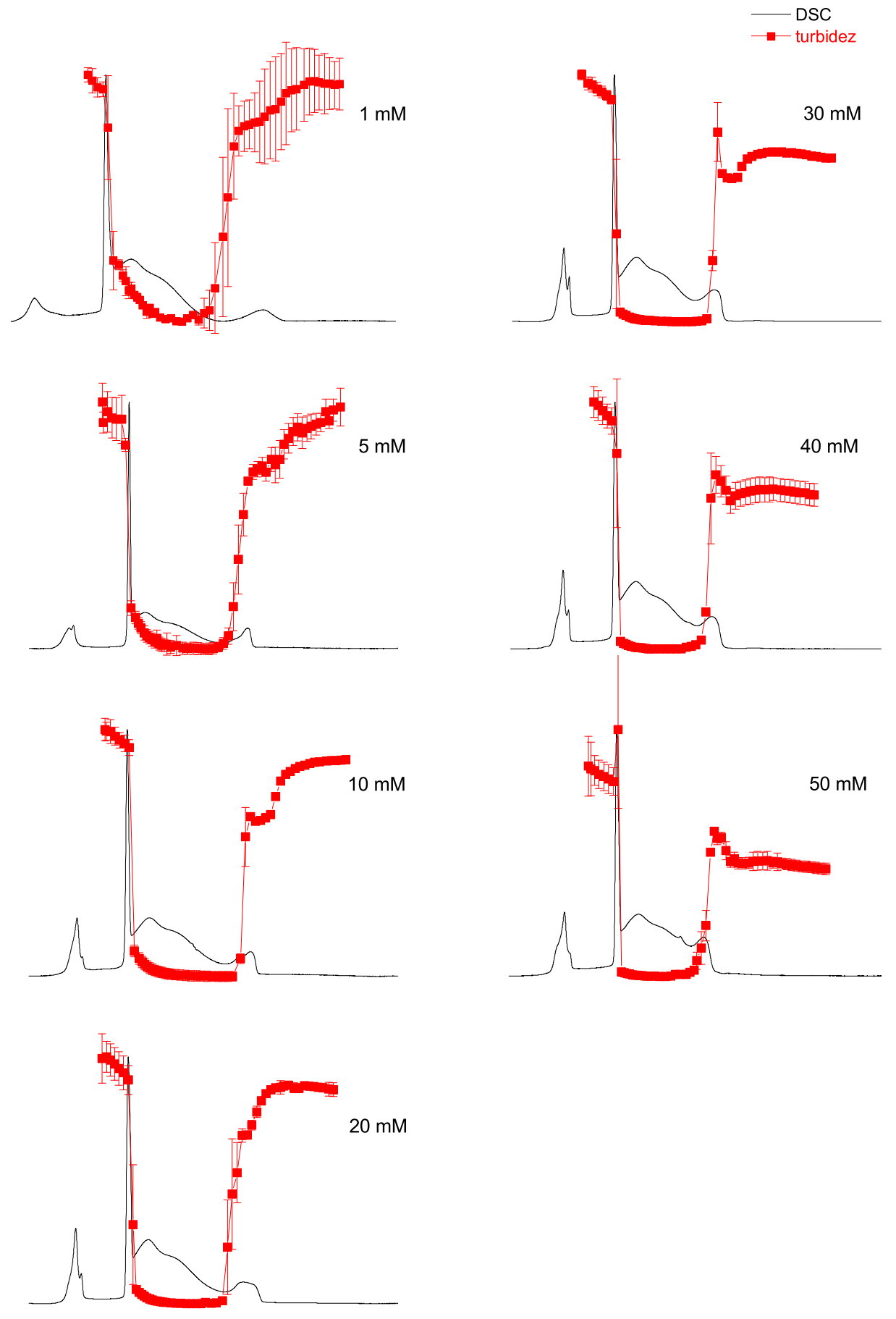

Figura 4.20: Sobreposição das curvas de DSC e de absorbância em 350 nm, em função da temperatura, para várias concentrações lipídicas. 


\subsubsection{Condutividade elétrica}

Considerando que a alta condutividade apresentada por dispersões de DMPG na região de transição esteja provavelmente relacionada à dissociação dos íons $\mathrm{Na}^{+}$dos grupos PG das cabeças polares (Riske et al., 1997; Riske et al., 1999; Tamashiro et al., 2005), investigações desta propriedade parecem ser um bom instrumento para a avaliação da carga dos agregados de DMPG. Com a implementação de um sistema automatizado para a aquisição dos dados de condutividade (ver seção de materiais e métodos) foi possível obter um nível de detalhamento muito bom para o perfil da condutividade em função da temperatura (precisão entre 0,5 e $1^{\circ} \mathrm{C}$ ), como será mostrado adiante.

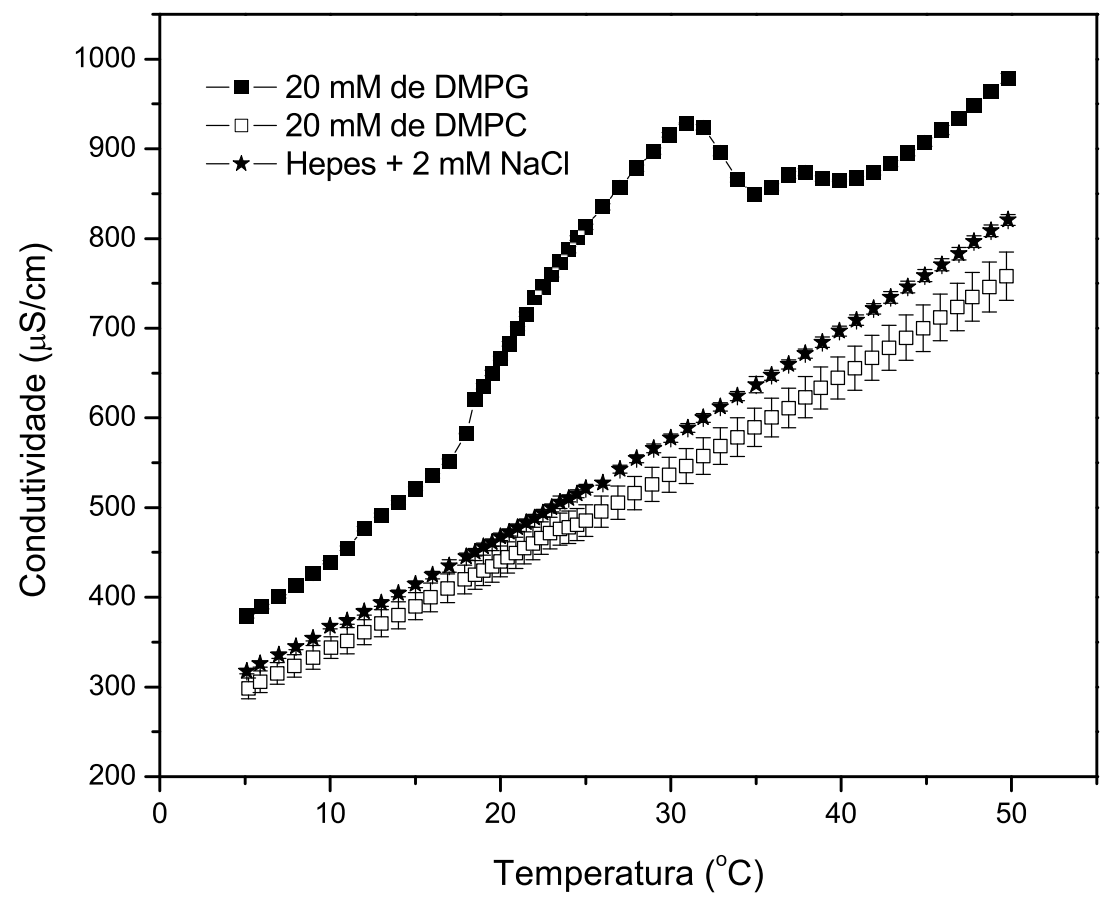

Figura 4.21: Condutividade em função da temperatura de dispersões de $20 \mathrm{mM}$ de DMPG e $20 \mathrm{mM}$ de DMPC em tampão Hepes com $2 \mathrm{mM}$ de $\mathrm{NaCl}$.

A figura 4.21 compara o comportamento térmico da condutividade de uma dispersão de DMPG com uma de DMPC (extrusado por filtro de $100 \mathrm{~nm}$ ), ambas com concentração lipídica de $20 \mathrm{mM}$ e no mesmo tampão. Enquanto a presença de DMPG aumenta a condutividade do tampão, ocorre o inverso para o DMPC, ou seja, a dispersão de DMPC exibe uma condutividade menor do que a do tampão. Lidgate et al., 1993 ob- 
servaram uma redução na condutividade do tampão devido à presença de vesículas, tanto unilamelares quanto multilamelares, sendo maior nestas últimas. Esta diminuição, que mostrou-se diretamente proporcional à concentração lipídica, foi atribuída à captura de parte dos íons presentes na dispersão pelo volume interno aquoso dos lipossomos, uma vez que os íons capturados não contribuiriam para a medida de condutividade. Portanto, é razoável supor tal efeito como o principal causador da diminuição da condutividade para a dispersão de DMPC. Para quantificar este efeito, vamos calcular a fração de volume, $\phi$, ocupada pelas vesículas da dispersão e compará-la à porcentagem de redução da condutividade do solvente, em uma dada temperatura. Em $30{ }^{\circ} \mathrm{C}$ (fase fluida), utilizando os parâmetros descritos na tabela 3.2, obtemos $\phi=0,071(1)$ (usando equação 3.23), ou seja, esperaríamos uma diminuição de 7,1\% na condutividade. Observamos, experimentalmente, que a condutividade do solvente sofre uma diminuição de $7(3) \%$, de acordo com a figura 4.21. Apesar da incerteza grande, este valor é compatível com o calculado. Pode ser também que haja alguma adsorção de íons do meio às vesículas de DMPC, diminuindo a condutividade total medida. Neste caso, as vesículas estariam carregadas e, portanto, comportariam-se como macro-íons trazendo uma contribuição a mais para a condutividade medida. A condutividade medida seria um balanço entre três efeitos: encapsulamento de íons, adsorção de íons e condutividade devida às vesículas carregadas. No entanto, parece mais razoável atribuir a diminuição na condutividade apenas ao encapsulamento dos íons. 


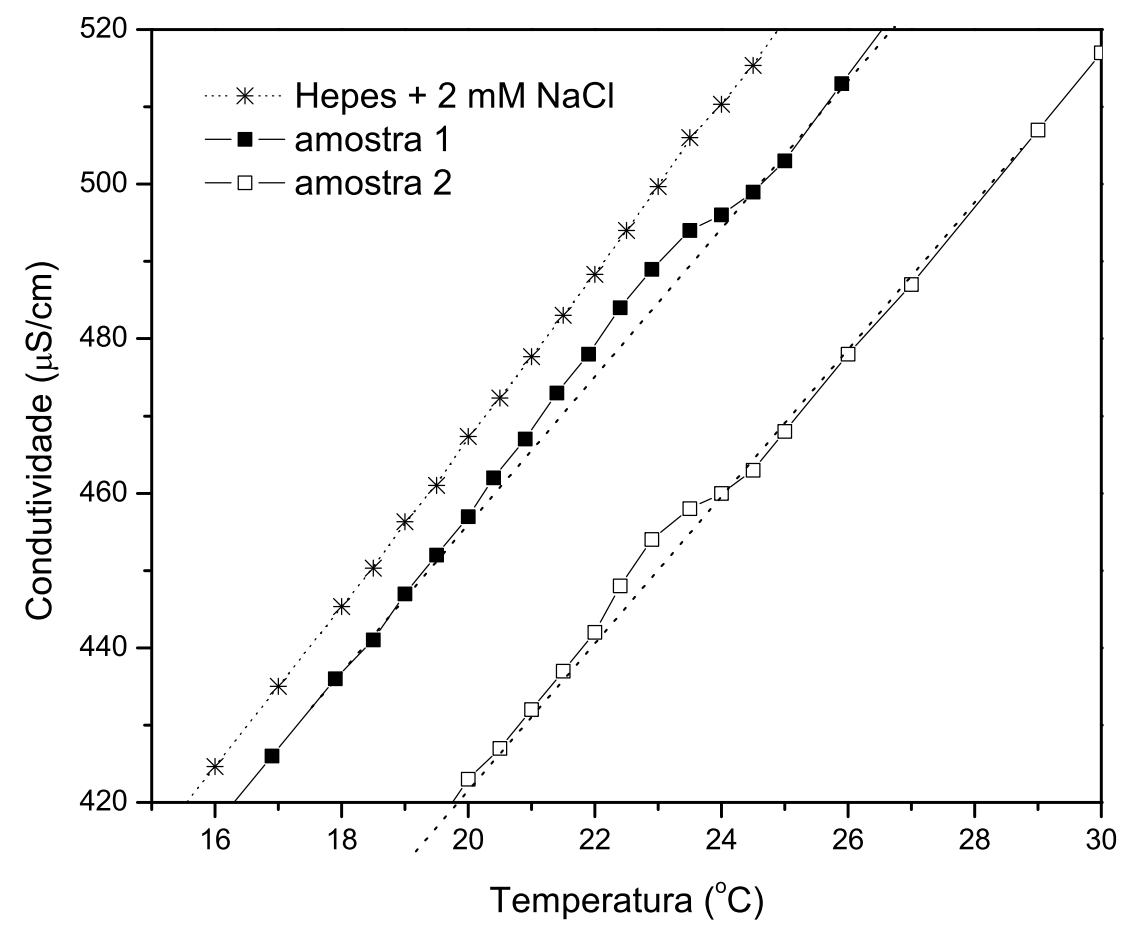

Figura 4.22: Condutividade em função da temperatura de duas dispersões de $20 \mathrm{mM}$ de DMPC em tampão Hepes com $2 \mathrm{mM}$ de $\mathrm{NaCl}$. As linhas tracejadas são apenas auxiliares para acompanhar a inclinação das curvas.

A figura 4.22 apresenta uma ampliação do perfil térmico da condutividade de duas dispersões de DMPC numa faixa de temperatura próxima à temperatura de transição de fase (a curva apresentada na figura 4.21 trata-se do valor médio entre elas). Podemos observar, para ambas as curvas, um pequeno aumento de condutividade neste intervalo de temperatura. Sabe-se que na temperatura de transição de fase de bicamadas lipídicas, há a abertura de poros transientes nas bicamadas (Nagle \& Scott, 1978, Antonov et al., 1980), resultando num pico de permeabilidade a íons, conforme observado experimentalmente (Papahadjopoulos et al., 1973) e também obtido por simulações teóricas (Doniach, 1978). É provável que o pequeno acréscimo na condutividade da dispersão de DMPC esteja relacionado, de alguma forma, a este efeito.

Voltando à figura 4.21, observamos que as condutividades do tampão e das duas dispersões aumentam com o aumento da temperatura. Isto está de acordo com o esperado, pois a condutividade iônica é inversamente proporcional à viscosidade do meio, a qual, por sua vez, diminui com o aumento da temperatura (Chang, 2000). Para descon- 
tar a contribuição do solvente, que acaba englobando o efeito da própria temperatura, expressaremos nossos dados em função da condutividade reduzida, $\sigma_{\text {red }}$, definida como:

$$
\sigma_{r e d}=\frac{\Delta \sigma}{\sigma_{0}(1-\phi)}
$$

onde $\Delta \sigma$ é a diferença entre a condutividade da dispersão e a do solvente, $\Delta \sigma=\sigma-\sigma_{0}(1-$ $\phi)$ e $\sigma_{0}$ é a condutividade do solvente. O termo $1-\phi$ trata-se de uma correção para levar em conta que os íons do tampão, aprisionados dentro do volume aquoso das vesículas, não devem participar da condutividade medida. Portanto, a grandeza $100 \sigma_{\text {red }}$ quantitativamente é igual a variação percentual na condutividade do solvente devido a presença do soluto. Por exemplo, $\sigma_{\text {red }}=0,15$ significaria um aumento de $15 \%$ na condutividade do solvente.

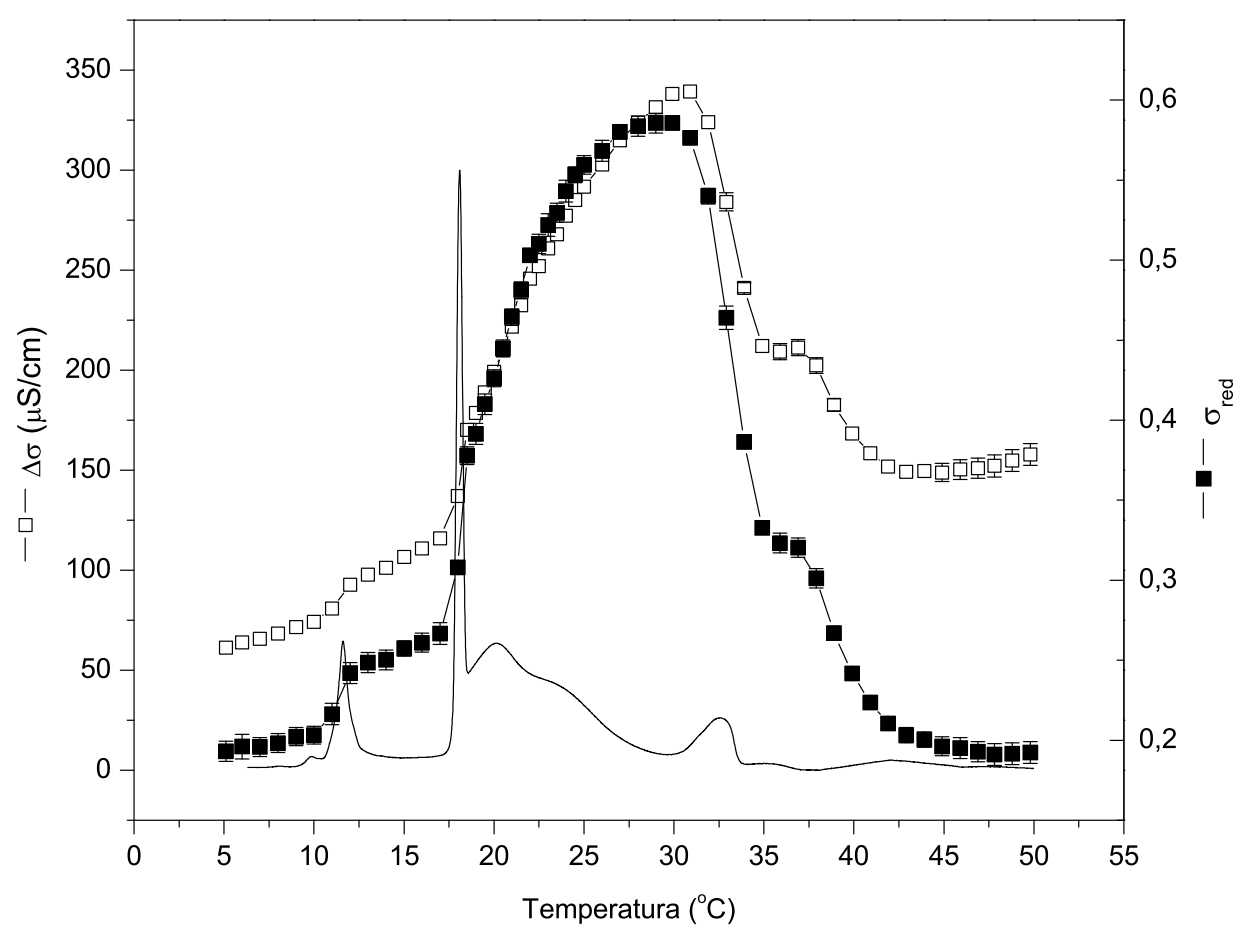

Figura 4.23: Diferença entre as condutividades da dispersão e do solvente (Hepes $+2 \mathrm{mM} \mathrm{de} \mathrm{NaCl}$ ), $\Delta \sigma$ e condutividade reduzida, $\sigma_{r e d}$ em função da temperatura. Linha cheia, em escala arbitrária, curva DSC da dispersão. [DMPG] $=20 \mathrm{mM}$.

A figura 4.23 apresenta $\sigma_{\text {red }}$ e $\Delta \sigma$ relativos à mesma dispersão da figura 4.21. Enquanto $\Delta \sigma$ cresce com a temperatura, refletindo, principalmente, a variação térmica 
da viscosidade do solvente, $\sigma_{\text {red }}$ desconta este efeito dando informações de mudanças na condutividade do solvente devidas apenas à presença dos agregados de DMPG. Conforme podemos observar na figura 4.23, na fase gel, os agregados de DMPG aumentam em torno de $20 \%$ a condutividade do solvente. A condutividade aumenta bruscamente em uma temperatura que coincide com o pico calorimétrico da pré-transição e continua crescendo lentamente até sofrer um novo aumento abrupto em $T_{m}{ }^{\text {on }}$. Suavemente, $\sigma_{\text {red }}$ prossegue crescendo até atingir um máximo, em torno de $30^{\circ} \mathrm{C}$, e cai sofrendo sucessivas quedas extensas até uma temperatura próxima a $T_{m}{ }^{\text {off }}$. Após isso, decresce suavemente até 50 ${ }^{\circ} \mathrm{C}$. Este decréscimo é marcado por uma pequena protuberância no perfil de $\sigma_{\text {red }}$ que pode estar associada a algum evento térmico que não tem correspondência no DSC.

Para o caso da dispersão de DMPG, em que a condutividade aumenta, além do efeito de encapsulamento dos íons do solvente, é preciso levar em conta a possível dissociação das cabeças polares do DMPG. Os contraíons sódio, $\mathrm{Na}^{+}$, em princípio associados às cabeças polares, dissociariam-se das mesmas e acabariam trazendo uma contribuição a mais para a medida de condutividade, aumentando-a. Além disto, os próprios agregados, devem portar-se como macroíons, também contribuindo para o acréscimo na condutividade. Estas últimas hipóteses serão confirmadas mais adiante. Também mostraremos que os agregados de DMPG apresentam mobilidades eletroforéticas da mesma ordem de grandeza que íons livres em solução. 
O aumento de concentração lipídica deve aumentar o número de contraíons em solução (dissociação). Os dados da figura 4.24a, mostrando o perfil de $\sigma$ em função da temperatura para várias concentrações de DMPG, estão de acordo com esta hipótese. Através da condutividade reduzida (figura 4.24b), que quantifica este efeito, vemos que, enquanto para concentração de $1 \mathrm{mM}$ o aumento máximo obtido na condutividade é menor que 5\%, obtemos um aumento de quase $180 \%$ para $50 \mathrm{mM}$ de DMPG.

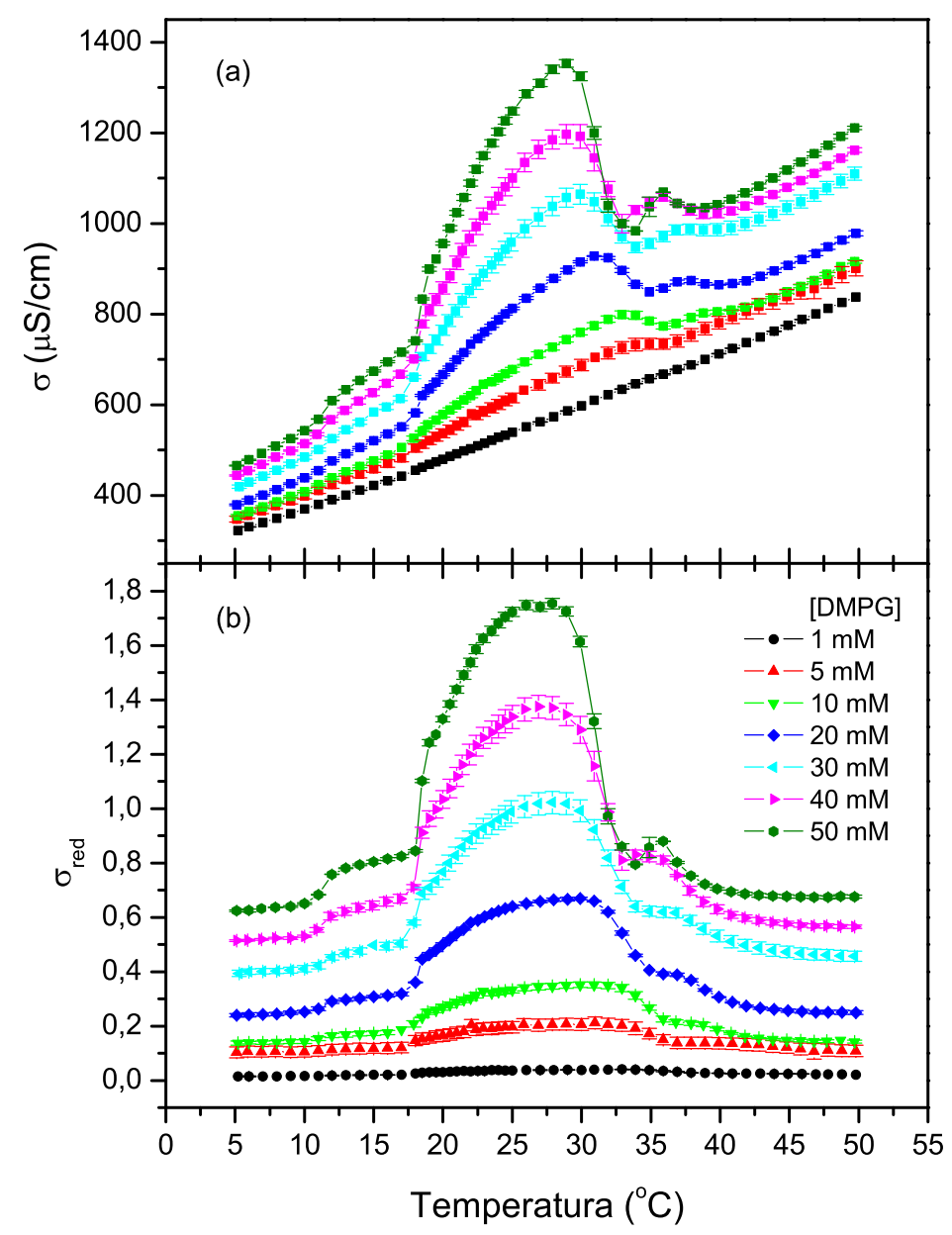

Figura 4.24: (a) Comportamento térmico da condutividade de dispersões de DMPG em Hepes $+2 \mathrm{mM}$ de $\mathrm{NaCl}$ para várias concentrações lipídicas. (b) $\sigma_{\text {red }}$ em função da temperatura para várias concentrações de DMPG. 

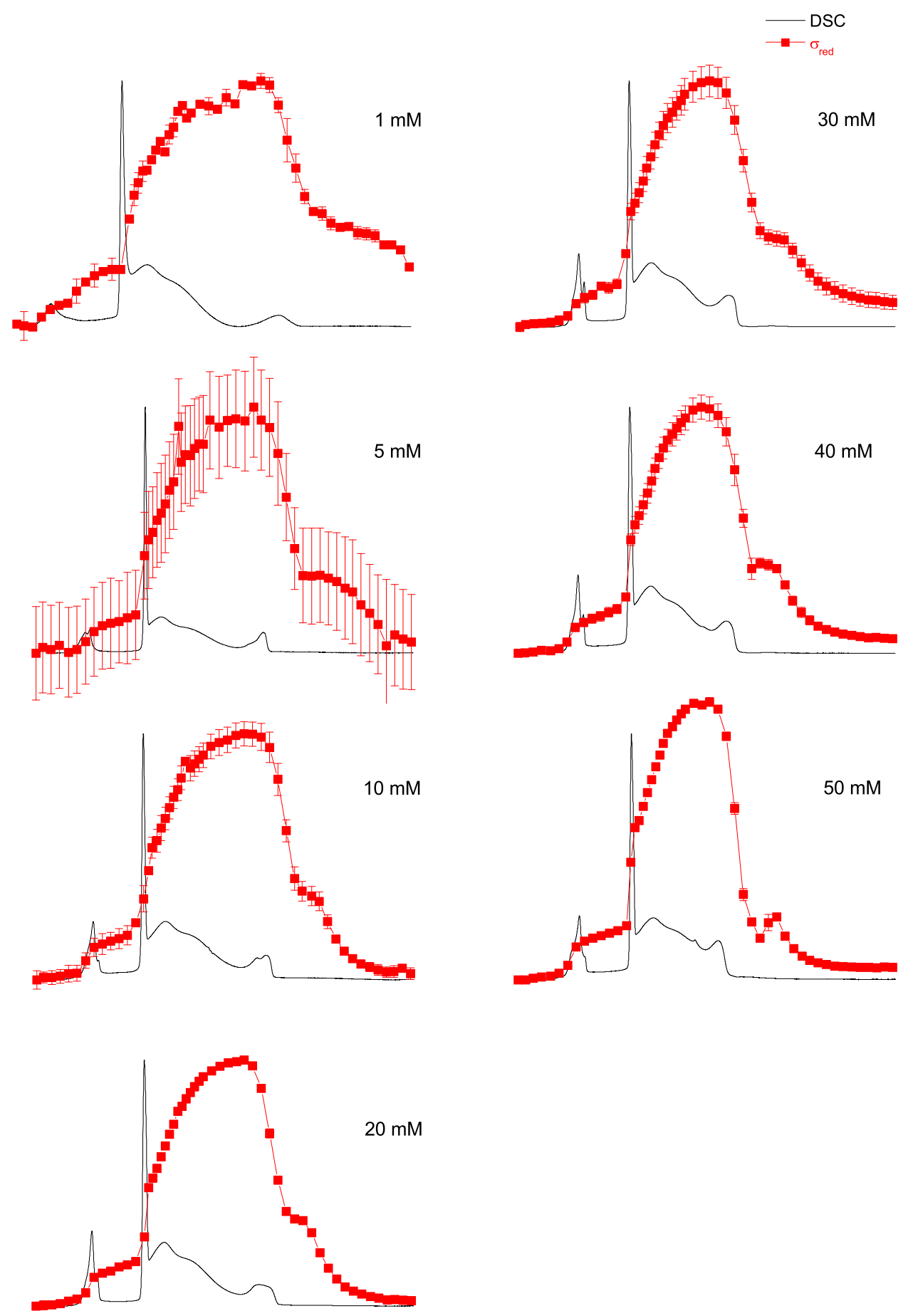

Figura 4.25: Sobreposição das curvas DSC e de $\sigma_{\text {red }}$, em função da temperatura, com várias concentrações lipídicas em Hepes $+2 \mathrm{mM}$ de $\mathrm{NaCl}$.

A figura 4.25 apresenta as curvas de $\sigma_{\text {red }}$ em função da temperatura sobrepostas às curvas DSC. Similarmente aos traços de DSC, a dependência térmica da condutividade elétrica segue a mesma tendência para todas as concentrações de DMPG. A condutivi- 
dade é muito maior ao longo da região de transição, conforme visto por Riske et al., 1997. Os dados mostraram-se bem reprodutíveis, como expressado pelas pequenas incertezas na figura 4.24. No entanto, outros fatores interessantes puderam ser detectados. Assim como já foi descrito para $20 \mathrm{mM}$ de DMPG, para todas as amostras é possível distinguir: i) um nítido aumento abrupto de $\sigma_{\text {red }}$ em uma temperatura próxima de $T_{p}$ (em torno de $11^{\circ} C$ ); ii) um crescimento suave de $T_{p}$ até $T_{m}{ }^{\text {on }}$; iii) um aumento abrupto em $T_{m}{ }^{\text {on }}$ ( em torno de $18^{\circ} \mathrm{C}$ ) seguido por um aumento contínuo até uma temperatura próxima de $T_{m}{ }^{\text {off }}$, a partir da qual a condutividade decresce abruptamente. É interessante notar uma protuberância observada em temperaturas altas, não associada a nenhum pico calorimétrico e que, para concentrações maiores, vai se tornando cada vez mais evidenciada, tornando-se praticamente um pico para $50 \mathrm{mM}$ de DMPG. Esta protuberância não é observada em varreduras feitas esfriando as amostras (dados não mostrados). Tal peculiaridade acima de $T_{m}{ }^{\text {off }}$, apenas em varreduras esquentando-se as amostras, também foi detectada através de espalhamento de luz (figura 4.17, Alakoskela \& Kinnunen, 2007; Alakoskela et al., 2010) e precisa de mais investigação. 
Embora a condutividade da dispersão seja maior para concentrações lipídicas maiores, verificamos que a condutividade por concentração lipídica é um pouco maior para dispersões com concentrações menores: as dispersões de 1 e 5 mM de DMPG possuem uma condutividade/[DMPG] maior do que as demais concentrações, conforme evidenciado pela figura 4.26a. Todavia, acima de $10 \mathrm{mM}, \sigma_{\text {red }} /[\mathrm{DMPG}]$ se mantém praticamente constante (melhor visualizado na figura 4.26b). É provável que para concentrações menores os lipídios estejam mais ionizados. Isto será investigado mais adiante, quando calcularemos o grau de ionização das bicamadas de DMPG.
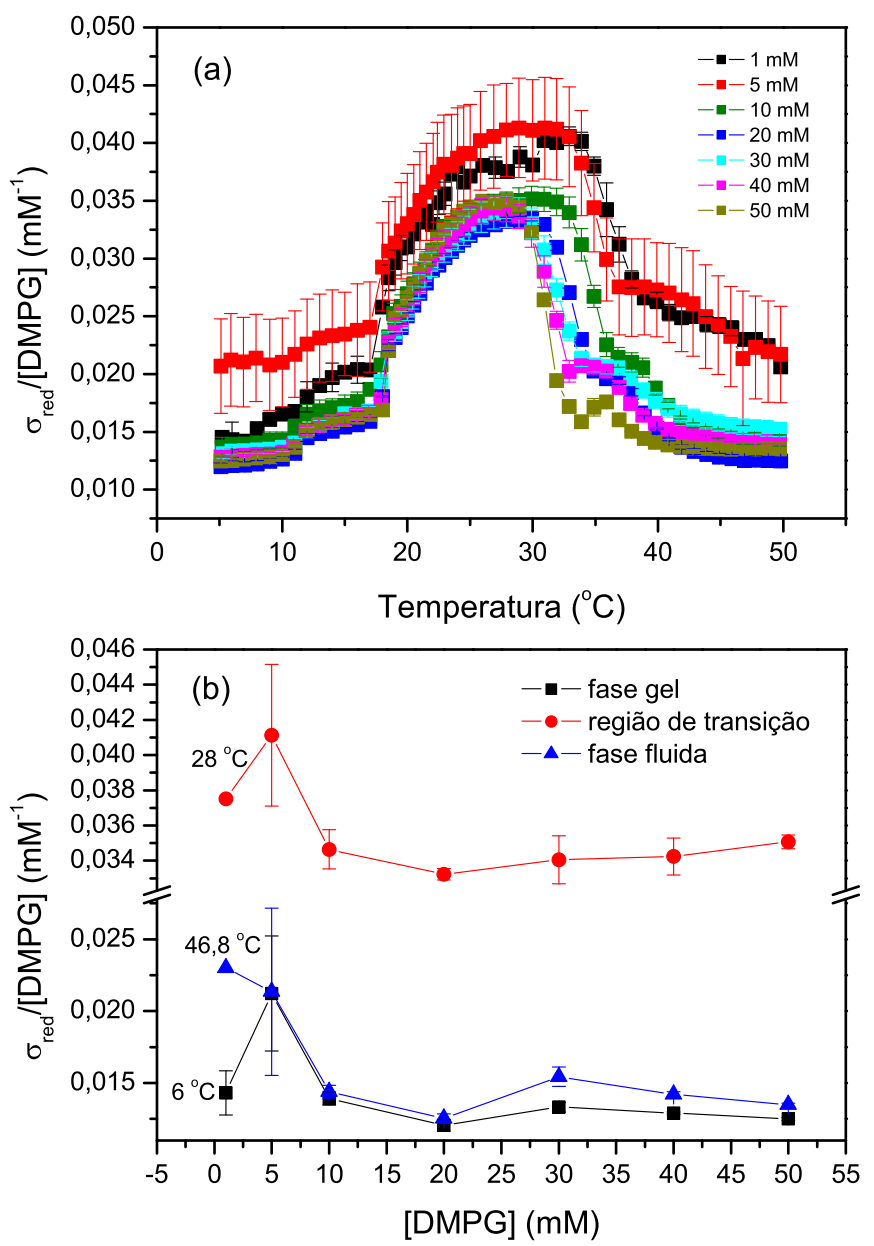

Figura 4.26: (a) Comportamento térmico de $\sigma_{\text {red }} /[\mathrm{DMPG}]$ normalizada pela concentração lipídica. (b) $\sigma_{\text {red }} /[\mathrm{DMPG}]$ em função da concentração em temperaturas representativas das fases gel, fluida e região de transição. 


\subsubsection{Mobilidade eletroforética e grau de ionização: carga e es- trutura dos agregados de DMPG}

$\mathrm{Na}$ análise dos dados de condutividade, além dos íons do tampão, é importante levar em conta tanto a contribuição dos contraíons quanto dos agregadados lipídicos carregados, sendo a condutividade total da dispersão uma soma de todas estas contribuições. A condutividade elétrica $\sigma$ pode ser escrita em função do grau de ionização aparente do DMPG, $\alpha$, e das mobilidades eletroforéticas dos agregados de DMPG e dos contra-íons $\mathrm{Na}^{+}$(equação 3.30).

A figura 4.27 apresenta o comportamento da mobilidade eletroforética, em função da temperatura, de dispersões de 1 a 20 mM de DMPG e do íon sódio.

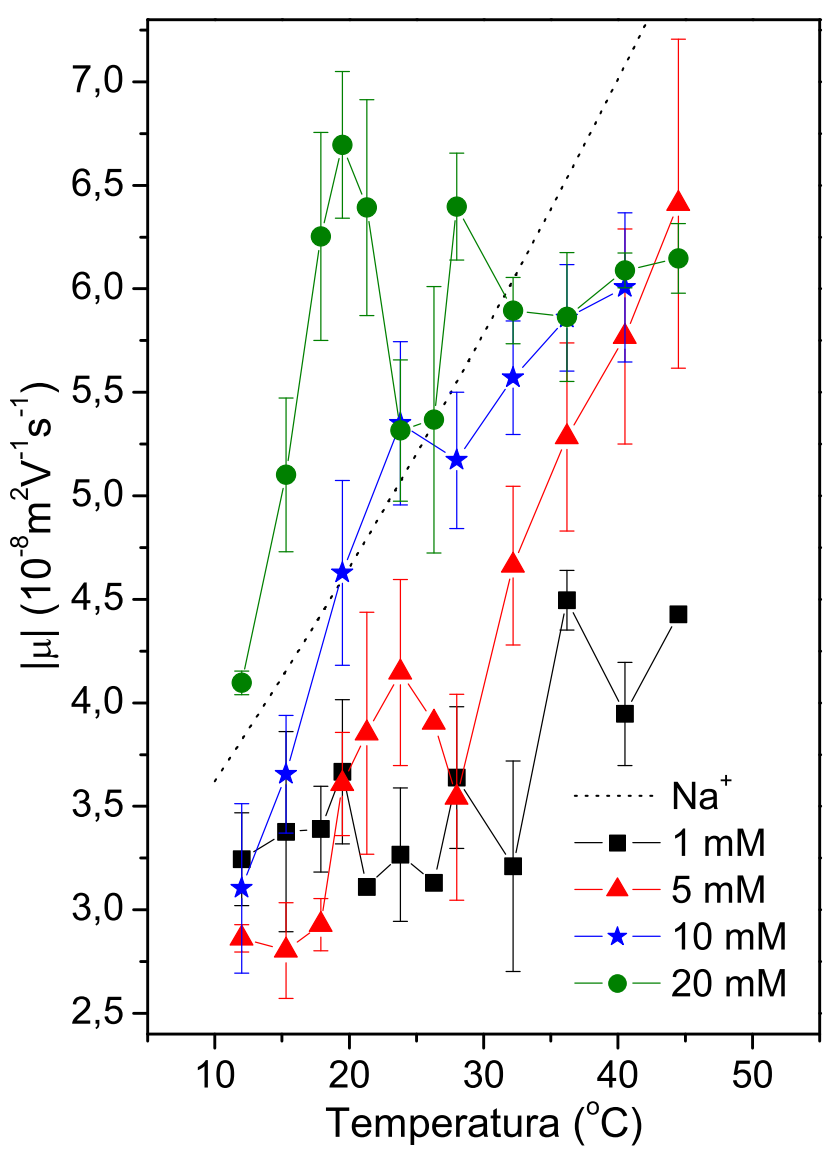

Figura 4.27: Valor absoluto da mobilidade eletroforética, em função da temperatura, do íon sódio (linha tracejada) e de dispersões de DMPG em Hepes $+2 \mathrm{mM}$ de $\mathrm{NaCl}$ com várias concentrações lipídicas.

Para calcular a mobilidade dos íons de sódio, $\mu^{\mathrm{Na}^{+}}$, utilizamos a seguinte equação 
empírica (Harned \& Owen, 1967):

$$
\mu^{\mathrm{Na}^{+}}=\frac{50,11+1,0916(T-25)+0,004715(T-25)^{2}-0,0000115(T-25)^{3}}{N_{A} e}
$$

onde $T$ é a temperatura em ${ }^{\circ} \mathrm{C}$. Observamos que a mobilidade do íon sódio cresce continuamente com o aumento de temperatura. De maneira análoga à condutividade, este comportamento é devido, em sua maior parte, ao decréscimo da viscosidade do meio (solvente) à medida que se aumenta a temperatura. Espera-se comportamento semelhante para macroíons esféricos, com carga e raio constantes ao longo da variação de temperatura. Contudo, para vesículas lipídicas ou outras partículas coloidais, temperaturas de transição de fase devem produzir uma descontinuidade na dependência térmica de $\mu$, indicando uma mudança na carga da partícula e/ou alterações em suas dimensões (Tatulian, 1987; Sierra-Martin et al., 2006). Esta situação é compatível com o perfil de mobilidade das dispersões de DMPG (figura 4.27): apesar do considerável espalhamento nos dados, é possível observar um aumento anômalo na mobilidade eletroforética ao longo da região de transição, entre $T_{m}{ }^{o n}\left(\sim 18^{\circ} \mathrm{C}\right)$ e $T_{m}{ }^{\text {off }}\left(\sim 30^{\circ} \mathrm{C}\right)$, principalmente para 5,10 e $20 \mathrm{mM}$ de DMPG. Portanto, este aumento anômalo na mobilidade é uma indicação de que, durante a região de transição, o agregado de DMPG está se modificando quanto à carga, tamanho, forma ou mais de uma dessas propriedades.

Experimentalmente, a mobilidade eletroforética é obtida através da luz espalhada pelos agregados lipídicos (maiores detalhes na seção de materiais e métodos). As incertezas grandes atribuídas aos dados são um reflexo de largas distribuições de mobilidade ${ }^{2}$. Este alargamento nas distribuições, muito provavelmente, está relacionado à polidispersidade das amostras, uma vez que elas não foram extrusadas.

\footnotetext{
${ }^{2}$ Para diminuir esta incerteza, repetimos os experimentos de maneira a ter pelo menos cinco amostras diferentes para cada concentração lipídica. As incertezas finais, expressas pelas barras de erro no gráfico da figura 4.2.4, são os desvios padrões da média relativos às diferentes amostras. Além deste agravante, também não foi possível fazer medidas para concentrações lipídicas acima de $20 \mathrm{mM}$, porque isto causava oxidação dos eletrodos. O mesmo ocorria no caso de repetir as medidas muitas vezes para a mesma amostra. Devido a tal fato, não pudemos fazer muitas medidas em várias temperaturas, como foi feito para as outras técnicas experimentais.
} 
Apresentamos na figura 4.28a, à guisa de ilustração, uma média dos valores das larguras das distribuições de mobilidade de todas concentrações, em cada temperatura, em função da temperatura. Verificamos também que a polidispersidade é maior na região de transição (figura 4.28b).

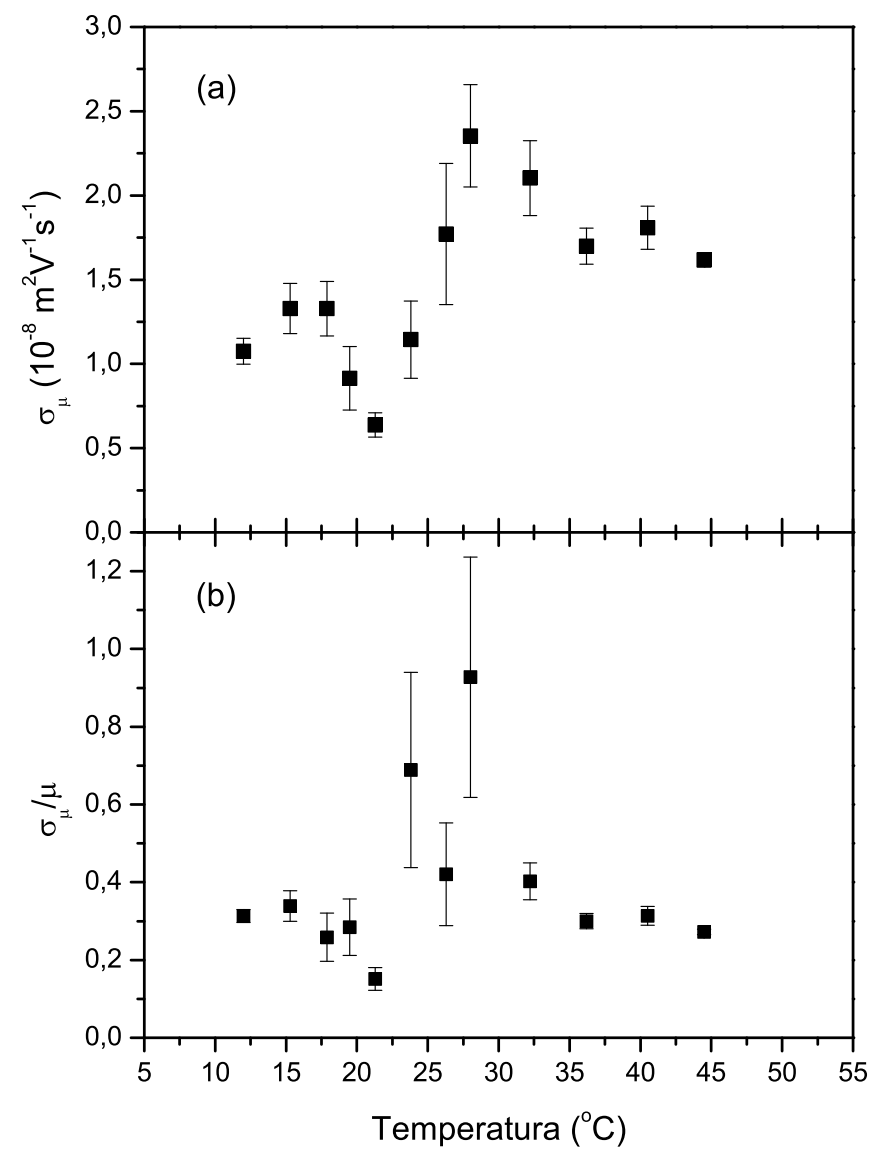

Figura 4.28: (a) Média das larguras das distribuições de mobilidade, $\sigma_{\mu}$, de todas as concentrações de DMPG em função da temperatura. (b) Razão entre largura da distribuição e mobilidade, $\sigma_{\mu} / \mu$, em função da temperatura

Através da equação 3.30, definida na seção de materiais e métodos, calculamos o grau de ionização das bicamadas de DMPG em função da temperatura (figura 4.29). Os parâmetros utilizados para o cálculo de $\alpha$ são apresentados na tabela 3.1, no capítulo de técnicas. 


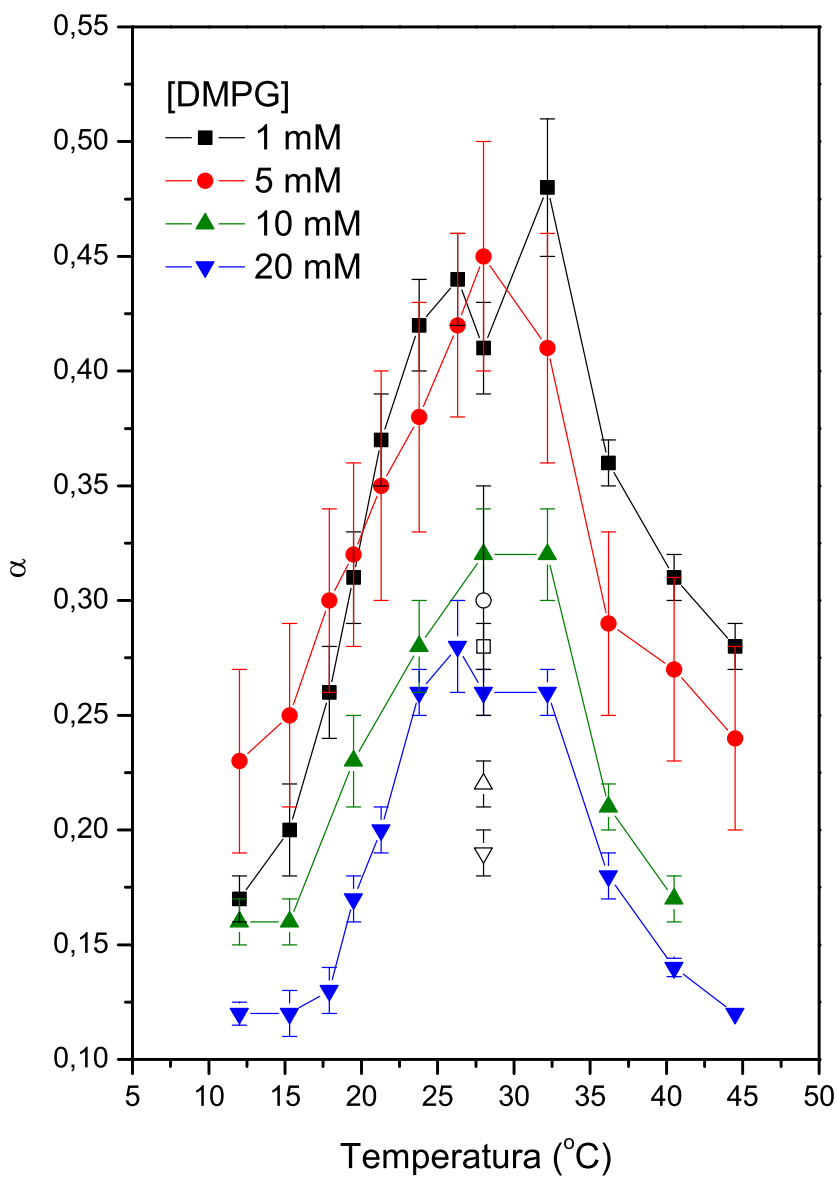

Figura 4.29: Dependência térmica do grau de ionização aparente de bicamadas lipídicas de DMPG. Os símbolos abertos em $28{ }^{\circ} \mathrm{C}$ representam um caso extremo em que todos os contraíons de dentro de vesículas totalmente permeáveis contribuiriam para a condutividade.

Observamos que o grau de ionização cresce consideravelmente ao longo da região de transição, com as fases gel e fluida mostrando valores similares para $\alpha$ (exceto para 1 $\mathrm{mM}$ de DMPG). Este aumento está de acordo com a hipótese de que na região de transição as bicamadas apresentam locais com curvaturas maiores, nas quais se espera que os lipídios estejam mais carregados. Além disso, o grau de ionização é maior para concentrações lipídicas menores. Também calculamos valores para o grau de ionização na região de transição $\left(28^{\circ} \mathrm{C}\right)$ para um caso extremo, em que todos os contraíons contribuiriam para a medida de condutividade, obtido da equação 3.30, substituindo o termo $\mu_{c}$ por $2 \mu_{c}$ e fazendo $\phi=0$. Embora pouco provável, neste caso, também veríamos um aumento na região de transição. 


\subsubsection{Viscosidade}

\subsubsection{Efeito da concentração lipídica na viscosidade}

Considerando que uma das peculiaridades do comportamento anômalo de dispersões de DMPG em baixa força iônica é sua alta viscosidade ao longo da região de transição (Schneider et al., 1999, Heimburg \& Biltonen, 1994), e a possível relação entre a viscosidade da amostra e outras medidas dinâmicas, tais como condutividade elétrica e mobilidade eletroforética, foram medidas viscosidades de dispersões com as mesmas concentrações de DMPG estudadas (1, 5, 10, 20, 30, 40 e $50 \mathrm{mM})$.

A figura 4.30 apresenta o comportamento térmico da viscosidade de uma dispersão lipídica contendo vesículas unilamelares de DMPC (extrusado por filtro de $100 \mathrm{~nm}$ ).

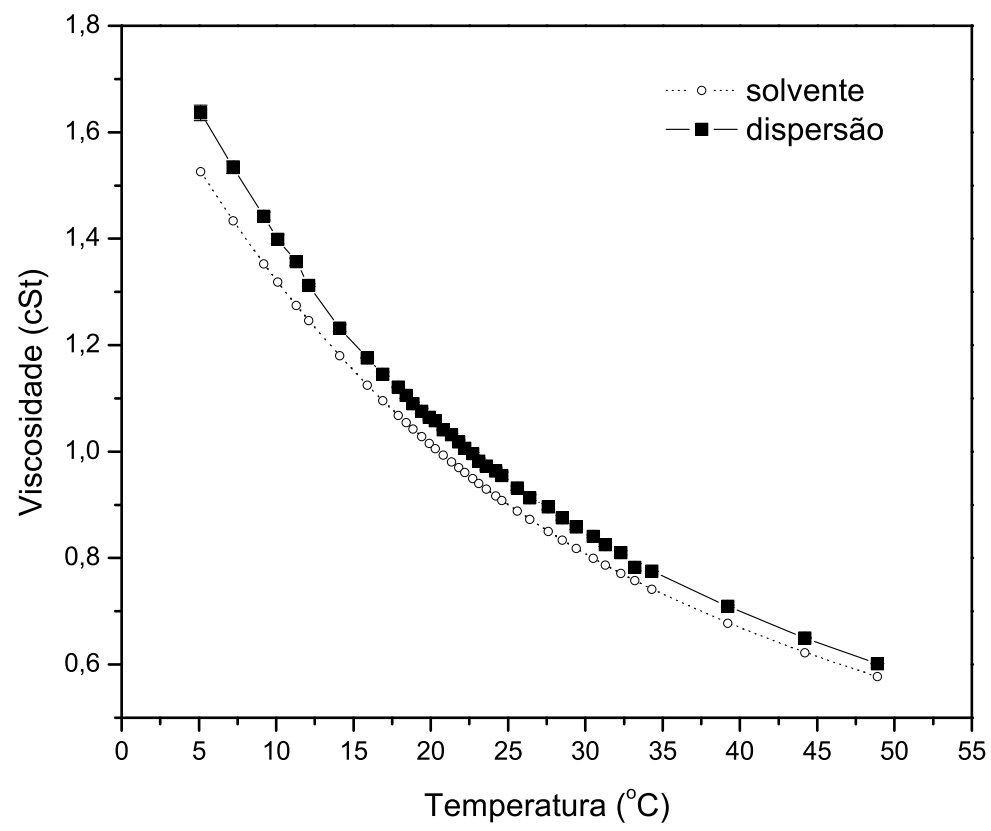

Figura 4.30: Comportamento térmico da viscosidade cinemática de dispersão de $10 \mathrm{mM}$ de DMPC (quadrados fechados) e de tampão Hepes $+2 \mathrm{mM}$ de $\mathrm{NaCl}$ (círculos abertos).

Conforme esperado, observamos uma viscosidade maior da dispersão em relação ao solvente. Analogamente à condutividade reduzida, calculamos o incremento de viscosidade relativa, $\eta_{i}$, para ver a influência na viscosidade causada apenas pelo soluto (vesículas de DMPC), ou seja, descontamos a viscosidade do solvente bem como a dependência da 
viscosidade com a temperatura. Para calcular $\eta_{i}$, de acordo com o capítulo de técnicas, precisamos subtrair da viscosidade total a do solvente, e como em alguns casos não foi possível realizar essa subtração ponto a ponto (não necessariamente a viscosidade do solvente foi tomada nas mesmas temperaturas que a viscosidade da solução), interpolamos alguns pontos através de um ajuste polinomial da viscosidade do solvente em função da temperatura (figura 4.31).

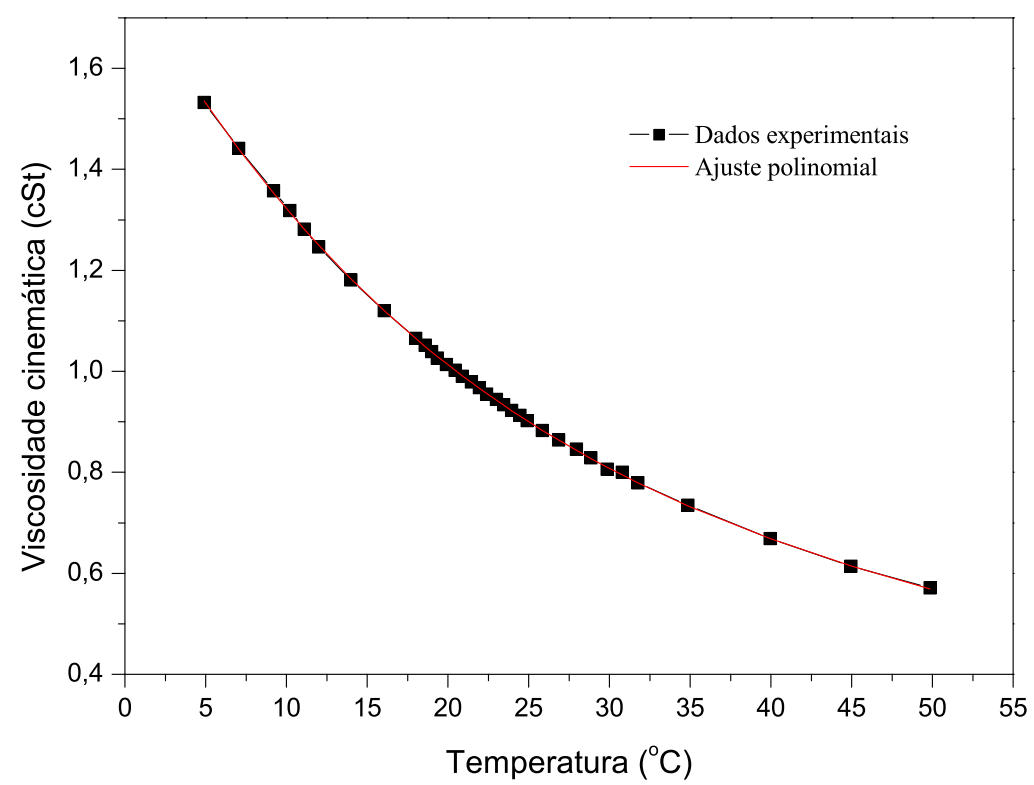

Figura 4.31: Viscosidade cinemática de $10 \mathrm{mM}$ de Hepes $+2 \mathrm{mM}$ de $\mathrm{NaCl}$ em função da temperatura.

Encontramos a seguinte equação para o ajuste da figura 4.31:

$$
\eta_{0}=1,78 T-0,00108 T^{2}-1,15123 \times 10^{-5} T^{3}+5,14939 \times 10^{-8} T^{4}
$$

onde $\eta_{0}$ é a viscosidade cinemática, em cSt, e $T$ a temperatura em ${ }^{\circ} \mathrm{C}$.

A partir do ajuste, calculamos o incremento de viscosidade relativa para os dados relacionados à figura 4.30, apresentado na figura 4.32. 


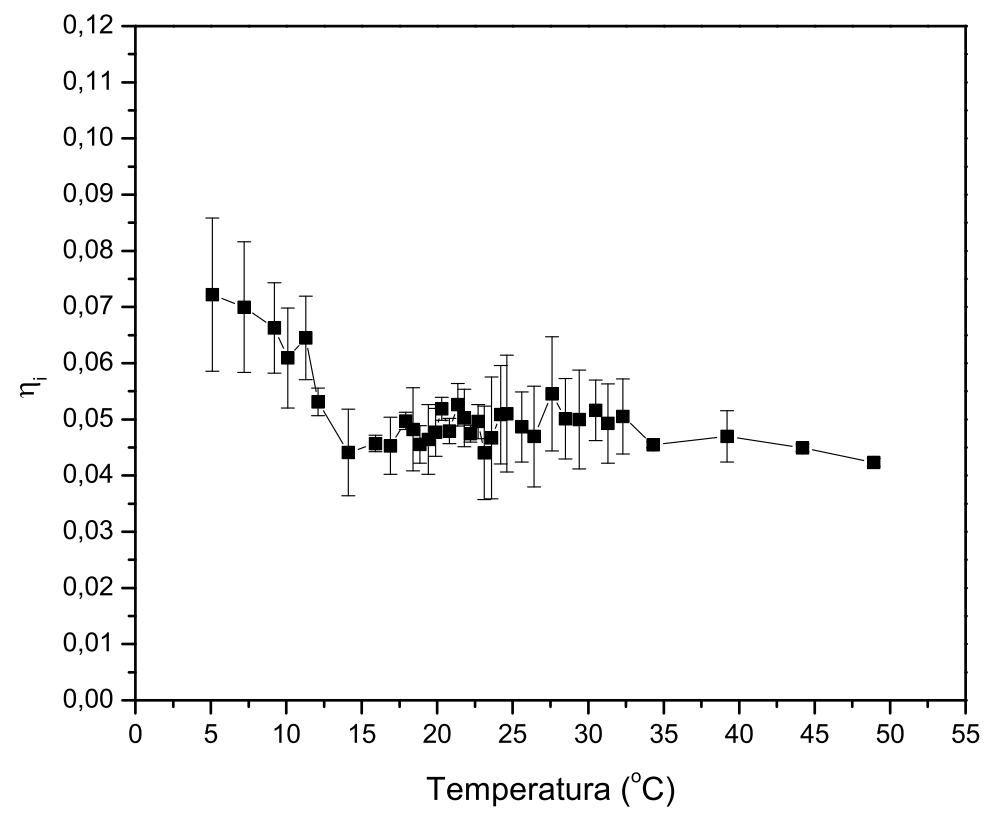

Figura 4.32: Incremento de viscosidade relativa de $10 \mathrm{mM}$ DMPC em Hepes $+2 \mathrm{mM}$ de $\mathrm{NaCl}$ em função da temperatura.

Observamos que o incremento de viscosidade relativa permanece constante na fase gel, sofre uma queda na pré-transição de fase e volta a permanecer constante na fase fluida. Curiosamente, não há variação na viscosidade na temperatura de transição.

Podemos extrair diretamente do incremento de viscosidade relativa (figura 4.32), o aumento que as vesículas do DMPC causam na viscosidade do tampão. Vemos um aumento em torno de $7 \%$ entre 5 e $11,3^{\circ} \mathrm{C}$ e em torno de $4 \%$ entre aproximadamente 14 e $50{ }^{\circ} \mathrm{C}$. Conhecendo a fração de volume ocupada pelas vesículas de DMPC, podemos obter, teoricamente, o valor de $\eta_{i}$. Usando os parâmetros da tabela 3.2, obtemos frações de volume de 0,029 e 0,036, para as fases gel e fluida, respectivamente. Usando estes valor na relação de Einstein (equação 3.40), chegamos a $\eta_{i}=0,073$ e $\eta_{i}=0,089$, para as fases gel e fluida. Para a fase gel, o valor encontrado é compatível com o experimental, enquanto que para a fase fluida é em torno de duas vezes o valor experimental. Esta incompatibilidade entre os valores teórico e experimental da fase fluida, talvez esteja ligada ao fato de que na fase fluida há uma maior flutuação das bicamadas, lembrando que a relação de Einstein pressupõe esferas rígidas.

A figura 4.33 apresenta o comportamento da viscosidade em função da tempera- 
tura de dispersões de $1 \mathrm{mM}$ de DMPG.

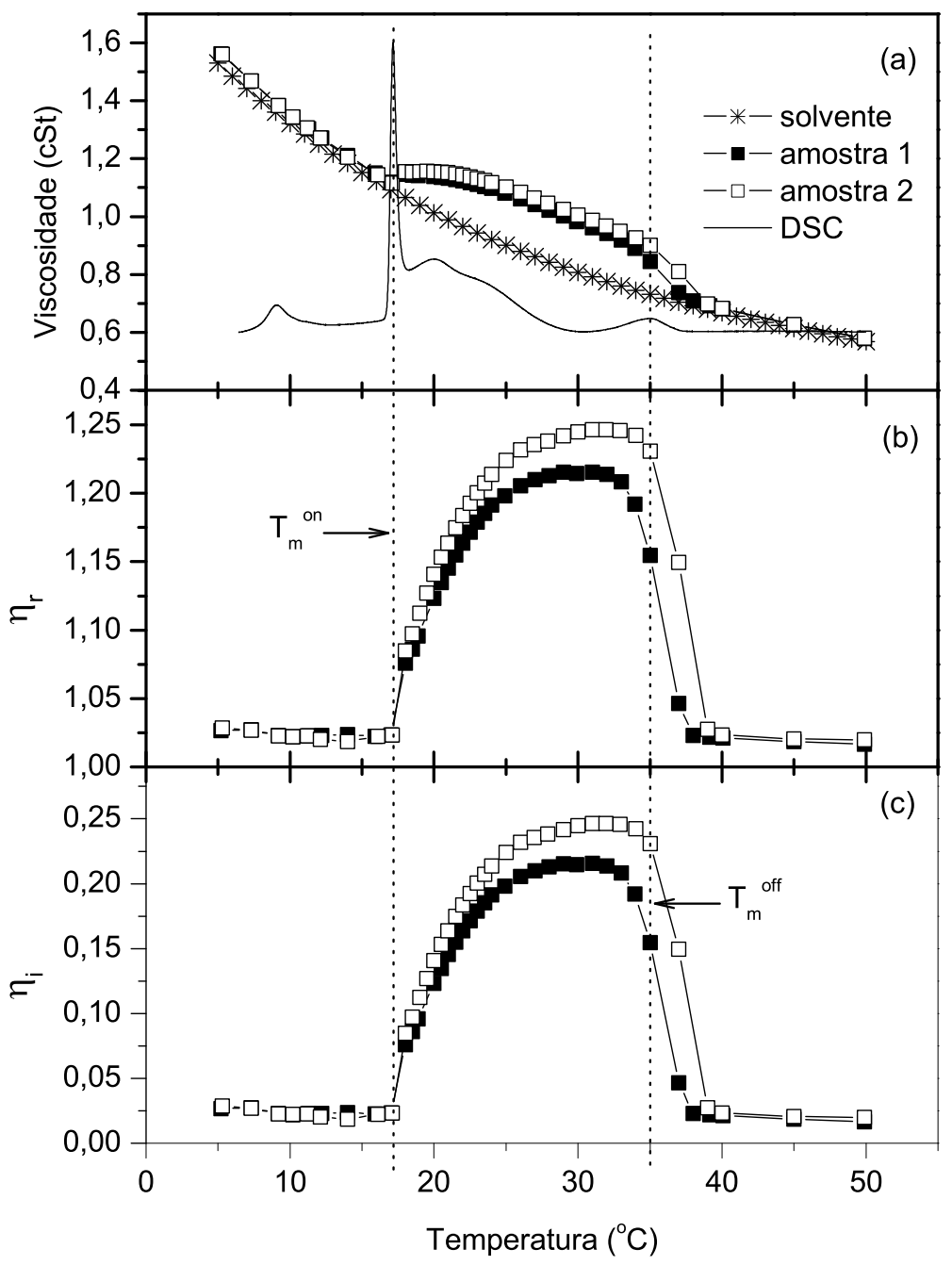

Figura 4.33: Comportamento térmico da viscosidade de dispersões de $1 \mathrm{mM}$ de DMPG: (a) viscosidade cinemática; (b) viscosidade relativa e (c) incremento de viscosidade relativa.

Nas fases gel e fluida, o perfil da viscosidade é semelhante ao do tampão (figura 4.33a). Porém, na região de transição, a viscosidade fica alta entre $T_{m}^{o n}$ e um pouco após $T_{m}^{o f f}$. Através da viscosidade relativa (figura 4.33b) é possível visualizar melhor a alteração na viscosidade do solvente devido à presença dos agregados de DMPG. Observase que a viscosidade sofre um aumento abrupto em $T_{m}^{o n}$ e continua crescendo lentamente até atingir um patamar, em torno de $30^{\circ} \mathrm{C}$, e volta a cair em $T_{m}^{o f f}$. Assim como ocorre com o perfil de condutividade, a queda da viscosidade é mais rápida do que seu aumento. Qualitativamente, o incremento de viscosidade relativa, $\eta_{i}$, apresenta a mesma informação 
que a viscosidade relativa. No entanto, ele é interessante em termos quantitativos, pois nos dá diretamente a porcentagem de acréscimo ou diminuição da viscosidade do solvente. Podemos observar, por exemplo, que mesmo uma concentração lipídica pequena (1 mM), na região de transição, causa um aumento de até $25 \%$ na viscosidade do tampão $\left(\eta_{i}=0,25\right.$ em torno de $31^{\circ} \mathrm{C}$ ).

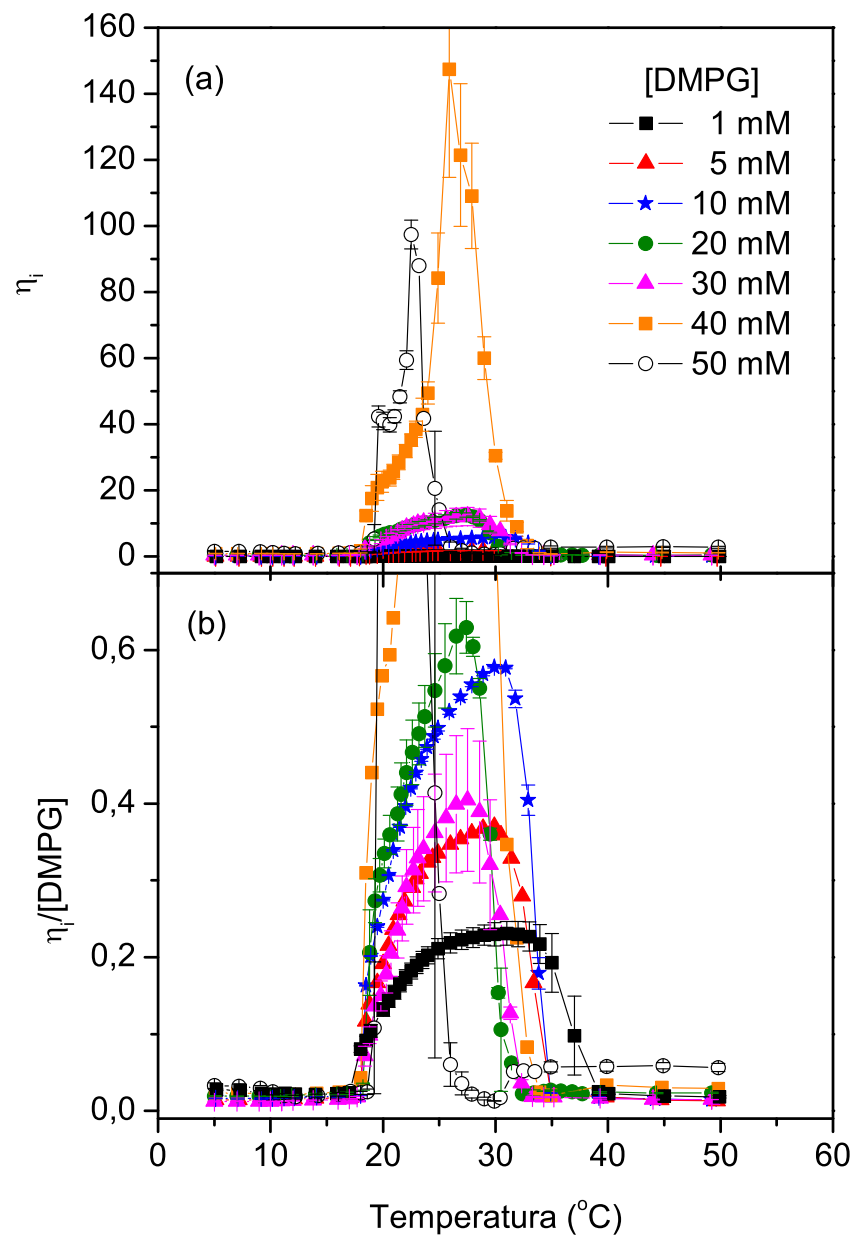

Figura 4.34: (a) Incremento de viscosidade relativa e (b) normalizado pela concentração lipídica, em função da temperatura de dispersões lipídicas de DMPG em várias concentrações.

As figuras 4.34a e 4.34b mostram o incremento de viscosidade relativa, e a mesma normalizada pela concentração lipídica, para várias concentrações de lipídio. O aumento anômalo da viscosidade da dispersão ao longo da região de transição foi observado para todas as concentrações. É evidente a forte dependência da viscosidade da amostra com a concentração ao longo da região de transição. A viscosidade da amostra para concentrações de DMPG entre 1 e $50 \mathrm{mM}$ varia significativamente ao longo da região de 
transição, embora para 40 e $50 \mathrm{mM}$ (figura 4.34, $\eta_{i}>20$ ), dentro da região de transição, os valores da viscosidade provavelmente estão fora da precisão do viscosímetro de Ostwald utilizado.

Fazendo algumas suposições acerca da forma dos agregados de DMPG, podemos estimar, teoricamente, o incremento de viscosidade relativa e compará-lo a nossos dados experimentais. Inicialmente, vamos assumir que, nas fases gel e fluida, nossos agregados sejam vesículas esféricas. Vamos calcular o valor de $\eta_{i}$ através das equações 3.40, 3.46 e 3.48. Para esta última equação é preciso saber o potencial de superfície nas bicamadas. Utilizando os valores encontrados para $\alpha$ (figura 4.29), podemos estimar o potencial de superfície dos agregados de DMPG, $\Psi_{0}$, através da seguinte equação (Riske et al., 1999):

$$
\Psi_{0}=-1000 \frac{k_{b} T}{e} \ln \left(\frac{e^{2} \alpha^{2}}{2 \epsilon \epsilon_{0} k_{b} T N_{A} a^{2} n_{b}}\right)
$$

onde $k_{b}$ é a constante de Boltzmann, $T$ a temperatura, $e$ a carga do elétron, $N_{A}$ o número de Avogadro, $a$ a área por cabeça polar ocupado pelos lipídios, $\epsilon$ a constante dielétrica do meio, $\epsilon_{0}$ a permissividade do vácuo, $n_{b}$ a força iônica da dispersão, em mM, e $\Psi_{0}$ está em unidades de $\mathrm{mV}$. Esta equação é obtida através da teoria de Gouy-Chapman-Stern (Evans \& Wennerstön, 1994), assumindo a superfície como sendo um plano infinito uniformemente carregado com densidade superficial de carga dada por e $\alpha / a$ e utilizando a aproximação $\left|e \Psi_{0}\right| \gg 2 k_{b} T$, isto é, $\left|\Psi_{0}\right|>50 \mathrm{mV}$. Tamashiro et al., 2005 mostraram através de um modelo teórico que, em baixas concentrações lipídicas $(10 \mathrm{mM})$, tal aproximação resulta praticamente nos mesmos valores de potencial assumindo as vesículas como sendo esferas. Os parâmetros utilizados para o cálculo da fração de volume interno, $\phi$, estão na tabela 3.1. 
As tabelas 4.2 e 4.3 apresentam valores experimentais e teóricos de $\eta_{i}$ para concentrações lipídicas de 1 a $20 \mathrm{mM}$ na fase gel, a $12{ }^{\circ} \mathrm{C}$, obtidos supondo um raio de 35 nm (de acordo com tabela 3.1).

\begin{tabular}{cccccc}
\hline \hline [DMPG] $(\mathrm{mM})$ & $\phi$ & $\eta_{i}^{\text {Einstein }}$ & $\eta_{i}^{\text {Batchelor }}$ & $\eta_{i}^{\text {Russel }}$ & $\eta_{i}^{\text {experimental }}$ \\
\hline \hline 1 & 0,0020 & 0,0049 & 0,0049 & 0,0049 & $0,022(2)$ \\
5 & 0,010 & 0,024 & 0,025 & 0,026 & $0,076(2)$ \\
10 & 0,020 & 0,049 & 0,051 & 0,054 & $0,16(1)$ \\
20 & 0,039 & 0,10 & 0,11 & 0,12 & $0,41(3)$ \\
\hline
\end{tabular}

Tabela 4.2: Incrementos de viscosidade relativa de dispersões de DMPG, na fase gel $\left(12{ }^{\circ} \mathrm{C}\right)$, obtidos através de modelos teóricos (equações 3.40 a 3.48).

\begin{tabular}{cccccc}
\hline \hline [DMPG] $(\mathrm{mM})$ & $\phi$ & $\eta_{i}{ }^{\text {Einstein }}$ & $\eta_{i}^{\text {Batchelor }}$ & $\eta_{i}^{\text {Russel }}$ & $\eta_{i}{ }^{\text {experimental }}$ \\
\hline \hline 1 & 0,0024 & 0,0060 & 0,0060 & 0,0061 & $0,021(2)$ \\
5 & 0,012 & 0,030 & 0,031 & 0,032 & $0,0876(4)$ \\
10 & 0,024 & 0,060 & 0,063 & 0,067 & $0,172(3)$ \\
20 & 0,048 & 0,12 & 0,13 & 0,14 & $0,50(3)$ \\
\hline
\end{tabular}

Tabela 4.3: Incrementos de viscosidade relativa de dispersões de DMPG, na fase fluida $\left(40,5{ }^{\circ} \mathrm{C}\right)$, obtidos através de modelos teóricos (equações 3.40 a 3.48 ).

Observamos uma grande discrepância entre os dados teóricos e experimentais nas fases gel e fluida. Para dispersões muito diluídas, como é o caso de $1 \mathrm{mM}$ de DMPG, podemos utilizar diretamente a relação de Einstein (usando a relação de Russel, equação 3.48, mesmo variando o grau de ionização de 0,04 a 0,99 , o valor de $\eta_{i}$ não sofre alterações e é igual ao obtido pela equação de Einstein). Usando o valor experimental da tabela 4.2 na relação de Einstein $\left(\eta_{i}=0,022\right)$, obtemos $\phi=0,0088$. Para este valor de fração de volume, seria preciso um diâmetro de $356 \mathrm{~nm}$. Analogamente, para a fase fluida obteríamos um diâmetro de $280 \mathrm{~nm}$. Sabemos que nossos agregados têm diâmetro médio, muito provavelmente, menor que $100 \mathrm{~nm}$, pois dispersões de DMPG extrusadas por filtro de $100 \mathrm{~nm}$ exibem um diâmetro em torno de $50 \mathrm{~nm}$ (Enoki et al., em fase de escrita). Experimentos de espalhamento de luz apresentam um diâmetro $\left(Z_{\text {average }}\right)$ de $70 \mathrm{~nm}$ para 
dispersões de $1 \mathrm{mM}$ de DMPG não extrusadas. Essa divergência entre os valores experimental e teórico de $\eta_{i}$ talvez seja uma indicação de assimetria nas vesículas de DMPG. Florence et al., 1999 estudando niossomos (vesículas de surfactantes não iônicos - ésteres ou éteres alquílicos de polioxietileno), observaram que os mesmos sofriam uma transição de fase térmica, passando de vesículas em forma de poliedros para vesículas esféricas, acarretando numa grande diminuição da viscosidade da dispersão. Portanto, pequenas assimetrias nas vesículas de DMPG podem resultar num incremento de viscosidade maior do que o previsto para o caso de vesículas esféricas.

Conforme já dito, a forma de um objeto influencia significativamente na maneira como ele flui. Utilizando este raciocínio, somos fortemente inclinados a supor que a forma dos agregados de DMPG, durante a região de transição, varia drasticamente, na medida em que a viscosidade também o faz. De um modo geral, na literatura acerca da reologia de coloides, a viscosidade intrínseca, $[\eta]$, é o principal parâmetro utilizado para obter informações sobre o tamanho e forma da partícula coloidal (Larson, 1999; Barnes et al., 1993). A seguir serão apresentados valores de viscosidade intrínseca para as fases gel, fluida e região de transição. 
A maneira mais usual de obter-se a viscosidade intrínseca, é construir um gráfico de $\eta_{i} /$ [soluto] em função da concentração e extrapolar para concentração zero. A figura 4.35b apresenta tal gráfico, relativo a temperaturas representativas das fases gel, fluida e região de transição.

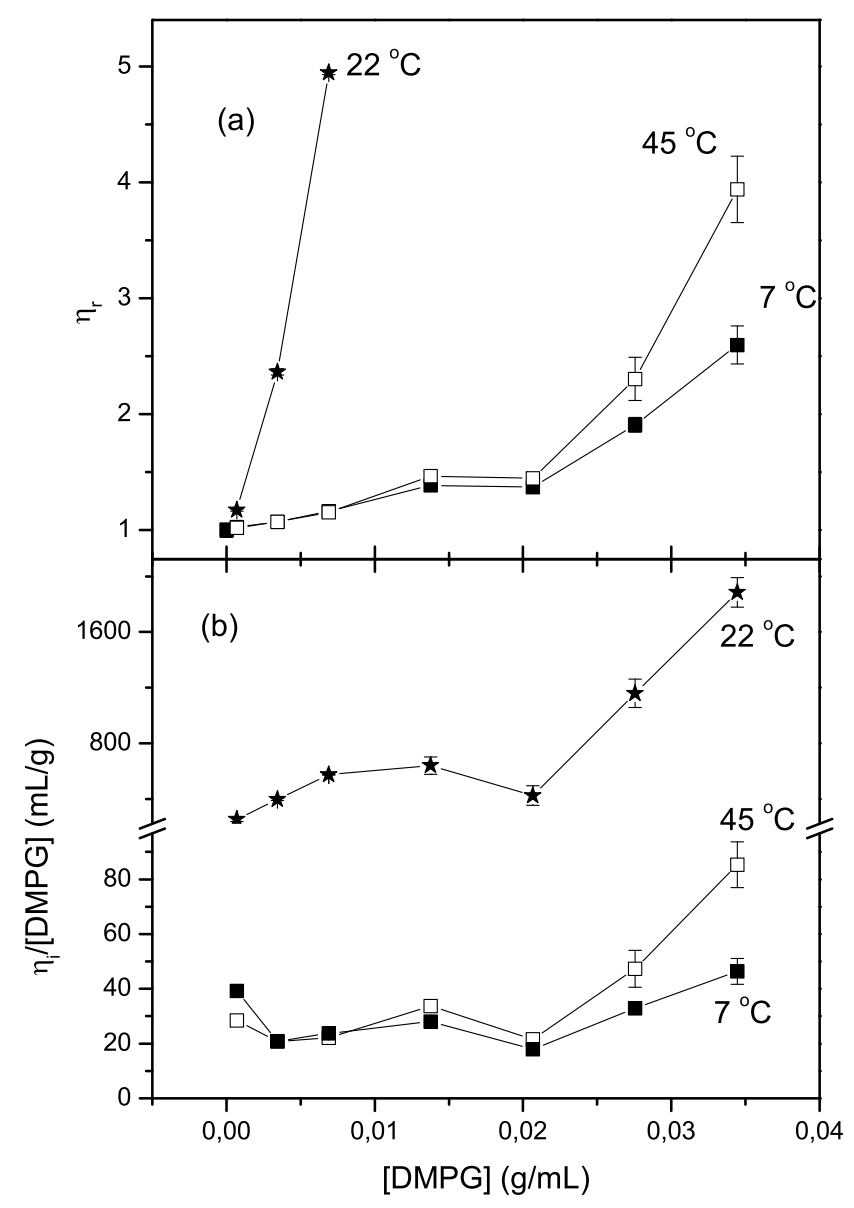

Figura 4.35: (a) Viscosidade relativa e (b) incremento de viscosidade relativa normalizada pela concentração lipídica, $\eta_{i} /[\mathrm{DMPG}]$, de dispersões de DMPG em função da concentração lipídica em temperaturas representativas das fases gel $\left(7^{\circ} \mathrm{C}\right)$, fluida $\left(45^{\circ} \mathrm{C}\right)$ e região de transição $\left(22^{\circ} \mathrm{C}\right)$.

Observamos que, mesmo para as concentrações mais baixas, exceto para $22{ }^{\circ} \mathrm{C}$, as curvas não seguem um padrão linear, sendo difícil obter uma estimativa confiável de $[\eta]$. Além disso, como devemos normalizar os valores do incremento de viscosidade relativa pela concentração, no caso de concentrações muito baixas, um pequeno erro na concentração acaba carregando um erro muito grande para a viscosidade reduzida. Assim sendo, optamos por obter a viscosidade intrínseca diretamente da curva de viscosidade 
relativa em função da concentração (equação 3.47). Para tanto, ajustamos um polinômio de segundo grau às curvas (figura 4.36), usando apenas os quatro primeiros pontos (concentrações lipídicas de 0,0007 a 0,02 g/ml, ou seja, de 1 a $20 \mathrm{mM}$, exceto para $45^{\circ} \mathrm{C}$, em que usamos apenas os três primeiros pontos) e atribuímos à viscosidade intrínseca o valor obtido para o coeficiente linear do ajuste.
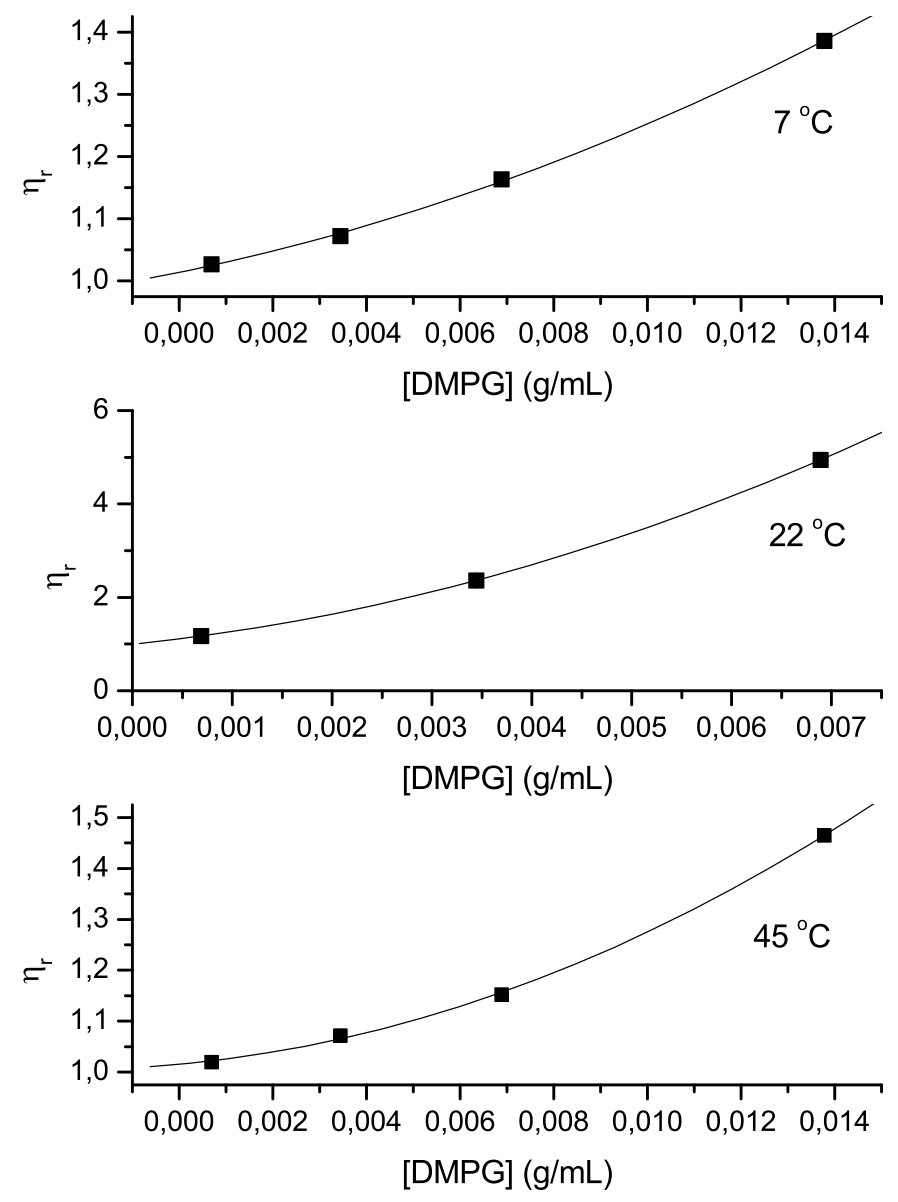

Figura 4.36: Ajuste polinomial dos gráficos da figura 4.35a. As linhas cheias representam os ajustes.

Na tabela 4.4, colocamos os valores das viscosidades intrínsecas. Observamos que as fases gel e fluida apresentam o mesmo valor de $[\eta]$ que, por sua vez, é muito menor do na região intermediária. Estes resultados sugerem, fortemente, que nas fases gel e fluida os agregados de DMPG possuem morfologias semelhantes, enquanto o estado intermediário seja formado por alguma macro-estrutura com forma bem diferente comparada às das fases gel e fluida. 


\begin{tabular}{|c|c|}
\hline \hline Temperatura $\left({ }^{\circ} \mathrm{C}\right)$ & {$[\eta](\mathrm{ml} / \mathrm{g})$} \\
\hline \hline 7 & $13(1)$ \\
22 & $218(14)$ \\
45 & $13(1)$ \\
\hline
\end{tabular}

Tabela 4.4: Viscosidades intrínsecas de dispersões de DMPG.

\subsubsection{Viscosidade local vs. macro-viscosidade}

Além do interesse do comportamento térmico da viscosidade das dispersões de DMPG por si só, é importante saber se a viscosidade medida é relevante para a discussão dos dados de condutividade e mobilidade eletroforética. A seguir, argumentaremos que a viscosidade medida da amostra (macro-viscosidade) não tem ou influencia muito pouco tanto nos dados de condutividade quanto de mobilidade eletroforética. Isto é, o coeficiente de atrito $b$ das partículas carregadas não tem relação com a macro-viscosidade medida na presença de vesículas lipídicas, embora a alta viscosidade medida ao longo da região de transição do DMPG certamente está relacionada a outras propriedades anômalas desta região.

Para estudar a relação entre condutividade e viscosidade, investigamos alguns sistemas para controle. Como discutido no capítulo de técnicas, a condutividade é dada por $\sigma=N q \mu=N q^{2} / b$, sendo $\mu=q / b$. De acordo com a proporcionalidade entre $b$ e $\eta$ (relação de Stokes), a condutividade de uma solução de $\mathrm{NaCl}$ varia com $1 / \eta$, quando aumentamos a viscosidade acrescentando quantidades de glicose (figura 4.37). De modo similar, a mobilidade eletroforética de dispersões de DMPG mostrou-se sensível à presença de glicose, diminuindo com o aumento de glicose (dados não mostrados). Neste caso, tanto a mobilidade de íons pequenos e de macro-íons são sensíveis à macro-viscosidade medida, quando a viscosidade da amostra é aumentada através da adição de moléculas pequenas, como glicose. 


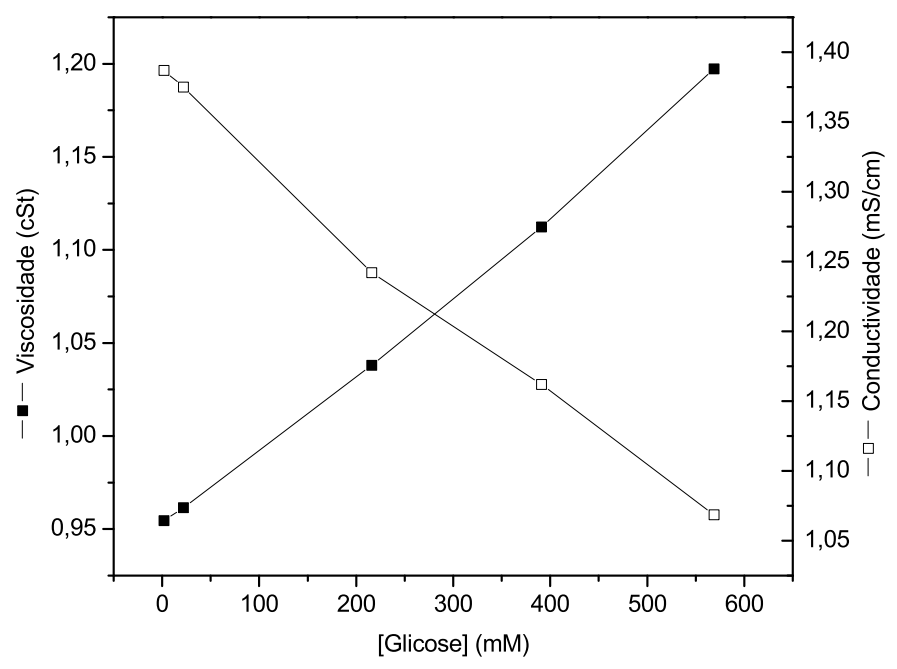

Figura 4.37: Variação da viscosidade e condutividade elétrica de solução de $1 \mathrm{mM}$ de $\mathrm{NaCl}$ em função do acréscimo de glicose.

Isto é completamente distinto dos resultados obtidos quando a viscosidade da amostra é variada pela adição de vesículas neutras. Embora a viscosidade da amostra aumente com a presença de vesículas, a condutividade elétrica não muda. Em uma solução de $1 \mathrm{mM}$ de $\mathrm{NaCl}$, acrescentamos $20 \mathrm{mM}$ de vesículas de DMPC. Embora a viscosidade tenha aumentado 14\%, a condutividade permaneceu inalterada. Este experimento claramente indica que a condutividade de íons pequenos (e portanto sua mobilidade) é insensível ao aumento de viscosidade causado por partículas coloidais neutras. Resultados similares serão discutidos abaixo relacionados à condutividade de macro-íons.

No caso de dispersões de DMPG, as dependências da condutividade e da macroviscosidade medidas com a concentração lipídica são muito diferentes. A condutividade reduzida por concentração lipídica é aproximadamente independente da concentração de DMPG, de 10 a 50 mM (figura 4.26b), mesmo na região de transição, enquanto que os valores da viscosidade reduzida são extremamente dependentes da concentração de DMPG (figura 4.35b). Nós podemos concluir que a macro-viscosidade não pode ser a viscosidade local sentida pelas partículas coloidais, proporcional ao coeficiente de atrito. Esta última conclusão se torna ainda mais forte da análise da dependência térmica da condutividade e viscosidade, fixando a concentração de DMPG. A condutividade $\sigma$ deve ser tomada proporcional a $q^{2} / \eta$. Supondo vesículas, e uma amostra de $10 \mathrm{mM}$ de DMPG, teremos o seguinte: no intervalo de temperatura de 10 a $28{ }^{\circ} \mathrm{C}$, enquanto a condutividade 
aumenta 2,3 vezes (figura 4.26), a carga cresce aproximadamente duas vezes (figura 4.29), e a viscosidade cresce de um fator de 35 (figura 4.34). Portanto, a condutividade dobra de valor, enquanto a razão $q^{2} / \eta$ decresce por um fator de nove, aproximadamente. Isto é outra clara evidência de que o aumento da macro-viscosidade da amostra não afeta a mobilidade ou condutividade do coloide devido tanto a íons pequenos como macroíons. Os argumentos acima são fortemente suportados pelos dados obtidos com $50 \mathrm{mM}$ de DMPG, em que observamos uma clara desconexão entre a queda na viscosidade e na condutividade, conforme mostra a figura 4.38 .

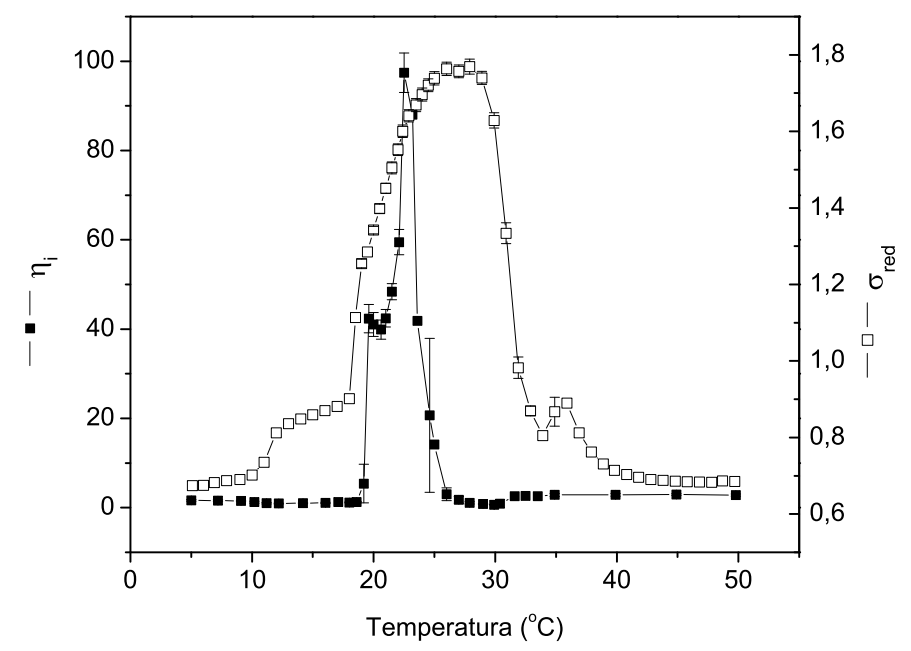

Figura 4.38: Dependência térmica da condutividade reduzida e incremento de viscosidade relativa de dispersão de $50 \mathrm{mM}$ de DMPG em Hepes $+2 \mathrm{mM}$ de $\mathrm{NaCl}$.

\subsection{Efeito da força iônica}

Para a compreensão do balanço de forças entre as interações repulsivas das cabeças polares e atrativas das cadeias hidrocarbônicas fizemos um estudo cuidadoso em função da força iônica. Mantivemos fixa a concentração de DMPG em 10 mM e variamos a concentração de $\mathrm{NaCl}$ no tampão de 2 a $250 \mathrm{mM}$. Observamos que o aumento da força iônica, como esperado, favorece a fase gel. 


\subsubsection{Calorimetria Exploratória Diferencial}

Na figura 4.39 são mostradas várias curvas DSC de dispersões de $10 \mathrm{mM}$ de DMPG em diferentes forças iônicas.

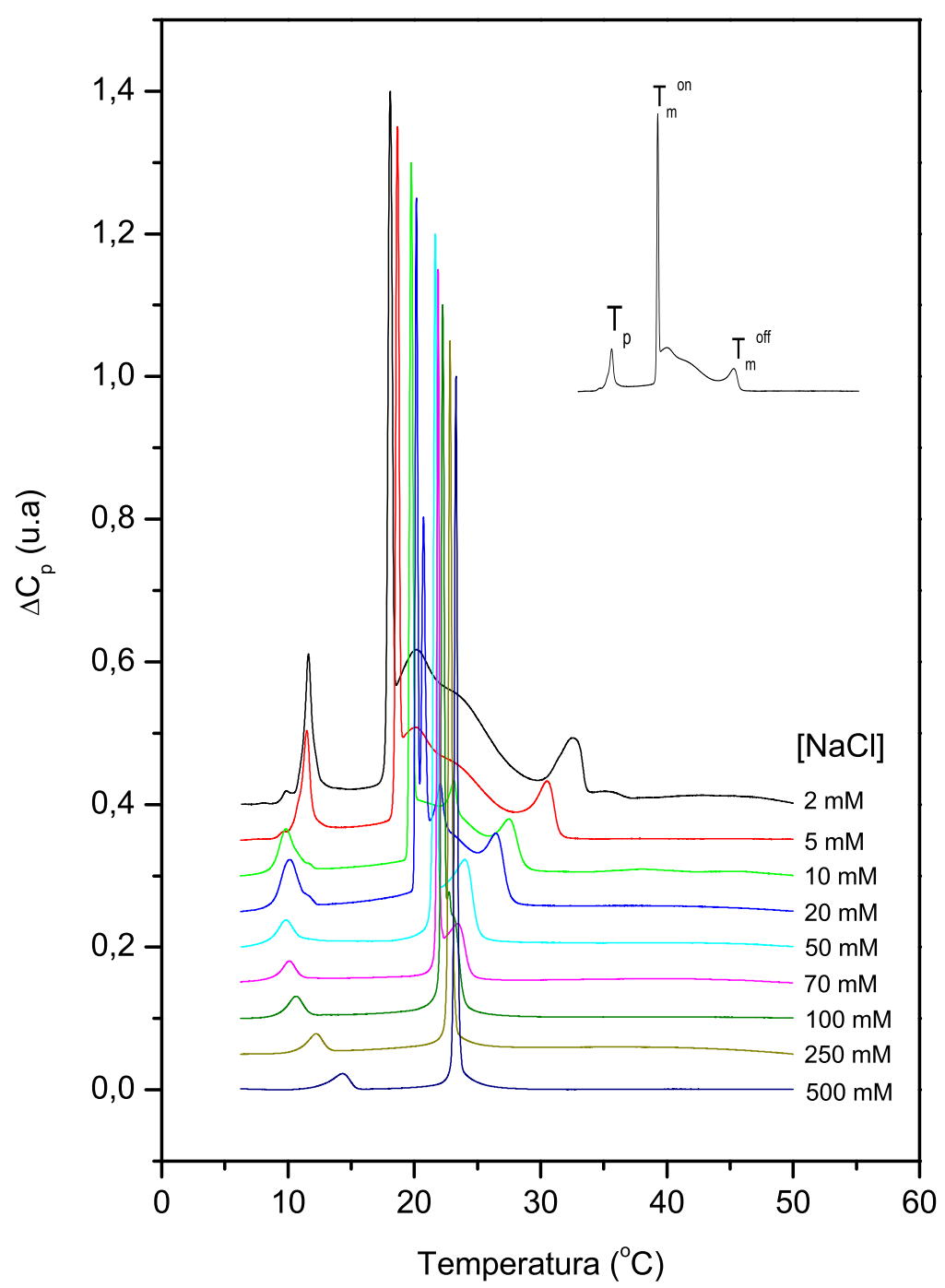

Figura 4.39: Curvas DSC de dispersões de $10 \mathrm{mM}$ de DMPG em Hepes com várias concentrações de sal. Taxa de aquecimento: $20^{\circ} \mathrm{C} / \mathrm{h}$. Para melhor visualização as curvas foram transladadas e normalizadas pelo valor máximo de calor específico.

Como já observado anteriormente (Kodama \& Miyata, 1995; Riske et al., 2009a), vemos que o aumento da força iônica causa um estreitamento da faixa de temperatura de transição. $\mathrm{O}$ acréscimo de $\mathrm{NaCl}$ à dispersão, aumenta $T_{m}{ }^{\text {on }}$ e tem um efeito pequeno sobre $T_{p}$. Contudo, o último evento térmico, em $T_{m}{ }^{\text {off } f}$, é muito mais sensível, decrescendo 
significativamente com o aumento da força iônica de 2 a $70 \mathrm{mM}$ de $\mathrm{NaCl}$. Portanto, o intervalo de temperatura em que ocorre a transição $\left(T_{m}{ }^{\text {off }}-T_{m}{ }^{\text {on }}\right)$ decresce com o aumento da força iônica. Acima de $70 \mathrm{mM}$ de $\mathrm{NaCl}$, as curvas DSC são caracterizadas apenas pelo pico da pré-transição em $T_{p}$ e um pico estreito em $T_{m}{ }^{o n}$. Tanto a entalpia da pré-transição quanto da transição (entre $T_{m}{ }^{o n}$ e $T_{m}{ }^{o f f}$ ) praticamente não se alteram em função da força iônica, sendo de 0,70 $\pm 0,03 \mathrm{kcal} / \mathrm{mol}$ e 6,3 $\pm 0,2 \mathrm{kcal} / \mathrm{mol}$, respectivamente. 
Um nível de detalhamento melhor da figura 4.39 é mostrado na figura 4.40, possibilitando observar com mais clareza os picos calorimétricos entre $T_{m}{ }^{o n}$ e $T_{m}{ }^{o f f}$.
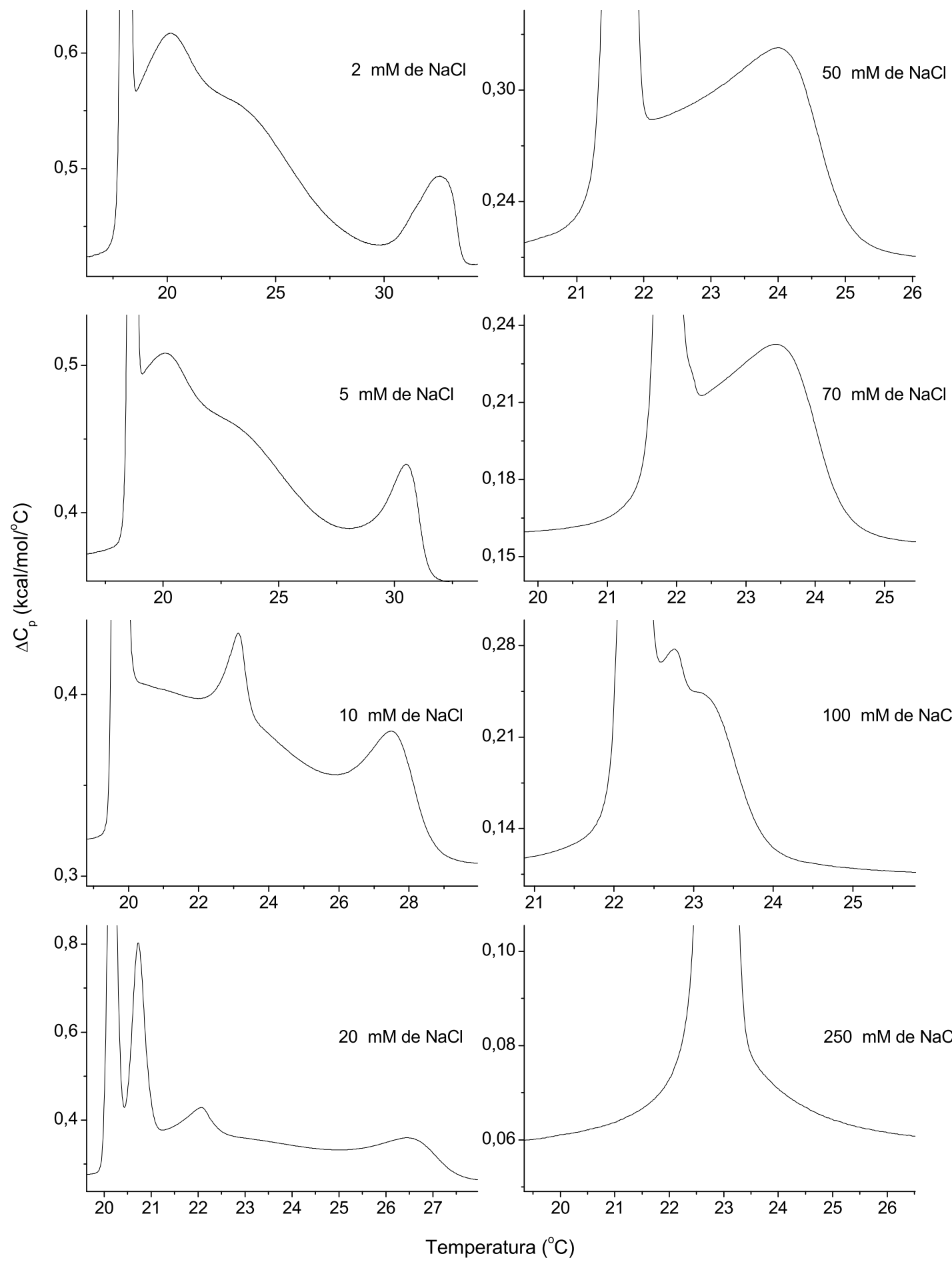

Figura 4.40: Ampliação da figura 4.39. 
Para as concentrações de sal de 2 e $5 \mathrm{mM}$, as curvas DSC são muito semelhantes, exibindo praticamente a mesma posição dos picos alargados entre $T_{m}{ }^{\text {on }}$ e $T_{m}{ }^{\text {off }}$. Em 10 $\mathrm{mM}$ de $\mathrm{NaCl}$, vemos o aparecimento de um pico estreito entre $T_{m}{ }^{\text {on }}$ e $T_{m}{ }^{\text {off }}$. Para $20 \mathrm{mM}$ de $\mathrm{NaCl}$ são observados dois picos calorimétricos entre $T_{m}{ }^{\text {on }}$ e $T_{m}{ }^{\text {off }}$. Entre 50 e $70 \mathrm{mM}$ de $\mathrm{NaCl}$, apenas $T_{m}{ }^{\text {on }}$ e $T_{m}{ }^{\text {off }}$ aparecem nas curvas DSC. Para $100 \mathrm{mM}$ de $\mathrm{NaCl}$, já não é possível identificar a presença de $T_{m}{ }^{\text {off }}$. Para $250 \mathrm{mM}$ e $500 \mathrm{mM}$ de $\mathrm{NaCl}$, as curvas DSC são caracterizados apenas pelos picos de pré e transição-principal.
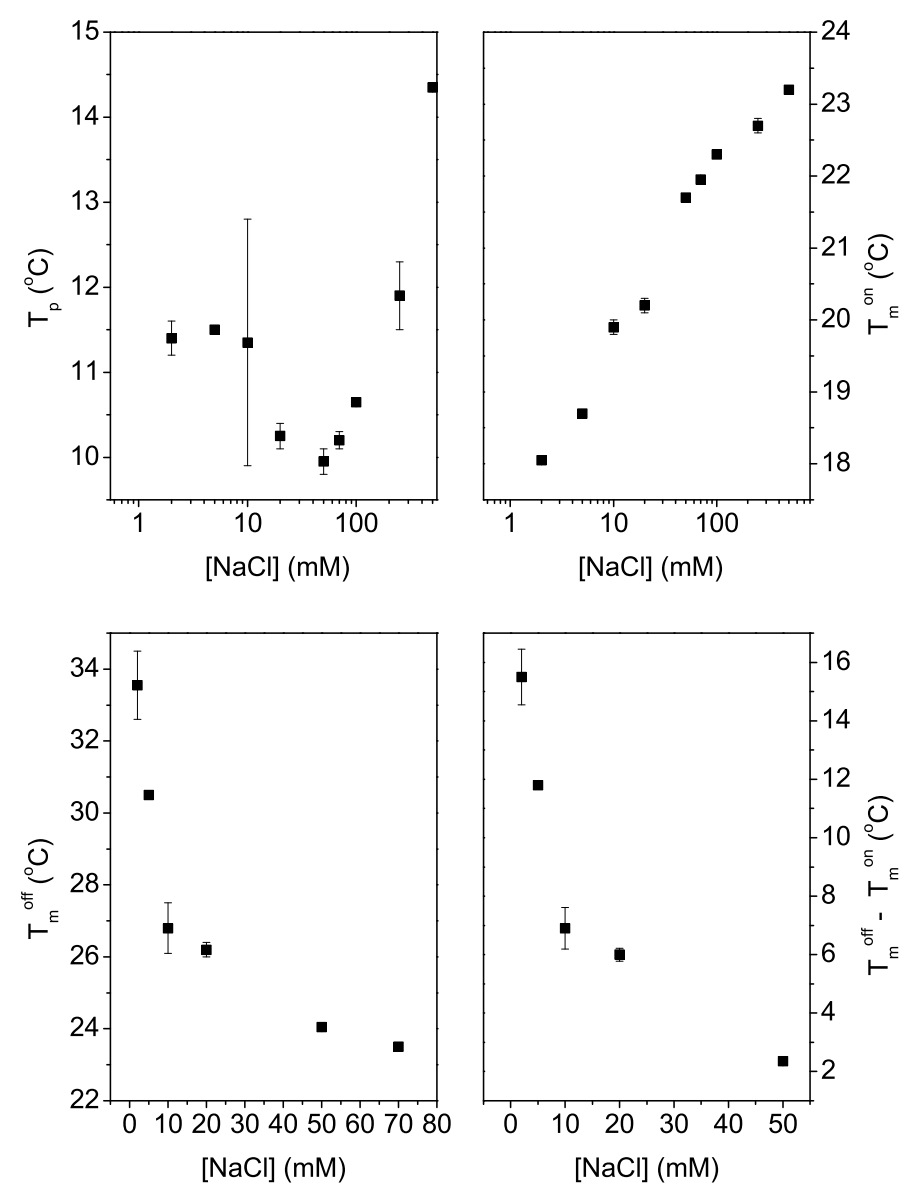

Figura 4.41: Posições dos picos em $T_{p}, T_{m}{ }^{\text {on }}$ e $T_{m}{ }^{\text {off }}$ em função da concentração de NaCl do tampão.

Para quantificar o efeito da concentração de sal na posição dos picos, medimos suas posições em função da força iônica (figura 4.41). $T_{p}$ mantém-se constante entre 2 e $10 \mathrm{mM}$ de $\mathrm{NaCl}\left(\sim 11,4{ }^{\circ} \mathrm{C}\right)$, fica em torno de $10{ }^{\circ} \mathrm{C}$ entre 10 e $50 \mathrm{mM}$ e cresce de $11 \mathrm{a}$ $14,4{ }^{\circ} \mathrm{C}$ entre 50 e $500 \mathrm{mM}$ de sal. $T_{m}{ }^{o n}$ cresce lentamente com a força iônica, indo de $\sim 18$ a $23{ }^{\circ} \mathrm{C}$ entre 2 e $500 \mathrm{mM}$ de $\mathrm{NaCl}$. Conforme já dito, $T_{m}{ }^{\text {off }}$ é a temperatura mais sensível à transição, caindo de 33,4 a $22,5^{\circ} \mathrm{C}$ entre 2 e $70 \mathrm{mM}$ de $\mathrm{NaCl}$. O intervalo de 
temperatura em que a transição ocorre $\left(T_{m}{ }^{\text {off }}-T_{m}{ }^{\text {on }}\right)$ diminui de 15,5 para $2,4{ }^{\circ} \mathrm{C}$ nesta mesma faixa de força iônica.

É sabido que o aumento da força iônica diminui a repulsão eletrostática entre as cabeças polares dos lipídios, de modo que há uma maior aproximação entre as mesmas e, consequentemente, uma estabilização da fase gel. Um reflexo disto, é o deslocamento da temperatura de transição para temperaturas mais altas (Traüble et al., 1976). Nossos resultados estão de acordo com tal situação, pois, com o acréscimo da força iônica, $T_{m}{ }^{\text {on }}$ aumenta e as curvas DSC vão se tornando cada vez mais semelhantes às de uma dispersão de DMPC, cujas cabeças polares apresentam carga resultante nula. 


\subsubsection{Turbidez}

A figura 4.42 apresenta o comportamento da turbidez de dispersões de $10 \mathrm{mM}$ de DMPG em várias forças iônicas.

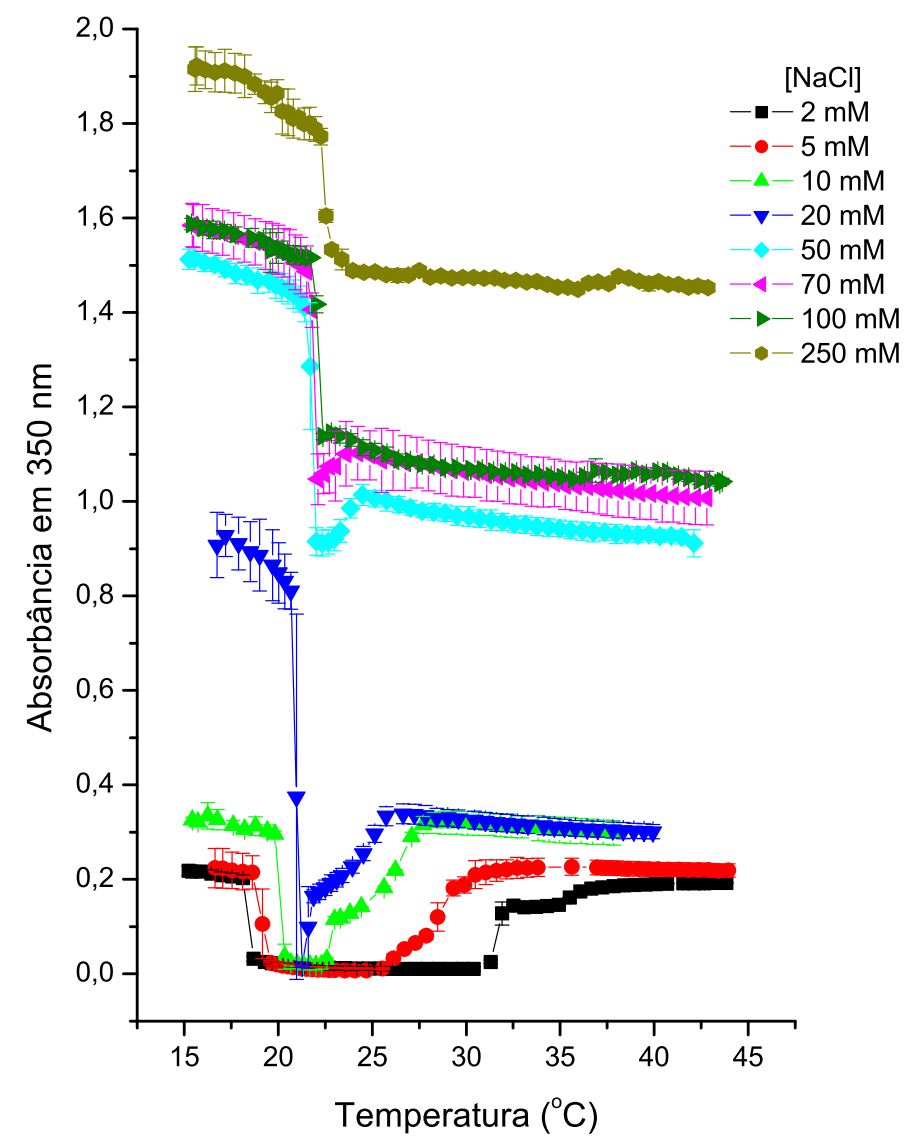

Figura 4.42: Dependência térmica da absorbância em $350 \mathrm{~nm}$ de dispersões de $10 \mathrm{mM}$ de DMPG em Hepes + várias concentrações de $\mathrm{NaCl}$. Caminho óptico $=2 \mathrm{~mm}$.

O intervalo de temperatura em que a absorbância permanece baixa, próxima de zero, diminui com o aumento da força iônica, variando de 11,7 a $1{ }^{\circ} \mathrm{C}$, para $2 \mathrm{mM}$ e 20 $\mathrm{mM}$ de $\mathrm{NaCl}$, respectivamente. A partir de $50 \mathrm{mM}$ de $\mathrm{NaCl}$, a absorbância não apresenta mais nenhuma faixa de temperatura em que a amostra seja transparente (absorbância próxima de zero), sendo a mesma turva durante toda a transição. No entanto, para 50 e $70 \mathrm{mM}$ de $\mathrm{NaCl}$, a absorbância apresenta uma pequena queda na região de transição. $\mathrm{O}$ aumento na turbidez de 20 para $50 \mathrm{mM}$ de $\mathrm{NaCl}$ pode estar indicando que as vesículas estão se tornando maiores e talvez também esteja relacionado à formação de vesículas multilamelares (Riske et al., 2009a). 
A figura 4.43 apresenta gráficos da absorbância em função da força iônica em temperaturas representativas das fases gel $\left(16,6^{\circ} \mathrm{C}\right)$, fluida $\left(36,5^{\circ} \mathrm{C}\right)$ e região de transição $\left(23,5{ }^{\circ} \mathrm{C}\right)$. Observamos um comportamento semelhante nas três temperaturas: há um crescimento da absorbância com o aumento da força iônica até $50 \mathrm{mM}$ de $\mathrm{NaCl}$, a partir de onde o crescimento se torna muito menor.

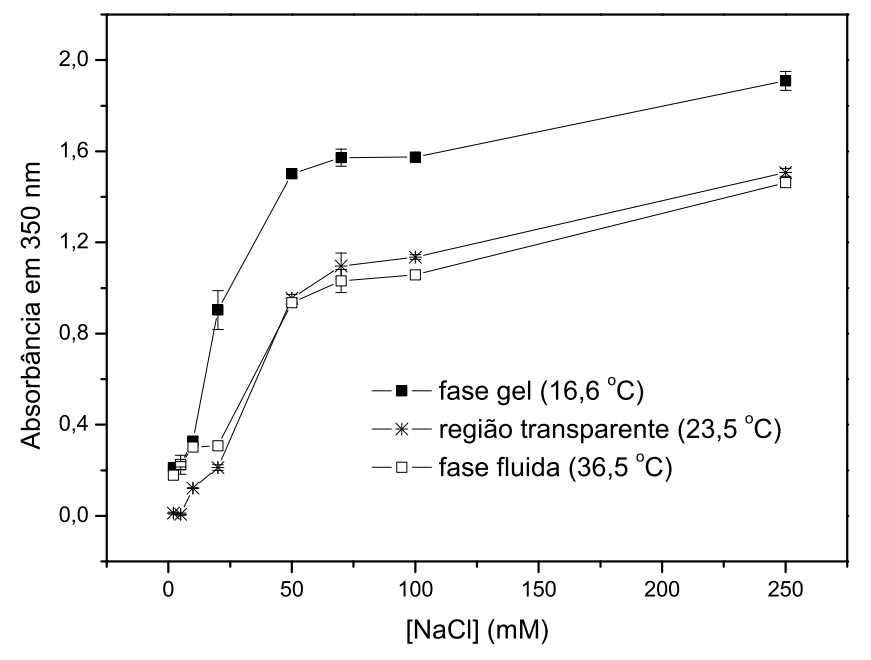

Figura 4.43: Dependência térmica da absorbância, medida em $350 \mathrm{~nm}$, de dispersões de DMPG com diferentes forças iônicas em temperaturas representativas das fases gel, fluida e região de transição. Caminho óptico $=2 \mathrm{~mm}$.

Assim como fizemos com os dados de variação de concentração lipídica, fizemos uma comparação dos dados de absorbância aos de calorimetria variando-se as concentrações de sal. A figura 4.44 apresenta as curvas DSC da figura 4.39 sobrepostas às curvas de absorbância da figura 4.42, ambas normalizados pelos valores máximos das ordenadas. 

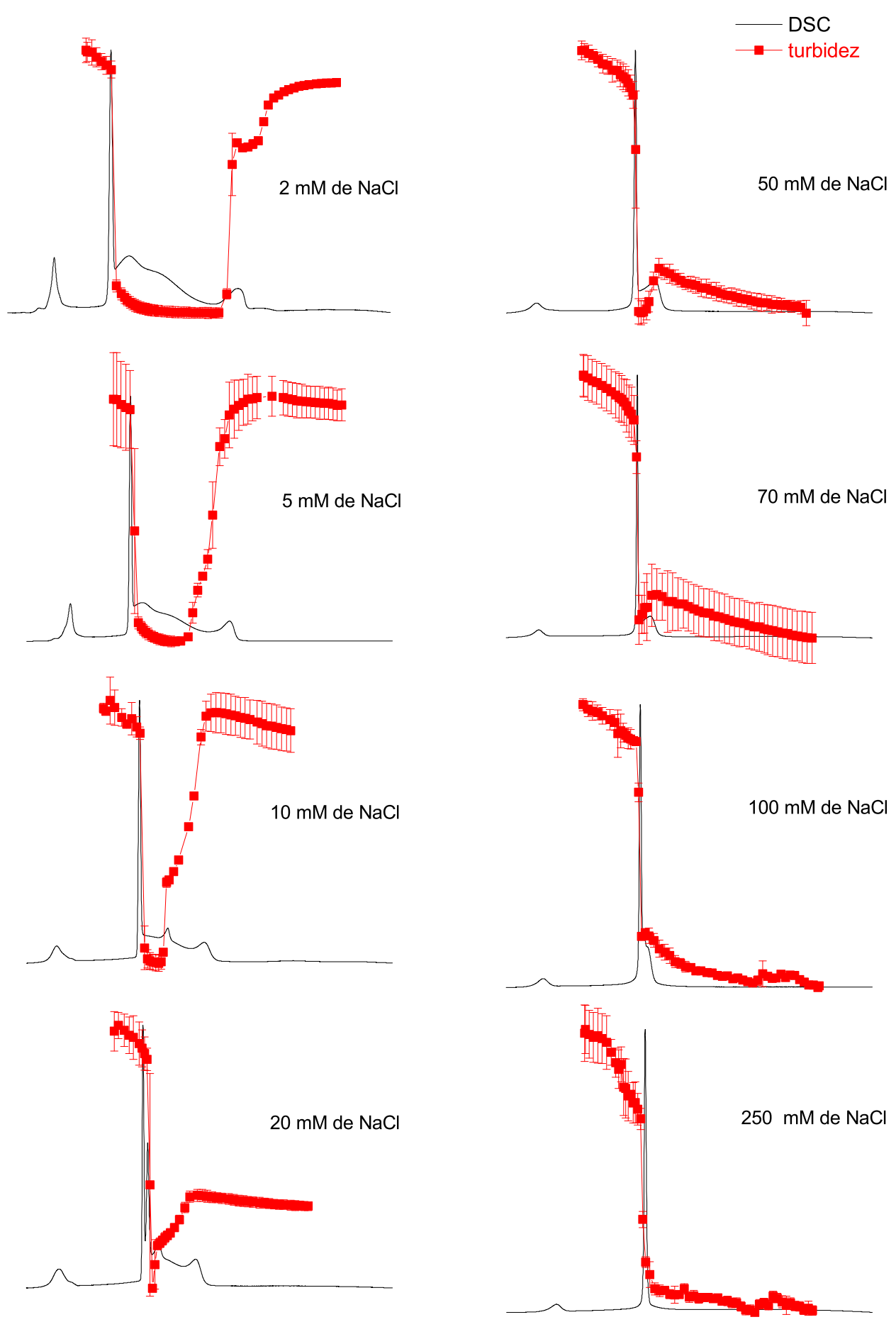

Figura 4.44: Sobreposição dos traços de DSC às curvas de turbidez em função da temperatura de dispersões de 10 mM de DMPG em várias forças iônicas.

Observamos que há uma correlação entre as curvas de absorbância e DSC. A absorbância sofre uma queda abrupta em $T_{m}{ }^{\text {on }}$ em todas as concentrações de sal. Para 10, 20, 50 e $70 \mathrm{mM}$ de $\mathrm{NaCl}$, após a queda da turbidez, o retorno para valores mais altos 
de turbidez coincidem com um pico calorimétrico. Este resultado é muito parecido ao observado quando se muda a força iônica a uma concentração lipídica fixa de $50 \mathrm{mM}$ (Riske et al., 2009a). Antes da publicação deste último trabalho, assumia-se que a região de baixa turbidez ficava entre $T_{m}{ }^{\text {on }}$ e $T_{m}{ }^{\text {off }}$. No entanto, assim como apontado em tal trabalho, observamos que a turbidez volta a subir, para 5, 10 e $20 \mathrm{mM}$ de $\mathrm{NaCl}$, antes do pico em $T_{m}{ }^{\text {off }}$, coincidindo com outro pico calorimétrico.

\subsubsection{Condutividade elétrica}

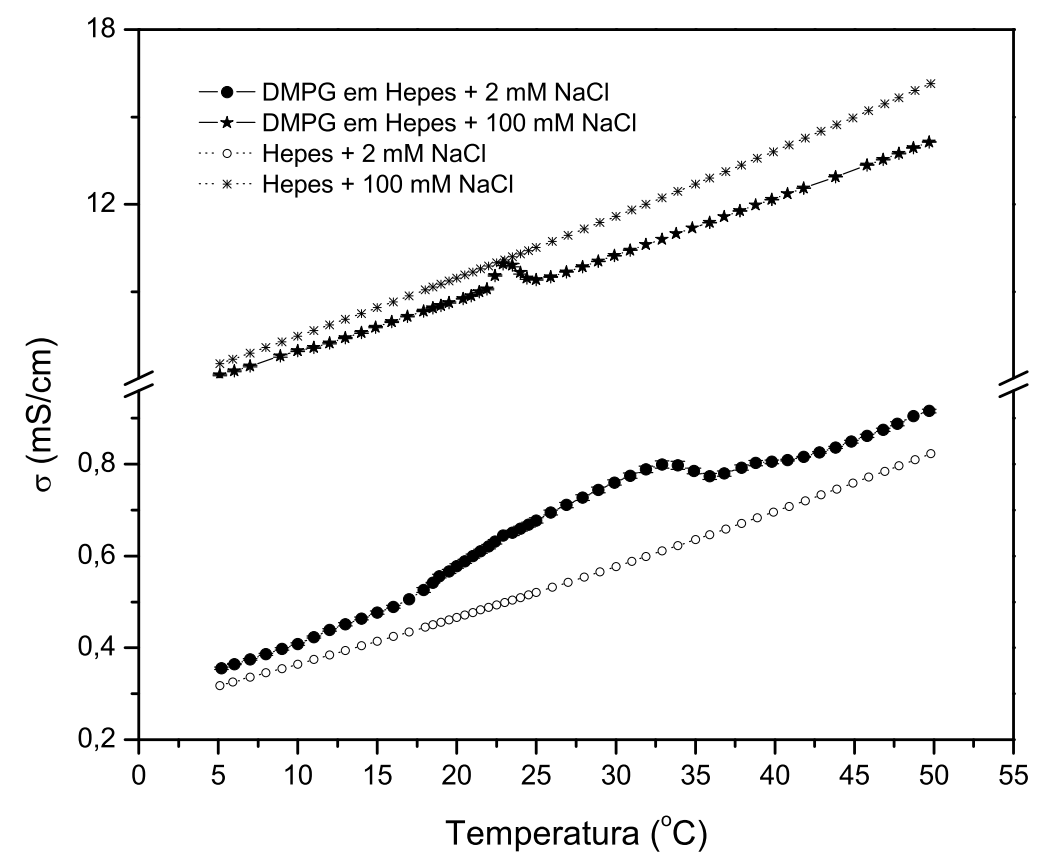

Figura 4.45: Dependência térmica da condutividade elétrica de dispersões de $10 \mathrm{mM}$ de DMPG em tampão Hepes com 2 e 100 mM de NaCl.

A figura 4.45 apresenta o comportamento térmico da condutividade elétrica de dispersões de DMPG em Hepes com 2 mM e 100 mM de NaCl. Enquanto a condutividade da dispersão com $2 \mathrm{mM}$ de $\mathrm{NaCl}$ se mantém maior do que a do tampão, notamos que com a dispersão em $100 \mathrm{mM}$ de $\mathrm{NaCl}$ a condutividade é menor do que a do tampão, levando a uma condutividade reduzida negativa, conforme será mostrado mais adiante. Este resultado é semelhante ao encontrado com DMPC (figura 4.21), em que o valor negativo de $\sigma_{r e d}$ estaria associado ao encapsulamento de parte dos íons da solução, como lá discutido. 
A figura 4.46 mostra o comportamento da condutividade reduzida, em função da temperatura, de dispersões de $10 \mathrm{mM}$ de DMPG em várias forças iônicas. Como não sabemos com precisão o tamanho dos agregados de DMPG em alta força iônica, é difícil calcular a fração de volume ocupado. Portanto, não vamos considerar sua contribuição para concentrações de sal maiores que $20 \mathrm{mM}$.

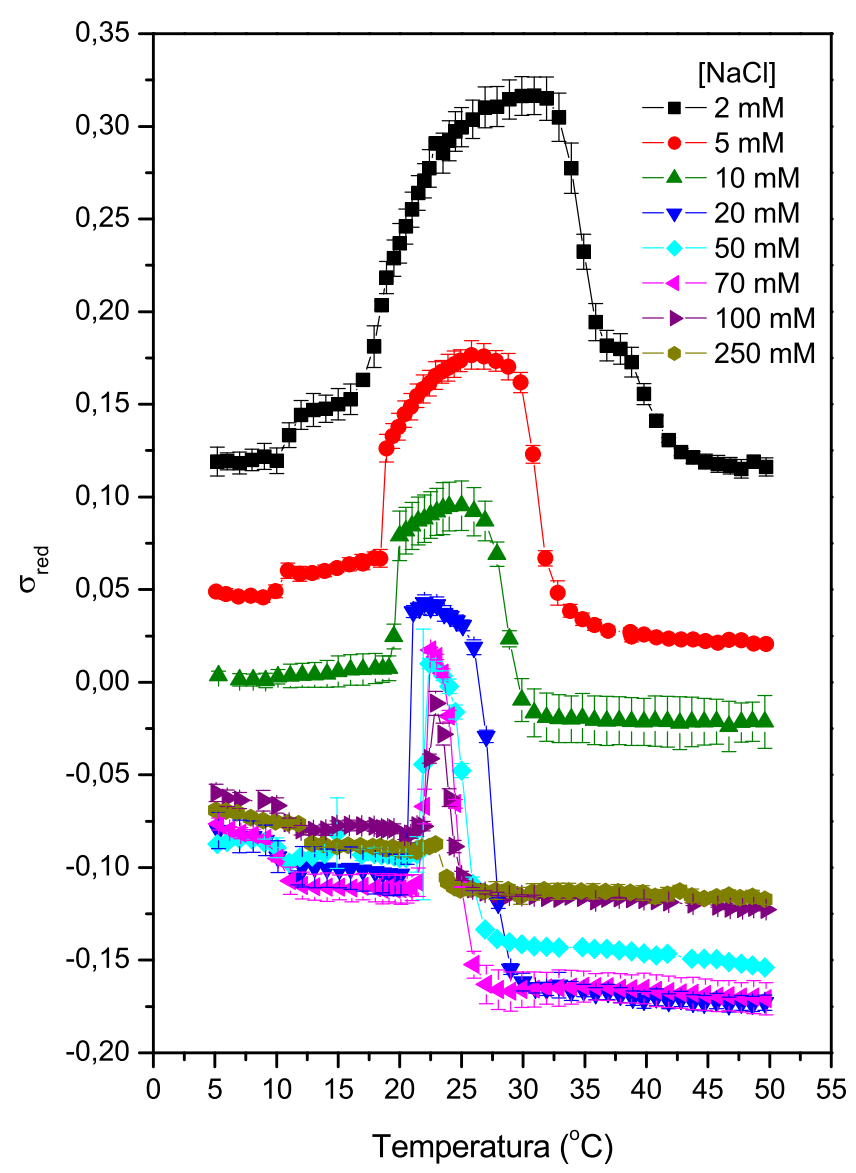

Figura 4.46: Dependência térmica da condutividade reduzida em várias concentrações de $\mathrm{NaCl}$

Em termos de condutividade, se caracterizarmos a região de transição de fase por apresentar uma alta condutividade elétrica, observamos que, analogamente ao visto pelas curvas DSC e de absorbância, a região de transição diminui com o aumento da força iônica, pois a faixa de temperatura em que a condutividade fica alta se torna mais estreita na medida em que a concentração de $\mathrm{NaCl}$ aumenta. Curiosamente, enquanto a condutividade sofre um pequeno aumento na pré-transição para 2, 5 e $10 \mathrm{mM}$ de $\mathrm{NaCl}$, ocorre o inverso para concentrações de sal a partir de $20 \mathrm{mM}$ de $\mathrm{NaCl}$, ou seja, há uma pequena 
diminuição da condutividade na pré-transição. A partir de $20 \mathrm{mM}$ de $\mathrm{NaCl}$, a condutividade reduzida assume valores negativos, de modo similar ao apresentado por dispersão de DMPC (figura 4.46), significando que a condutividade da dispersão é menor do que a do solvente. Provavelmente esta diminuição na condutividade é devida ao encapsulamento dos íons do solvente por parte das vesículas de DMPG. Nitidamente há uma mudança no comportamento da condutividade de 10 para $20 \mathrm{mM}$ de $\mathrm{NaCl}$, de maneira análoga ao observado com os dados de turbidez (figura 4.42). 

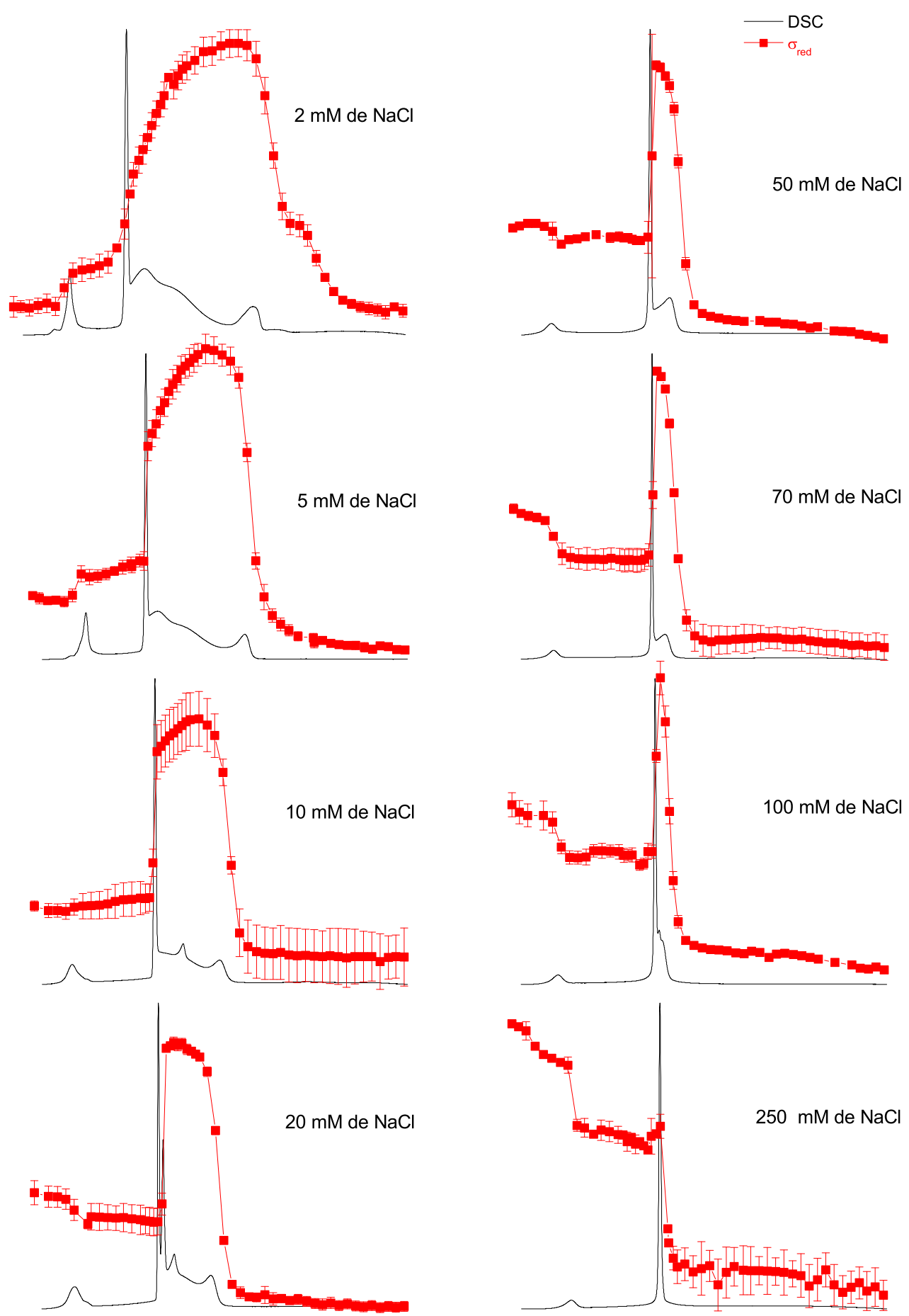

Figura 4.47: Condutividades reduzidas e curvas DSC sobrepostas para várias forças iônicas.

Na figura 4.47 são apresentadas as condutividades reduzidas sobrepostas às curvas DSC para as várias forças iônicas estudadas. Conforme já dito, a $\sigma_{\text {red }}$ é sensível tanto a pré quanto a transição principal, já que há mudanças bruscas em seu comportamento 
coincidindo com os picos calorimétricos em $T_{p}, T_{m}{ }^{\text {on }}$ e $T_{m}{ }^{\text {off }}$. Entretanto, diferentemente da turbidez, parece não haver correlação entre os outros picos calorimétricos entre $T_{m}{ }^{\text {n }}$ e $T_{m}{ }^{\text {off }}$ e a condutividade.

\subsubsection{Mobilidade eletroforética}

A figura 4.48 apresenta a mobilidade eletroforética de dispersões de $10 \mathrm{mM}$ de DMPG com concentrações de sal de 2 a $20 \mathrm{mM}$ de NaCl. Acima desta concentração salina não foi possível realizar medidas, pois os eletrodos oxidavam rapidamente.

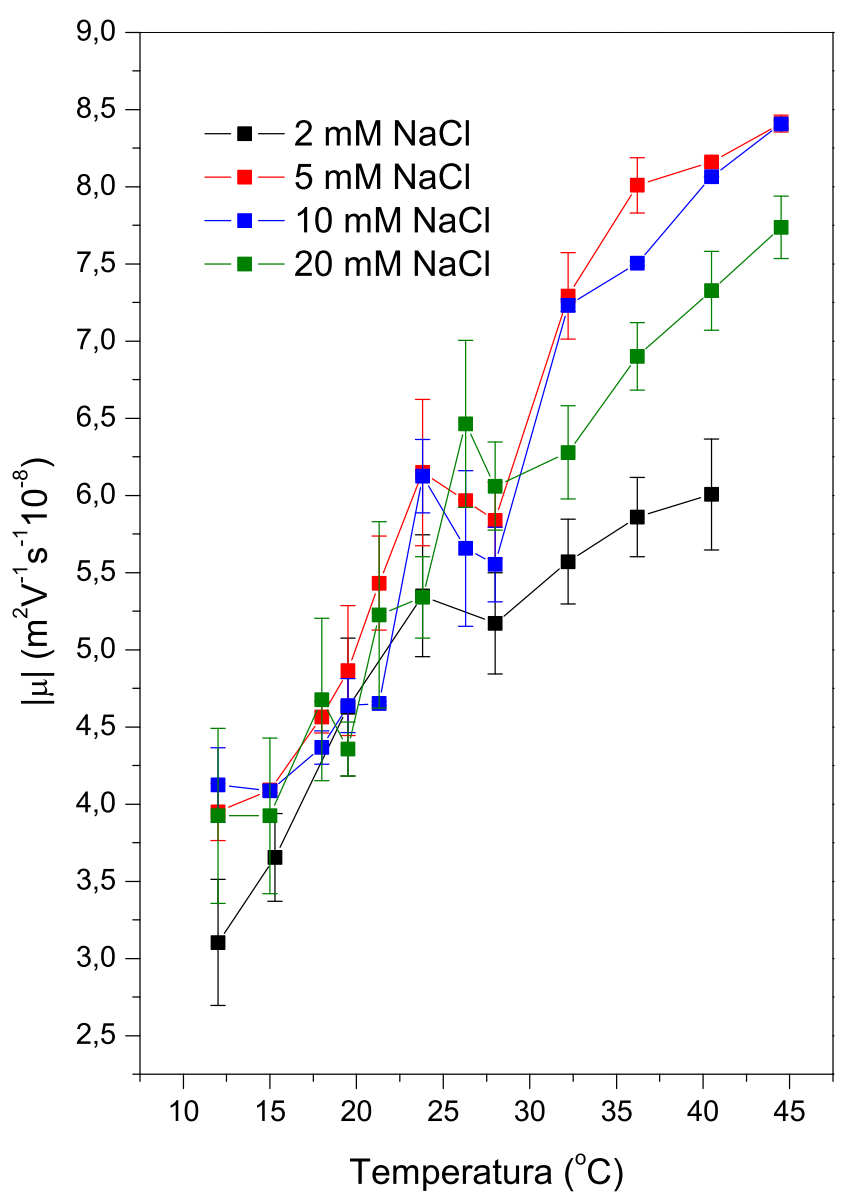

Figura 4.48: Valor absoluto da mobilidade eletroforética em função da temperatura de dispersões de $10 \mathrm{mM}$ de DMPG em várias forças iônicas.

Tanto na fase gel quanto na região de transição, os valores das mobilidades são semelhantes para todas as concentrações de $\mathrm{NaCl}$, sendo difícil extrair alguma informação dos dados. Entretanto, contrário ao esperado, a mobilidade das vesículas de DMPG 
parece ser menor em presença de $2 \mathrm{mM}$ de $\mathrm{NaCl}$ do que para concentrações maiores de sal (retornaremos a esse ponto mais adiante). Este resultado é nitidamente visto para temperaturas maiores, quando os lipídios encontram-se na fase fluida. Exceto por uma temperatura, as mobilidades em 5 e $10 \mathrm{mM}$ de $\mathrm{NaCl}$, acima de $30{ }^{\circ} \mathrm{C}$ são idênticas. As mobilidades em $20 \mathrm{mM}$ de $\mathrm{NaCl}$, também na fase fluida, apresentam-se menores do que as de 5 e $10 \mathrm{mM}$ de $\mathrm{NaCl}$.

A seguir vamos calcular o grau de ionização para a dispersão de DMPG com 5 mM de $\mathrm{NaCl}$, supondo que as vesículas tenham o mesmo tamanho que as vesículas em $2 \mathrm{mM}$ de $\mathrm{NaCl}$ (equação 3.30 e parâmetros da tabela 3.1). Esta hipótese parece razoável, tendo em vista que as curvas DSC para tais concentrações de sal são semelhantes (figuras 4.39 e 4.40), além da similaridade nos valores de absorbância (turbidez, figura 4.42). Para as demais concentrações de sal, não é possível calcular o grau de ionização sem que o mesmo traga consigo uma incerteza grande, pois não temos informações quanto ao tamanho dos agregados lipídicos.

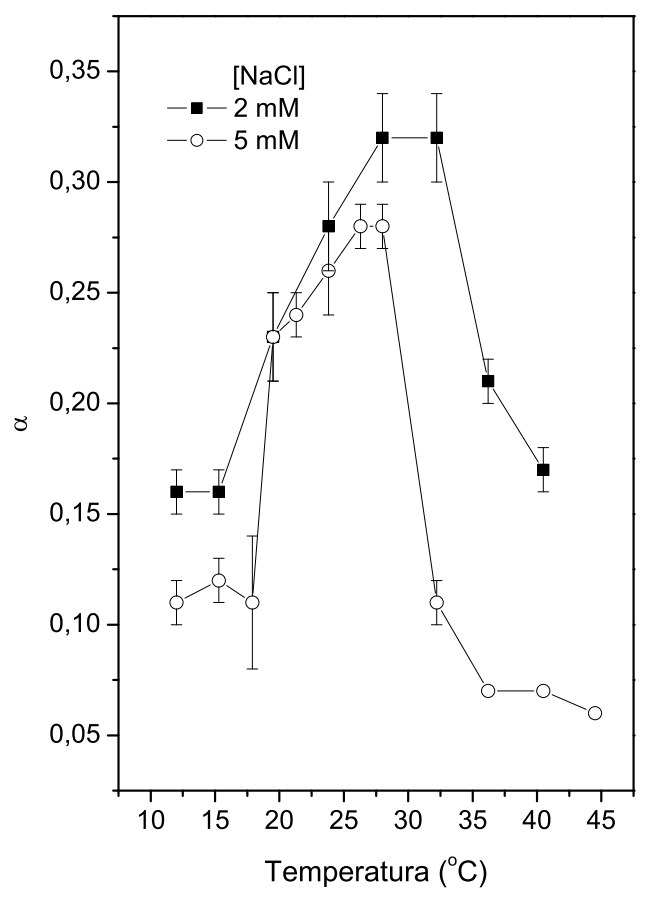

Figura 4.49: Dependência térmica do grau de ionização aparente de vesículas de DMPG $10 \mathrm{mM}$ em Hepes com 2 e $5 \mathrm{mM}$ de $\mathrm{NaCl}$. 
Observamos que, conforme esperado, as vesículas estão menos carregadas em 5 mM de $\mathrm{NaCl}$ do que em $2 \mathrm{mM}$ de $\mathrm{NaCl}$ (figura 4.49), pois para esta última concentração de sal os valores de $\alpha$ são maiores do que em $5 \mathrm{mM}$ de $\mathrm{NaCl}$. O intervalo de temperatura em que o grau de ionização se mantém alto também diminui com o aumento de força iônica.

Lembrando que a mobilidade eletroforética de uma partícula é dada pela razão entre sua carga e seu coeficiente de atrito, $\mu=q / b$, um aumento de $\mu$ com a força iônica, indica que a carga está aumentando e/ou o coeficiente de atrito diminuindo. No entanto, sabemos que o aumento de força iônica deve diminuir a carga das vesículas, o que está de acordo com a figura 4.49. Portanto, para que $\mu$ cresça é preciso que $b$ diminua. O coeficiente de atrito está ligado ao tamanho e à forma das partículas. Ele é maior quanto maior a partícula e menor quanto mais simétrica for a partícula. Conforme vimos anteriormente, nossos dados de condutividade e turbidez sugerem que o aumento de força iônica esteja aumentando o tamanho das vesículas. O aumento da mobilidade na fase fluida, de 2 para 5 e $10 \mathrm{mM}$ de $\mathrm{NaCl}$, pode estar indicando que as vesículas de DMPG, na fase fluida, estejam tornando-se mais simétricas. Todavia, para $20 \mathrm{mM}$ de $\mathrm{NaCl}$, a mobilidade é menor do que 5 e $10 \mathrm{mM}$ de $\mathrm{NaCl}$, embora ainda maior do que para $2 \mathrm{mM}$ de $\mathrm{NaCl}$. Neste caso, é possível que a carga tenha diminuído e/ou b diminuído, tanto pelo aumento do tamanho e/ou maior assimetria das vesículas nesta concentração de sal (20 $\mathrm{mM})$. 


\subsubsection{Viscosidade}

A figura 4.50 apresenta o incremento de viscosidade relativa em função da concentração de sal de dispersões de $10 \mathrm{mM}$ de DMPG.
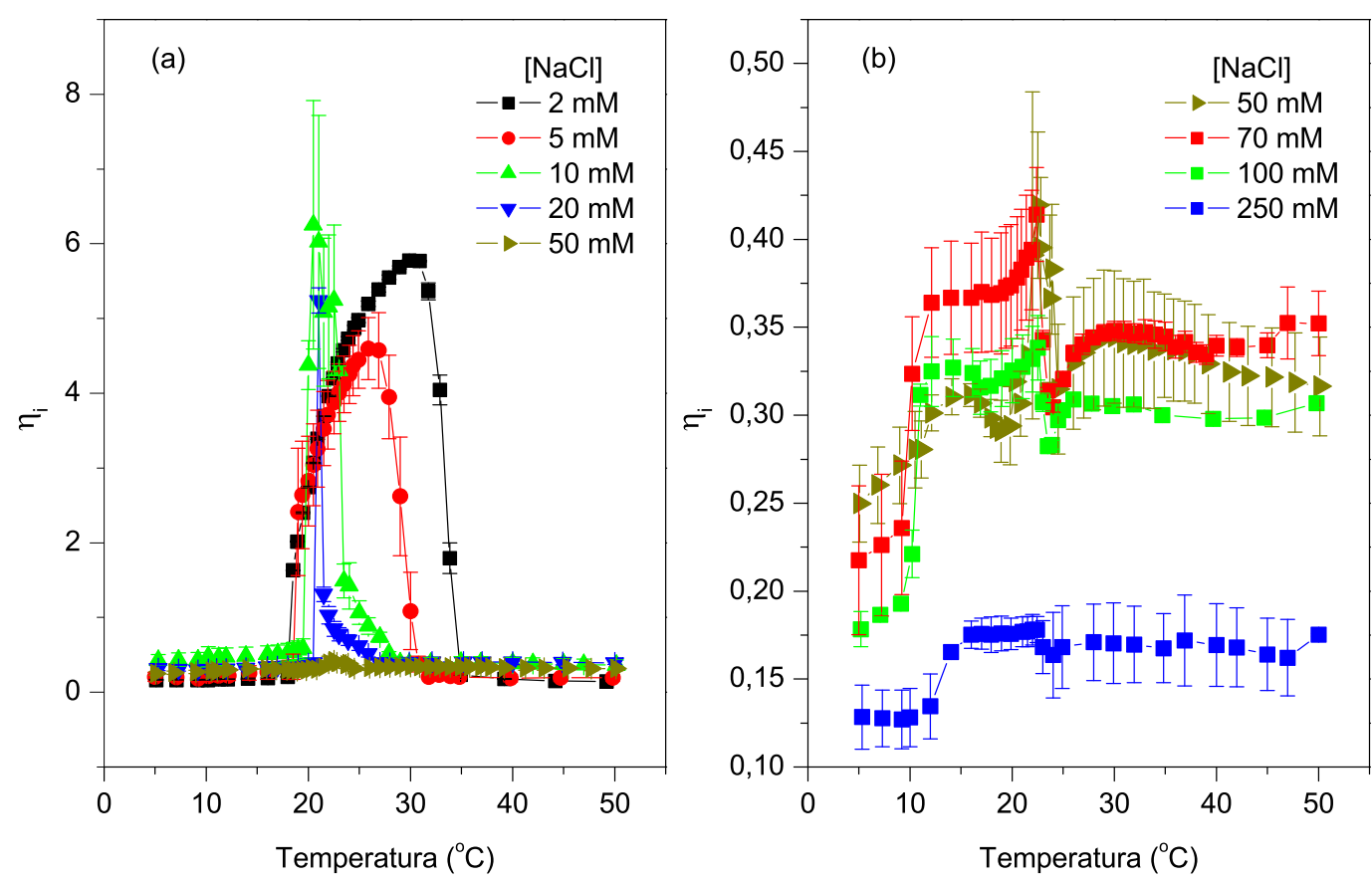

Figura 4.50: Dependência térmica do incremento de viscosidade relativa de dispersões de $10 \mathrm{mM}$ de DMPG em baixas (a) e altas (b) força iônicas.

Há uma nítida diferença entre o comportamento térmico do incremento de viscosidade relativa em baixa (2 a $20 \mathrm{mM}$ de $\mathrm{NaCl}$ ) e alta força iônica (50 a $250 \mathrm{mM}$ de $\mathrm{NaCl}$ ). Em baixa força iônica, os perfis de condutividade são caracterizados por um intervalo de temperatura em que a condutividade se mantém alta e que coincide com a região de transição, conforme será mostrado mais adiante (figura 4.51). Esta faixa de temperatura, em que a viscosidade é alta, diminui com o aumento da força iônica. Os valores máximos atingidos pela viscosidade, entre 2 e $20 \mathrm{mM}$ de $\mathrm{NaCl}$ não são muito diferentes, como acontece quando se varia a concentração (figura 4.34). A partir de $50 \mathrm{mM}$ de $\mathrm{NaCl}$, a viscosidade é muito baixa em todas as temperaturas. $\eta_{i}$ sofre um aumento abrupto em $T_{p}$, cresce lentamente e mantém-se num patamar até cair em $T_{m}{ }^{\text {on }}$ e novamente permanecer num patamar. Vesículas gigantes de dispersões de DMPG formam multibicamadas a 
partir de $50 \mathrm{mM}$ de $\mathrm{NaCl}$ (Fernandez et al., 2008). É possível que esta situação também ocorra para nossas dispersões, o que seria refletido pela mudança brusca no comportamento de $\eta_{i}$ de 20 para $50 \mathrm{mM}$ de $\mathrm{NaCl}$. Além disso, a carga dos agregados tem um papel relevante na viscosidade, pois esta depende das interações entre eles (Larson, 1999). De fato, vemos valores muito menores de $\eta_{i}$ em altas concentrações de sal (50 a $250 \mathrm{mM}$ ) comparados aos em baixas. A figura 4.51 mostra a correlação entre o comportamento da viscosidade e os traços de DSC. Há uma relação evidente entre o pico calorimétrico da pré-transição e um aumento em $\eta_{i}$ para todas as concentrações de $\mathrm{NaCl}$ (entre 2 e $20 \mathrm{mM}$ de $\mathrm{NaCl}$ melhor visualizado na figura 4.52). 

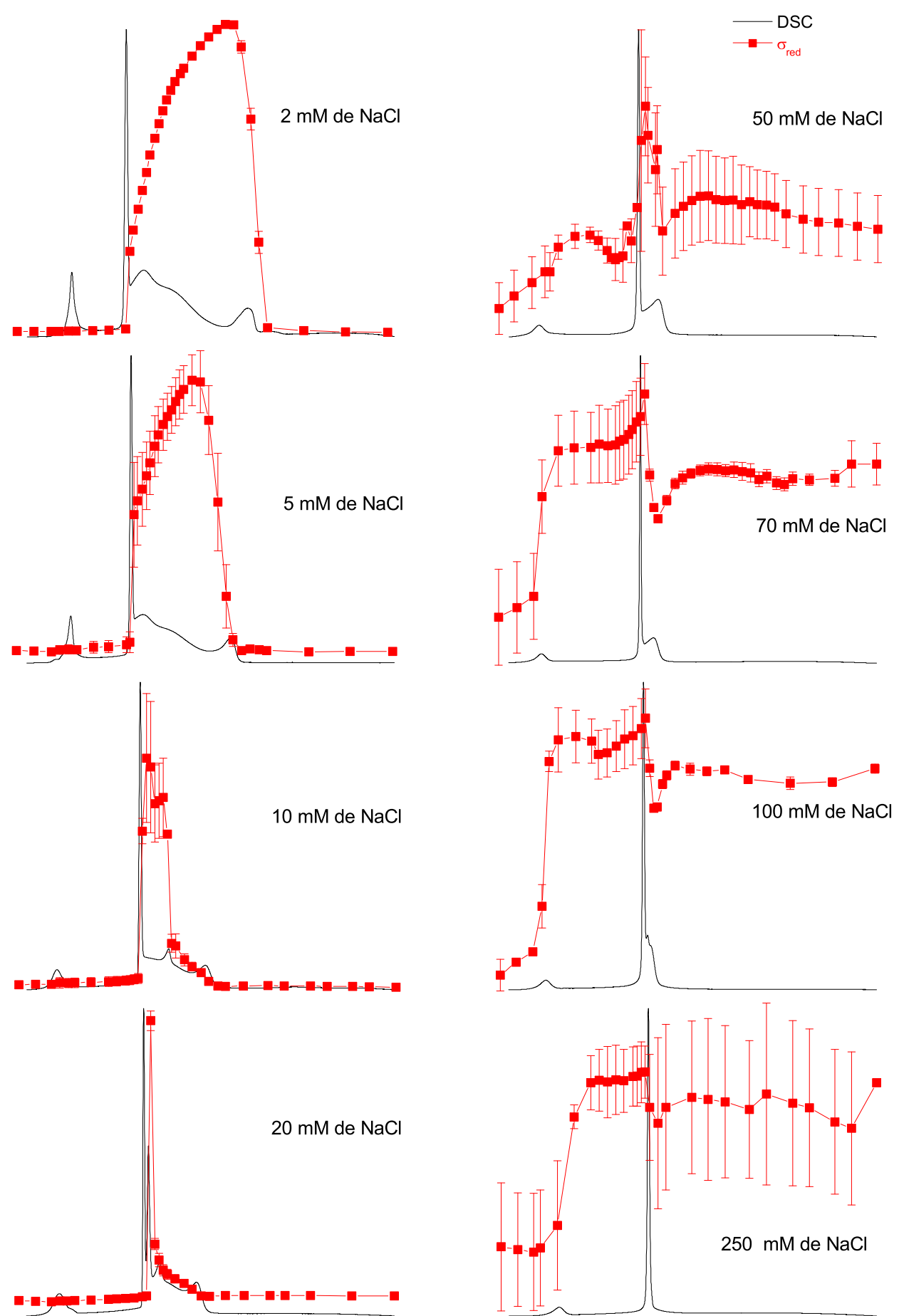

Figura 4.51: Dependência térmica do incremento de viscosidade relativa sobreposto aos traços de DSC de dispersões de $10 \mathrm{mM}$ de DMPG em várias forças iônicas. 


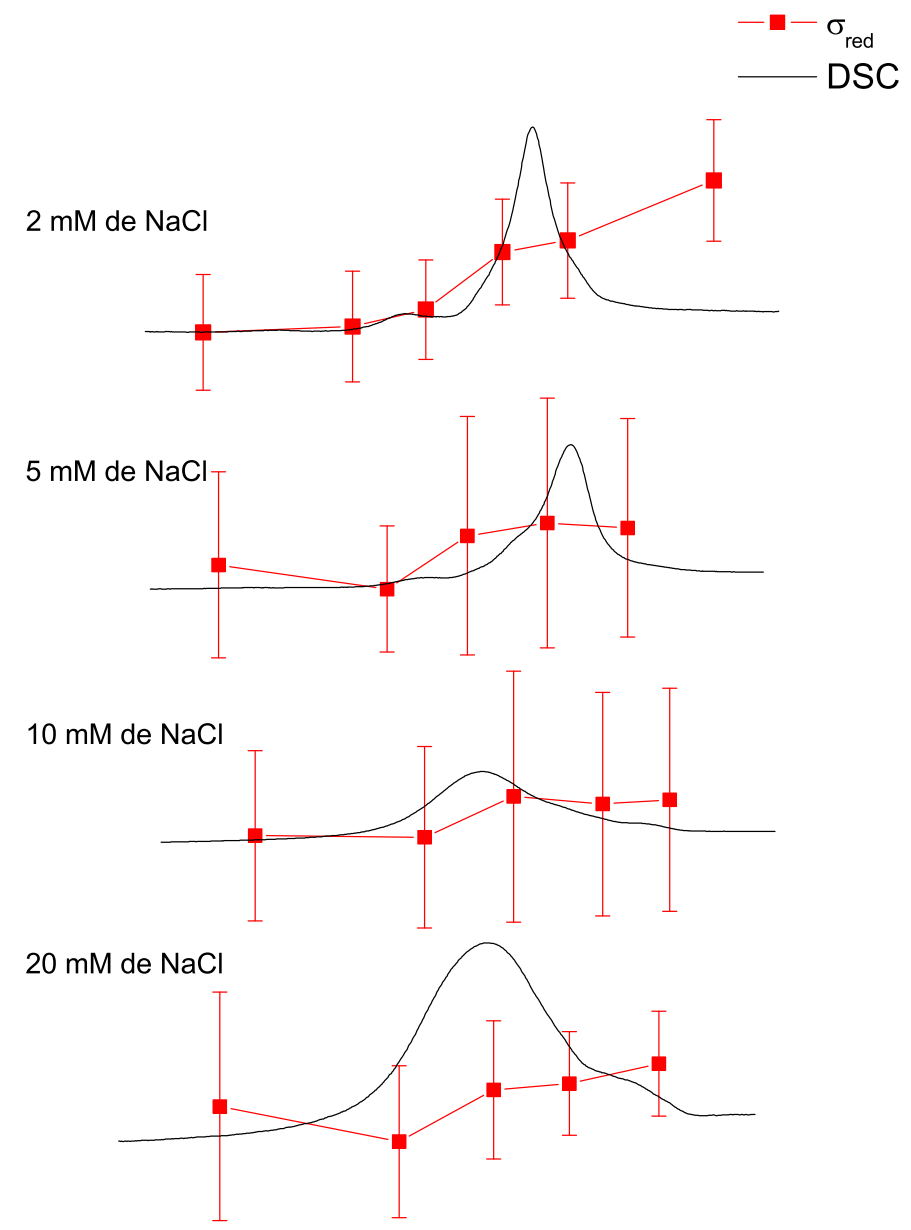

Figura 4.52: Ampliação da figura 4.51 na região da pré-transição de fase em baixas forças iônicas. 


\subsubsection{A correspondência entre aumentar a concentração lipídica ou a de $\mathrm{NaCl}$}

De um modo geral, com todas as técnicas estudadas, observamos que a variação da força iônica do solvente, portanto da concentração de $\mathrm{NaCl}$, tem um efeito similar à variação de concentração lipídica. De fato, um aumento da concentração de DMPG produz um aumento na concentração de contraíons $\mathrm{Na}^{+}$na solução, devido à diminuição no volume de solvente. A equivalência desses dois regimes, o aumento da concentração de macro-íons ou da força iônica da amostra, já foi apontado em um trabalho anterior, com respeito à mobilidade eletroforética de macro-íons com forma e dissociação fixos (Lobaskin et al., 2007). Utilizando os dados obtidos por calorimetria, apresentaremos uma demonstração de tal equivalência.

A figura 4.16 mostrou que conforme a concentração de DMPG aumenta, o início da transição principal $\left(T_{m}{ }^{o n}\right)$ aumenta e o final $\left(T_{m}{ }^{\text {off }}\right)$ diminui. De acordo com o que foi visto na subseção anterior, um comportamento similar foi obtido fixando-se a concentração de DMPG e aumentando a força iônica do meio. Podemos racionalizar a equivalência sallipídio, no caso de dispersões lipídicas, da seguinte forma:

$$
\left[\mathrm{Na}^{+}\right]=\left[\mathrm{Na}^{+ \text {bulk }}\right]+[\text { contraions }]
$$

onde $\mathrm{Na}^{+}$é a concentração total de íons $\mathrm{Na}^{+}$em solução. A concentração de contraíons é a dada por $[$ contraions $]=\alpha[\mathrm{DMPG}]$, onde $\alpha$ é o grau de ionização efetivo do $\mathrm{PG}$. Portanto a concentração iônica em solução aumenta tanto com $\left[\mathrm{Na}^{+}\right]$adicionado quanto com $[\mathrm{DMPG}]$. 
Para examinar o efeito de aumentar a concentração de lipídio ou de sal sobre $T_{m}{ }^{\text {on }}$ e $T_{m}{ }^{\text {off }}$, a figura 4.53 apresenta a variação de $T_{m}^{\text {on }}$ e $T_{m}{ }^{\text {off }}$ com a [ $\left.\mathrm{NaCl}\right]$ adicionada para uma dispersão de $10 \mathrm{mM}$ de DMPG em tampão Hepes, pH 7,4. Se compararmos estes dados com os de uma dispersão de $50 \mathrm{mM}$ de DMPG, sob a hipótese de que $T_{m}{ }^{\text {on }}$ e $T_{m}{ }^{\text {off }}$ dependem da concentração de íons sódio na solução, podemos sugerir que uma dispersão de 50 mM de DMPG (em tampão Hepes pH 7,4 +2 mM de $\mathrm{NaCl}$ ) é equivalente a uma dispersão de $10 \mathrm{mM}$ de DMPG em Hepes pH 7,4 com aproximadamente $6 \mathrm{mM}$ de $\mathrm{NaCl}$ (ver linhas pontilhadas na figura 4.53).

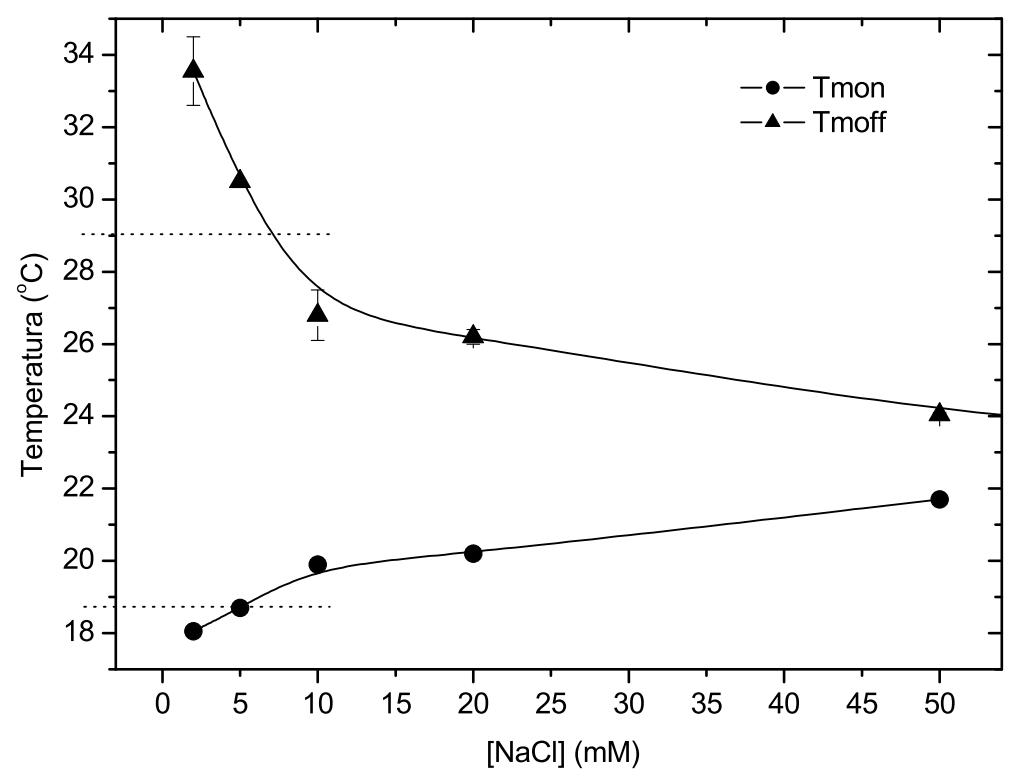

Figura 4.53: Dependência de $T_{m}{ }^{\text {on }}$ e $T_{m}{ }^{\text {off }}$ de dispersão de $10 \mathrm{mM}$ de DMPG em Hepes com diferentes concentrações de $\mathrm{NaCl}$. As linhas pontilhadas correspondem a $T_{m}{ }^{\text {on }}$ (valor menor) e $T_{m}{ }^{\text {off }}$ (valor maior) de uma dispersão de $50 \mathrm{mM}$ de DMPG em Hepes com $2 \mathrm{mM}$ de $\mathrm{NaCl}$.

Vamos comparar as concentrações de íons para as duas dispersões, assumindo que o DMPG está organizado em vesículas unilamelares ocupando frações de volume $\phi$. Considerando o grau de ionização $\alpha$ da monocamada externa, os contra-íons dissociados na solução estarão dissolvidos num volume $V(1-\phi)$. Portanto, a concentração de $N a^{+}$ na solução é:

$$
\left[\mathrm{Na}^{+}\right]_{\left[\mathrm{Na}^{+}{ }_{b u l k}\right] ;[\mathrm{DMPG}]}=\left[\mathrm{Na}^{+}{ }_{b u l k}\right]+\frac{\alpha[\mathrm{DMPG}]}{2(1-\phi)}
$$

onde $\left[\mathrm{Na}^{+}{ }_{\text {bulk }}\right]=\left[\mathrm{Na}^{+}\right.$devida a $10 \mathrm{mM}$ de tampão Hepes em pH 7.4 $]+\left[\mathrm{Na}^{+}\right.$adicionado $]=$ $4+\left[\mathrm{Na}^{+}\right.$adicionado], onde 4 é a concentração de $\mathrm{Na}^{+}$devido à $10 \mathrm{mM}$ de tampão Hepes 
em pH 7,4. Todas as concentrações estão em mM.

Portanto, para $50 \mathrm{mM}$ de DMPG com $2 \mathrm{mM}$ de $\mathrm{NaCl}$ adicionado, temos:

$$
\left[N a^{+}\right]_{6 ; 50}=6+\alpha \frac{25}{0,90}
$$

Enquanto que, para $10 \mathrm{mM}$ de DMPG com 6 de $\mathrm{NaCl}$ adicionado, obtemos:

$$
\left[N a^{+}\right]_{10 ; 10}=10+\alpha \frac{5}{0,98}
$$

Em equilíbrio, para vesículas não-interagentes, espera-se o mesmo grau de ionização $\alpha$ para as mesmas concentrações de íons na solução. Considerando que $\left[\mathrm{Na}^{+}\right]$é a mesma para as duas dispersões lipídicas, como elas apresentam valores similares de $T_{m}{ }^{\text {on }}$, podemos calcular o grau de ionização igualando as equações 4.8 e 4.9. Obtemos um valor para $\alpha$ de 0,18 . Mesmo com essas hipóteses bem simples, chegamos em um valor similar aos valores calculados para as fases gel e fluida de uma dispersão de $10 \mathrm{mM}$ de DMPG, usando os dados de mobilidade eletroforética e condutividade (figura 4.29). Portanto, a dependência do perfil de DSC com a concentração de DMPG parece estar relacionada ao grau de ionização da bicamada de DMPG. 


\section{Capítulo 5}

\section{Discussão geral e conclusões}

Para entender melhor o comportamento térmico de dispersões de DMPG, foram utilizadas várias técnicas experimentais para obtenção das seguintes propriedades macroscópicas das dispersões: variação de calor específico, turbidez, condutividade e viscosidade. Tais características foram obtidas em baixa força iônica variando-se a concentração lipídica e também fixando-se a concentração de DMPG em 10 mM e variando-se a força iônica. Conforme podemos observar (figuras 5.1 e 5.2), houve uma clara correlação entre os dados obtidos através das diversas técnicas experimentais utilizadas. 

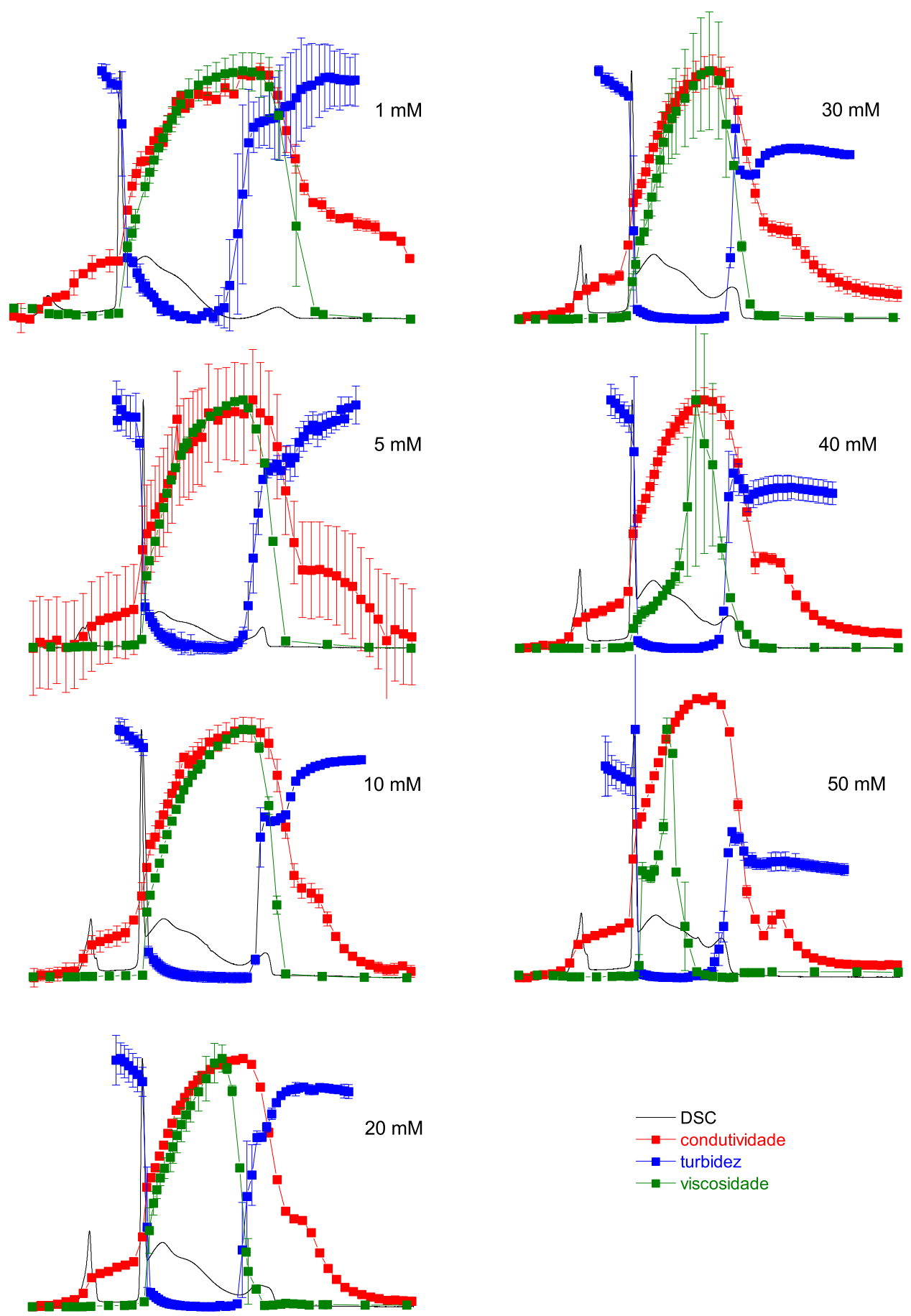

- turbidez
- viscosidade

Figura 5.1: Sobreposição do perfil térmico de dispersões de DMPG em Hepes $+2 \mathrm{mM}$ de $\mathrm{NaCl}$ visto por DSC, viscosidade, condutividade e turbidez, para várias concentrações lipídicas.

Para praticamente todas as concentrações lipídicas estudadas, a correlação mais marcante é entre o pico calorimétrico em $T_{m}{ }^{o n}$ e mudanças bruscas nos comportamentos da turbidez, condutividade e viscosidade. Também há uma clara correlação entre o pico 
calorimétrico atribuído à pré-transição de fase e um aumento brusco na condutividade. Esse aumento da condutividade em $T_{p}$ reforça a discussão sobre esta temperatura estar relacionada ao início da transição de fase gel-fluida.
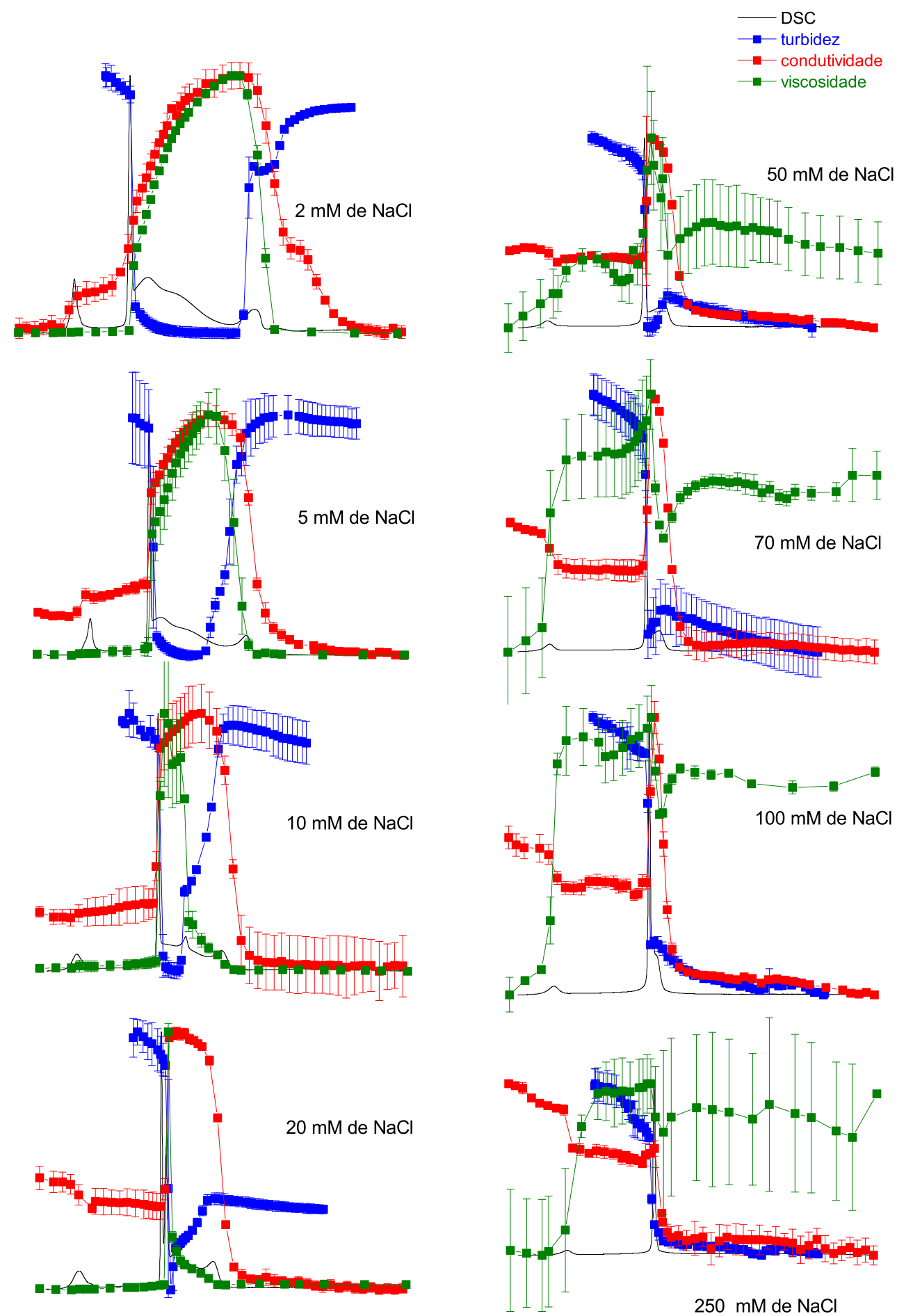

Figura 5.2: Sobreposição do perfil térmico de dispersões de $10 \mathrm{mM} \mathrm{DMPG}$ visto por DSC, viscosidade, condutividade e turbidez, para várias forças iônicas. 
Variando-se a força iônica da dispersão (figura 5.2), a mais marcante correlação também reside na coincidência entre mudanças bruscas na viscosidade, turbidez e condutividade com o pico calorimétrico em $T_{m}{ }^{o n}$. Em 10 e $20 \mathrm{mM}$ de $\mathrm{NaCl}$ também é notável a correlação entre um pequeno pico calorimétrico com o aumento abrupto na turbidez após sua queda em $T_{m}^{\text {on }}$, e a queda brusca da viscosidade da dispersão.
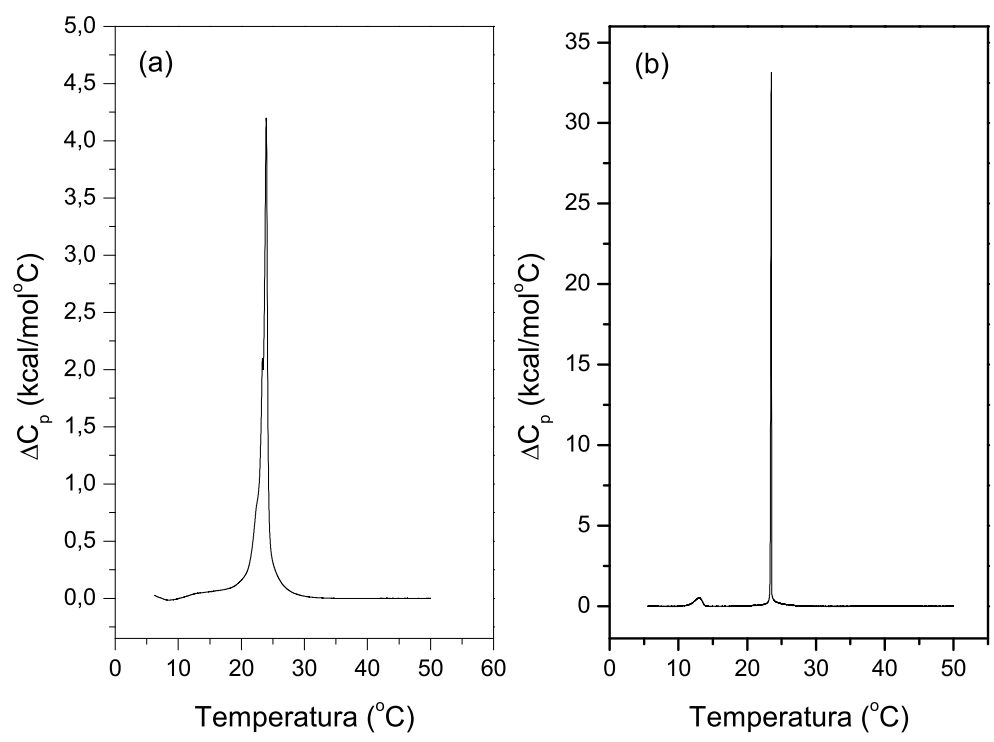

Figura 5.3: Curva DSC de dispersão lipídica de vesículas unilamelares (a) e multilamelares (b) de DMPC com concentração de $5 \mathrm{mM}$. Taxa de aquecimento: $20^{\circ} \mathrm{C} / \mathrm{h}$.

Na figura 5.3a é mostrada a curva DSC de uma dispersão de vesículas unilamelares de DMPC, extrusadas por filtro de $100 \mathrm{~nm}$. Não é mais possível detectar a pré-transição de fase e o pico em $T_{m}$ é muito menos intenso e mais largo quando comparado ao da curva DSC de vesículas multilamelares (5.3b). Quanto mais estreito e intenso o pico calorimétrico, mais cooperativa é a transição. Portanto, a transição é muito mais cooperativa em vesículas multilamelares grandes do que unilamelares pequenas. Alguns trabalhos mostraram que curvaturas maiores na bicamada alargam o pico calorimétrico (Mabrey-Gaud, 1981 e referências contidas nele; Heimburg, 2000). Os lipídios da monocamada externa podem possuir mais mobilidade de movimento do que os da monocamada interna, de maneira que as monocamadas podem apresentar temperaturas de transição de fase diferentes, o que causaria um alargamento no pico de calor específico, ou mesmo um desdobramento em mais picos. Esta situação torna-se muito mais relevante em grandes 
curvaturas. Portanto, a curvatura das bicamadas tem forte influência sobre o perfil da curva de DSC de dispersões lipídicas.

Imagens de microscopia eletrônica de dispersões de DMPG, na região de transição, foram interpretadas como sendo uma rede de bicamadas lipídicas, formando uma fase tipo esponja (Schneider et al., 1999). Baseados nesta interpretação, os autores propuseram que os vários picos calorimétricos nas dispersões de DMPG, na região de transição, estariam relacionados às várias curvaturas presentes em uma fase tipo esponja. Embora a hipótese da fase esponja possa ser descartada (Lamy-Freund \& Riske, 2003, Alakoskela \& Kinnunen, 2007), a ideia de relacionar os vários picos calorimétricos a diferentes curvaturas dos agregados lipídicos parece ser bem razoável. Na região de transição, experimentos de microscopia óptica com vesículas gigantes de DMPG (Riske et al., 2009a) mostraram que as mesmas desapareciam do plano focal do microscópico, possivelmente por perda de contraste óptico das bicamadas lipídicas. Aumentando a temperatura, as vesículas reapareciam na fase fluida. Durante todo o processo foi possível notar flutuações de tamanho e forma das vesículas. É possível que grandes flutuações, maiores na região de transição em relação às fases gel e fluida, sejam responsáveis pela perda de contraste óptico das bicamadas. Teoricamente, é sabido que alto calor específico está ligado a grandes flutuações de energia, densidade, área, entre outros. Portanto, é muito plausível que os vários picos calorimétricos ao longo da região de transição estejam relacionados a flutuações. Além disso, curvaturas diferentes também podem estar relacionadas a grandes flutuações.

Mostramos que os agregados de DMPG organizam-se em vesículas na fase fluida. Muito provavelmente a fase gel e a região de transição também sejam compostas por vesículas, já que, nesta faixa de temperatura, experimentos de EPR e fluorescência mostraram que não há fusão dos agregados de DMPG. No entanto, na região de transição, a forma destas vesículas deve mudar drasticamente, conforme podemos concluir de nossos dados de viscosidade, em que a viscosidade intrínseca é uma ordem de grandeza maior do que nas fases gel e fluida. Estas vesículas, possivelmente deformadas e sujeitas a intensas flutuações de forma, devem apresentar regiões com várias curvaturas diferentes, o que poderia explicar, conforme descrito no parágrafo anterior, os vários picos de calor específico observados nas curvas DSC. Flutuações de forma podem ser responsáveis pela perda de contraste óptico observado em bicamadas de vesículas gigantes de DMPG na região de transição. Neste caso, as flutuações também poderiam explicar a baixa turbidez. 
Vimos que a dependência das curvas DSC com a concentração lipídica, em baixa força iônica, provavelmente é devida a diferentes graus de ionização das bicamadas lipídicas. Com o aumento da concentração, a bicamada torna-se menos ionizada devido ao aumento na concentração de íons $\mathrm{Na}^{+}$na dispersão. O efeito no perfil de DSC de aumentar a concentração de DMPG é similar ao efeito de aumentar a concentração de $\mathrm{NaCl}$, e permitiu o cálculo do grau de ionização de vesículas com 10 mM de DMPG. O grau de ionização calculado de dados de condutividade elétrica e mobilidade eletroforética, concorda com o valor obtido de DSC, e também indica que as vesículas de DMPG estão menos carregadas em altas concentrações lipídicas.

As medidas de viscosidade das dispersões mostraram que existe uma nítida diferença de regime para concentrações de DMPG acima de $40 \mathrm{mM}$.

A macro-viscosidade das dispersões de DMPG mostrou-se distinta da viscosidade local sentida tanto pelos íons ou agregados de DMPG carregados, nas medidas de condutividade ou mobilidade eletroforética. No entanto, o que quer que inicie a transição em $T_{m}{ }^{o n}$ é responsável pelo grande aumento na viscosidade, possivelmente relacionado ao aumento da interação entre os agregados de DMPG sob fluxo.

Variando-se a força iônica das dispersões de DMPG, as medidas de viscosidade mostraram uma clara diferença entre dispersões até $20 \mathrm{mM}$ de $\mathrm{NaCl}$ e com mais sal: até $20 \mathrm{mM}$ há um aumento da viscosidade na região de transição; a partir de $50 \mathrm{mM}$, a viscosidade se mantém baixa para praticamente todas temperaturas. Curiosamente, o aumento da condutividade da amostra em $T_{p}$, transforma-se em uma queda para concentrações de sal de $20 \mathrm{mM}$ e maiores. Este resultado pode estar indicando modificações na forma dos agregados para maiores concentrações de sal. É interessante notar também que as medidas de turbidez indicam uma clara diferença para vesículas até $20 \mathrm{mM}$ de $\mathrm{NaCl}$. Estas ainda apresentam uma estreita faixa de temperatura onde a turbidez é quase nula. A partir de $50 \mathrm{mM}$ de $\mathrm{NaCl}$ a turbidez é muito maior que para as concentrações de sal menores, o que pode estar ligado a uma possível presença de multibicamadas a partir de $50 \mathrm{mM}$ de $\mathrm{NaCl}$.

Um pequeno pico em baixo ângulo de experimentos de SAXS, observado apenas na região de transição, deu origem à interpretação de que tal pico estaria relacionado à uma medida da distância média entre poros formados nas vesículas. Através deste modelo, foi possível ajustar as curvas de SAXS (Spinozzi et al., 2010). Na fase fluida, 
em que os lipídios possuem uma maior mobilidade em relação à fase gel, é esperado que haja maior passagem de água pelas bicamadas (Lawaczeck, 1979). A hipótese de vesículas perfuradas ao longo de toda região de transição partilha desta ideia para tentar explicar a queda da turbidez, ou seja, haveria maior passagem de água pelos poros causando alterações no índice de refração das bicamadas (Riske et al., 2004). Seguindo esta linha de pensamento, podemos atribuir a queda da turbidez da fase gel para fase fluida como resultado de um afrouxamento das bicamadas. Usando raciocínio similar, se na região de transição houver bicamadas cujos lipídios estejam extremamente frouxos, num estado de maior mobilidade do que em uma fase fluida convencional, conforme sugerido por experimentos de EPR (Lamy-Freund e Riske, 2003), isto poderia explicar a queda na turbidez. No caso de vesículas perfuradas, os lipídios presentes nos poros certamente se enquadrariam nesta situação de maior mobilidade. Todavia, a presença de poros, neste contexto, é apenas uma possibilidade entre outras. Basta haver regiões com grandes curvaturas, como protuberâncias, por exemplo, onde também haveria lipídios com grande mobilidade.

Experimentos de espalhamento de luz mostraram que dispersões lipídicas de DMPG, extrusadas por filtros de $100 \mathrm{~nm}$, apresentam, nas fases gel e fluida, agregados com diâmetros da ordem de $50 \mathrm{~nm}$ (Enoki et al., em fase de escrita). Portanto, dispersões de DMPG não extrusadas, as quais apresentam tamanhos de aproximadamente $70 \mathrm{~nm}$ de diâmetro ( $Z_{\text {average }}$ obtido por experimentos de espalhamento de luz), devem possuir alguns poucos agregados grandes (com diâmetro maior que $100 \mathrm{~nm}$ ) e uma grande maioria de agregados menores. Usando um raio de $35 \mathrm{~nm}$ e espessura de bicamada de $5 \mathrm{~nm}$, o número de lipídios na monocamada externa é em torno de $30 \%$ maior do que na monocamada interna (ver equações 3.20 e 3.21). Essa diferença entre o número de lipídios nas monocamadas da bicamada, que é cada vez maior para vesículas com diâmetros menores, poderia gerar empacotametos diferentes das monocamadas, favorecendo deformações na bicamada. Juntamente com o fato do DMPG possuir cadeias hidrocarbônicas curtas, este efeito de deformações das bicamadas seria recrudescido pela presença de carga nas cabeças polares, principalmente pela monocamada externa ser mais carregada que a interna. Aumentando a temperatura, além do aumento do grau de ionização, de acordo com o que sugerem nossos resultados, as cadeias hidrocarbônicas adquirem mais liberdade e, em virtude de seu curto comprimento, a interação hidrofóbica se torna menos intensa, 
facilitando mudanças estruturais. Assim sendo, propomos que a região de transição seja composta por vesículas perfuradas e deformadas, possuindo poros e protuberâncias, e sujeitas a intensas flutuações.

Acreditamos que o trabalho apresentado aqui contribui para uma melhor entendimento de dispersões carregadas de DMPG. No entanto, várias questões permanecem em aberto. Certamente, um modelo termo-estatístico que explique os dados experimentais está faltando. Ele deve levar em conta as diferentes interações presentes no sistema, entre as cabeças polares carregadas do DMPG e as cadeias hidrocarbônicas em meio aquoso. Além disso, seria interessante especular acerca da relevância biológica de grandes flutuações nas bicamadas lipídicas. 


\section{Referências Bibliográficas}

Alakoskela, J. M., Parry, M. J., \& Kinnunen, P. K. J. 2010. The Intermediate State of DMPG Is Stabilized by Enhanced Positive Spontaneous Curvature. Langmuir, 26, 4892-4900.

Alakoskela, J. M. I., \& Kinnunen, P. K. J. 2007. Thermal phase behavior of DMPG: The exclusion of continuous network and dense aggregates. Langmuir, 23, 4203-4213.

Allen, T. M., \& Everest, J. M. 1983. Effect of liposome size and drug release properties on pharmacokinetics of encapsulated drug in rats. JPET, 223, 539-544.

Amon, M. A., Ali, M., Bender, V., Hall, K., Aguilar, M. I., Aldrich-Wright, J., \& Manolios, N. 2008. Kinetic and conformational properties of a novel T-cell antigen receptor transmembrane peptide in model membranes. J. Pept. Sci., 14, 714-724.

Anderson, F. P., Brookes, H. C., Hotz, M. C. B., \& Spong, A. H. 1969. Measurement of electrolyte conductance with a four-electrode alternating current potentiometer. $J$. Phys. E, 2, 499-502.

Antonov, V. F., Petrov, V. V, Molnar, A. A., Predvoditelev, D. A., \& Ivanov, A. S. 1980. Appearance of single-ion channels in unmodified lipid bilayer-membranes at the phase-transition temperature. Nature, 283, 585-586.

Barnes, H. A., Hutton, J. F., \& Walters, K. 1993. An introduction to rheology. Elsevier Science Publisher B. V.

Batchelor, G. K. 1972. The determination of the bulk stress in a suspension of spherical particles to order c2. J. Fluid Mecha., 56, 421-427.

Biaggi, M. H., Riske, K. A., \& Lamy-Freund, M. T. 1997. Melantropic peptides - lipid 
bilayer interaction. Comparison of the hormone a-MSH to a biologically more potent analog. Biophys. Chem., 67, 139-149.

Broemstrup, T., \& Reuter, N. 2010. How does Proteinase 3 interact with lipid bilayers? Phys. Chem. Chem. Phys., 12, 7487-7496.

Callen, H. B. 1985. Thermodynamics and an introduction to thermostatistics. John Willey and Sons.

Chang, R. 2000. Physical Chemistry With Applications to Biological Systems. MacMillan.

Chia, C. S. B., Torres, J., Cooper, M. A., Arkin, I. T., \& Bowie, J. H. 2002. The orientation of the antibiotic peptide maculatin 1.1 in DMPG and DMPC lipid bilayers. Support for a pore-forming mechanism. Febs Lett., 512, 47-51.

Deamer, D. W., \& Bramhall, J. 1986. Permeability of lipid bilayers to water and ionic solutes. Chem. Phys. Lipids, 40, 167-188.

Disalvo, E. A. 1991. Optical properties of lipid dispersions induced by permeant molecules. Chem. Phys. Lipids, 59, 199-206.

Doniach, S. 1978. Thermodynamic fluctuations in phospholipid bilayers. J. Chem. Phys., 68, 4912-4916.

Einstein, A. 1906. Ann. Phys., 19, 289-290.

Engelman, D. M. 2005. Membranes are more mosaic than fluid. Nature, 438, 578-580.

Epand, R. M., \& Hui, S. W. 1986. Effect of Electrostatic Repulsion on the Morphology and Thermotropic Transitions of Anionic Phospholipids. Febs Lett., 209, 257-260.

Evans, D. F., \& Wennerstön, H. 1994. Electrostatic interactions in colloidal systems. In: Evans, D. F., \& Wennerstön, H. (eds), The Colloidal Domain: Where Physics, Chemistry, Biology, and Technology Meet. New York: VCH.

Fernandez, R. M., Riske, K. A., Amaral, L. Q., Itri, R., \& Lamy, M. T. 2008. Influence of salt on the structure of DMPG studied by SAXS and optical microscopy. Biochim. Biophys. Acta, 1778, 907-916. 
Florence, A. T., Arunothayanun, P., Kiri, S., Bernard, M. S., \& Uchegbu, I. F. 1999. Some rheological properties of nonionic surfactant vesicles and the determination of surface hydration. J. Phys. Chem. B, 103, 1995-2000.

Fox, R. W. 1988. Introdução à Mecânica dos Fuidos. Editora Guanabara S.A.

Gennis, R. B. 1989. Biomembranes. Molecular structure and function. Springer-Verlag.

Goldman, C. 2001. Modified surface fluctuations by impurity binding in amphiphilic dispersions. J. Chem. Phys., 114, 6242-6248.

Goldman, C., Riske, K. A., \& Lamy-Freund, M. T. 1999. Role of soft and hard aggregates in the thermodynamics of lipid dispersions. Phys. Rev. E, 60, 7349-7353.

Harned, H. S., \& Owen, B. B. 1967. The Physical Chemistry of Electrolytic Solutions. Reinhold Publishing Corp.

Heerklotz, H. 2004. The microcalorimetry of lipid membranes. J. Phys.: Condens. Matter, 16, R441-R467.

Heimburg, T. 2000. A model for the lipid pretransition: Coupling of ripple formation with the chain-melting transition. Biophys. J., 78, 1154-1165.

Heimburg, T. 2007. Thermal Biophysics of Membranes. Wiley-VCH Verlag GmbH and Co. KGaA.

Heimburg, T., \& Biltonen, R. L. 1994. Thermotropic Behavior of Dimyristoylphosphatidylglycerol and Its Interaction with Cytochrome-C. Biochemistry, 33, 9477-9488.

Höhne, G., Hemminger, W., \& Flammersheim, H. J. 2003. Differential Scanning Calorimetry. Springer.

Hiemenz, P. C. 1986. Principles of Colloid and Surface Chemistry. Marcel Dekker.

Janiak, M. J., Small, D. M., \& Shipley, G. G. 1976. Nature of the Thermal Pretransition of Synthetic Phospholipids: Dimyristoyl- and Dipalmitoyllecithin. Biochemistry, 15, $4575-4580$.

Kinoshita, M., Kato, S., \& Takahashi, H. 2008. Effect of bilayer morphology on the subgel phase formation. Chem. Phys. Lipids, 151, 30-40. 
Kodama, M., \& Miyata, T. 1995. Effect of Na+ concentrations on both size and multiplicity of multilamellar vesicles composed of negatively charged phospholipid as revealed by differential scanning calorimetry and electron microscopy. Thermochim. Acta, 267, $365-372$.

Kubo, R. 1966. The Fluctuation-dissipation theorem. Rep. Prog. Phys., 29, 255-284.

Lamy-Freund, M. T., \& Riske, K. A. 2003. The peculiar thermo-structural behavior of the anionic lipid DMPG. Chem. Phys. Lipids, 122, 19-32.

Larson, R. G. 1999. The Structure and Rheology of Complex Fluids. Oxford University Press.

Lawaczeck, R. 1979. Permeability of water-molecules across vesicular lipid bilayers. J. Membr. Biol., 51, 229-261.

Lehninger, A.L. 1984. Princípios de Bioquímica. Ed. Sarvier.

Lidgate, D. M., Hegde, S. G., \& Maskiewicz, R. 1993. Conductivity Measurement as a Convenient Technique for Determination of Liposome Capture Volume. Int. J. Pharm., $96,51-58$.

Lobaskin, V., Dunweg, B., Medebach, M., Palberg, T., \& Holm, C. 2007. Electrophoresis of colloidal dispersions in the low-salt regime. Phys. Rev. Lett., 98, 176105.

Mabrey-Gaud, S. 1981. Differential Scanning Calorimetry of liposomes. In: Knight, C.G. (ed), Liposomes: From Physical Structure to Therapeutic Applications. Amsterdam: Elsevier/North-Holland Biomedical Press.

Marsh, D., \& Phil, M. A. 1990. CRC Handbook of Lipid Bilayers. CRC Press.

Mouritsen, O. G., \& Bloom, M. 1984. Mattress model of lipid-protein interactions in membranes. Biophys. J., 46, 141-153.

Mozsolits, H., Wirth, H. J., Werkmeister, J., \& Aguilar, M. I. 2001. Analysis of antimicrobial peptide interactions with hybrid bilayer membrane systems using surface plasmon resonance. Biochim. Biophys. Acta, 1512, 64-76. 
Nagle, J. L., \& Scott, H. L. 1978. Appearance of single-ion channels in unmodified lipid bilayer-membranes at the phase-transition temperature. Biochim. Bypohys. Acta, 513, $236-243$.

Papahadjopoulos, D., Jacobson, K., Nir, S., \& Isac, T. 1973. Phase-transitions in phospholipid vesicles - fluorescence polarization and permeability measurements concerning effect of temperature and cholesterol. Biochim. Biophys. Acta, 311, 330-348.

Paradis-Bleau, C., Cloutier, I., Lemieux, L., Sanschagrin, F., Laroche, J., Auger, M., Garnier, A., \& Levesque, R. C. 2007. Peptidoglycan lytic activityof the Pseudomonas aeruginosa phage fKZgp144 lytic transglycosylase. Microbiol Lett., 266, 201-209.

Plotnikov, V. V., Brandts, J. M., Lin, L., \& Brandts, J. F. 1997. A new ultrasensitive scanning calorimeter. Anal. Biochem., 250, 237-244.

Poste, G., \& Papahadjopoulos, D. 1976. Lipid vesicles as carriers for introducing materials into cultured cells: Influence of vesicle lipid composition on mechanism(s) of vesicle incorporation into cells. Proc. Natl. Acad. Sci. USA, 73, 1603-1607.

Prenner, E. J., Lewis, R. N. A. H., Kondejewski, L. H., Hodgesa, R. S., \& McElhaney, R. N. 1999. Differential scanning calorimetric study of the effect of the antimicrobial peptide gramicidin $\mathrm{S}$ on the thermotropic phase behavior of phosphatidylcholine, phosphatidylethanolamine and phosphatidylglycerol lipid bilayer membranes. Biochim. Biophys. Acta, 1417, 211-223.

Riske, K. A., Politi, M. J., Reed, W. F., \& Lamy-Freund, M. T. 1997. Temperature and ionic strength dependent light scattering of DMPG dispersions. Chem. Phys. Lipids, $89,31-44$.

Riske, K. A., Nascimento, O. R., Peric, M., Bales, B. L., \& Lamy-Freund, M. T. 1999. Probing DMPG vesicle surface with a cationic aqueous soluble spin label. Biochim. Biophys. Acta, 1418, 133-146.

Riske, K. A., Amaral, L. Q., \& Lamy-Freund, M. T. 2001. Thermal transitions of DMPG bilayers in aqueous solution: SAXS structural studies. Biochim. Biophys. Acta, 1511, 297-308. 
Riske, K. A., Dobereiner, H. G., \& Lamy-Freund, M. T. 2002. Gel-fluid transition in dilute versus concentrated DMPG aqueous dispersions. J. Phys. Chem. B, 106, 239-246.

Riske, K. A., Fernandez, R. M., Nascimento, O. R., Bales, B. L., \& Lamy-Freund, M. T. 2003. DMPG gel-fluid thermal transition monitored by a phospholipid spin labeled at the acyl chain end. Chem. Phys. Lipids, 124, 69-80.

Riske, K. A., Amaral, L. Q., Dobereiner, H. G., \& Lamy, M. T. 2004. Mesoscopic structure in the chain-melting regime of anionic phospholipid vesicles: DMPG. Biophys. J., 86, $3722-3733$.

Riske, K. A., Amaral, L. Q., \& Lamy, M. T. 2009a. Extensive Bilayer Perforation Coupled with the Phase Transition Region of an Anionic Phospholipid. Langmuir, 25, 1008310091.

Riske, K. A., Barroso, R. P., Vequi-Suplicy, C. C., Germano, R., Henriques, V. B., \& Lamy, M. T. 2009b. Lipid bilayer pre-transition as the beginning of the melting process. Biochim. Biophys. Acta, 1788, 954-963.

Rouser, G., Fleischer, S., \& Yamamotto, A. 1970. 2 Dimensional Thin Layer Chromatographic Separation of Polar Lipids and Determination of Phospholipids by Phosphorus Analysis of Spots. Lipids, 19, 289-290.

Russel, W. B. 1978. The rheology of suspensions of charged rigid spheres. J. Fluid Mecha., 85, 209-232.

Salonen, I. S., Eklund, K. K., Virtanen, J. A., \& Kinnunen, P. K. J. 1989. Comparison of the Effects of $\mathrm{NaCl}$ on the Thermotropic Behavior of Sn-1'-Isomers and Sn3'-Stereoisomers of 1,2-Dimyristoyl-Sn-Glycero-3-Phosphatidylglycerol. Biochim. Biophys. Acta, 982, 205-215.

Schenkman, S., Araujo, P. S., Dukmanb, R., Quina, F. H., \& Chaimovich, H. 1981. Effects of temperature and lipid composition on the serum albumin-induced aggregation and fusion of small unilamellar vesicles. Biochim. Biophys. Acta, 649, 633-641.

Schneider, M. F., Marsh, D., Jahn, W., Kloesgen, B., \& Heimburg, T. 1999. Network formation of lipid membranes: Triggering structural transitions by chain melting. Proc. Natl. Acad. Sci. USA, 96, 14312-14317. 
Sierra-Martin, B., Romero-Cano, M. S., Fernandez-Nieves, A., \& Fernandez-Barbero, A. 2006. Thermal control over the electrophoresis of soft colloidal particles. Langmuir, 22, 3586-3590.

Simha, R. 1940. The Influence of Brownian Movement on the Viscosity of Solutions. J. Phys. Chem., 44, 25-34.

Singer, S. J., \& Nicolson, G. L. 1972. The fluid mosaic model. Science, 175, 720-731.

Spinozzi, F., Paccamiccio, L., Mariani, P., \& Amaral, L. Q. 2010. Melting Regime of the Anionic Phospholipid DMPG: New Lamellar Phase and Porous Bilayer Model. Langmuir, 26, 6484-6493.

Strayer, L. 1997. Biochemistry. Freeman and Co.

Sturtevant, J. M. 1987. Biochemical applications of differential scanning calorimetry. Ann. Rev. Phys. Chem., 38, 463-488.

Tamashiro, M. N., Henriques, V. B., \& Lamy, M. T. 2005. Aqueous suspensions of charged spherical colloids: Dependence of the surface charge on ionic strength, acidity, and colloid concentration. Langmuir, 21, 11005-11016.

Tatulian, S. A. 1987. Fluidity-Dependence of Membrane Adhesiveness Can Be Explained by Thermotropic Shifts in Surface-Potential. Biochim. Biophys. Acta, 901, 161-165.

Traüble, H., Teubner, M., Wooley, P., \& Eibl, H. 1976. Electrostatic interactions at charged lipid membranes. I. Effects of $\mathrm{pH}$ and univalent cations on membrane structure. Biophys. Chem., 4, 319-342.

Turchiello, R. F., Riske, K. A., Juliano, L., Ito, A. S., \& Lamy-Freund, M. T. 1999. A spin label comparative study of the interaction of bradykinin and related peptides with lipid vesicles. Biophys. J., 76, A217-A217.

Turchiello, R. F., Juliano, L., Ito, A. S., \& Lamy-Freund, M. T. 2000. How bradykinin alters the lipid membrane structure: a spin label comparative study with bradykinin fragments and other cations. Biopolymers, 54, 211-221. 
Turchiello, R. F., Lamy-Freund, M. T., Hirata, I. Y., L, L. Juliano, \& Ito, A. S. 2002. Ortho-aminobenzoic acid-labeled bradykinins in interaction with lipid vesicles: Fluorescence study. Biopolymers, 65, 336-346.

Umeyama, M., Kira, A., Nishimura, K., \& Naito, A. 2006. Interactions of bovine lactoferricin with acidic phospholipid bilayers and its antimicrobial activity as studied by solid-state NMR. Biochim. Biophys. Acta, 1758, 1523-1528.

Vereb, G., Szollosi, J., Matko, J., Nagy, P., Farkas, T., Vigh, L., Matyus, L., Waldmann, T. A., \& Damjanovich, S. 2003. Dynamic, yet structured: The cell membrane three decades after the Singer-Nicolson model. Proc. Natl. Acad. Sci. USA, 100, 8053-8058.

Yi, P. N., \& MacDonald, R. C. 1973. Temperature dependence of optical properties of aqueous dispersions of phosphatidylcholine. Chem. Phys. Lipids, 11, 114-134.

Zborowski, J., Roerdinka, F., \& Scherphof, G. 1977. Leakage of sucrose from phosphatidylcholine liposomes induced by interaction with serum albumin. Biochim. Biophys. Acta, 497, 183-191. 